\title{
The Brazilian Society of Rheumatology guidelines for axial spondyloarthritis - 2019
}

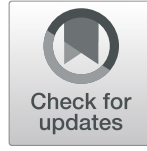

\author{
Gustavo Gomes Resende ${ }^{1 *}$ (D) Eduardo de Souza Meirelles², Cláudia Diniz Lopes Marques ${ }^{3}$, Adriano Chiereghin ${ }^{4}$, \\ Andre Marun Lyrio ${ }^{5}$, Antônio Carlos Ximenes ${ }^{6}$, Carla Gonçalves Saad ${ }^{2}$, Célio Roberto Gonçalves ${ }^{2}$, \\ Charles Lubianca Kohem7, Cláudia Goldenstein Schainberg ${ }^{2}$, Cristiano Barbosa Campanholo ${ }^{8}$, \\ Júlio Silvio de Sousa Bueno Filho ${ }^{9}$, Lenise Brandao Pieruccetti ${ }^{10}$, Mauro Waldemar Keiserman ${ }^{11}$, \\ Michel Alexandre Yazbek ${ }^{12}$, Penelope Esther Palominos ${ }^{7}$, Rafaela Silva Guimarães Goncalves ${ }^{3}$, \\ Ricardo da Cruz Lage ${ }^{1}$, Rodrigo Luppino Assad ${ }^{13}$, Rubens Bonfiglioli ${ }^{5}$, Sônia Maria Alvarenga Anti ${ }^{14}$, \\ Sueli Carneiro ${ }^{15}$, Thauana Luíza Oliveira ${ }^{16}$, Valderílio Feijó Azevedo ${ }^{17}$, Washington Alves Bianchi ${ }^{18}$, \\ Wanderley Marques Bernardo ${ }^{19}$, Marcelo de Medeiros Pinheiro ${ }^{16}$ and Percival Degrava Sampaio-Barros ${ }^{19}$
}

\begin{abstract}
Spondyloarthritis is a group of chronic inflammatory systemic diseases characterized by axial and/or peripheral joints inflammation, as well as extra-articular manifestations. The classification axial spondyloarthritis is adopted when the spine and/or the sacroiliac joints are predominantly involved. This version of recommendations replaces the previous guidelines published in May 2013.

A systematic literature review was performed, and two hundred thirty-seven studies were selected and used to formulate 29 recommendations answering 15 clinical questions, which were divided into four sections: diagnosis, non-pharmacological therapy, conventional drug therapy and biological therapy. For each recommendation the level of evidence supporting (highest available), the strength grade according to Oxford, and the degree of expert agreement (inter-rater reliability) is informed.

These guidelines bring evidence-based information on clinical management of axial SpA patients, including, diagnosis, treatment, and prognosis.
\end{abstract}

\section{Introduction}

According to recent definition, spondyloarthritis (SpA) is a group of diseases characterized by spine and peripheral joints inflammation, as well as extra-articular manifestations, including anterior uveitis, psoriasis and inflammatory bowel disease, with a genetic predisposition linked to the human leukocyte antigen B27 (HLA-B27). The SpA spectrum includes ankylosing spondylitis (AS), psoriatic arthritis (PsA), reactive arthritis (ReA), enteropathic arthritis (EA) and undifferentiated spondyloarthritis (uSpA). Based on the Assessment of SpondyloArthritis international Society (ASAS) classification criteria, the spine and/or the sacroiliac joints involvement is named as axial spondyloarthritis (axial SpA) [1,2]. The exclusive appendicular joints involvement is called as peripheral spondyloarthritis (p-SpA). On the other hand, if a patient has both clinical features, he should be classified according to the predominance (i.e., predominantly axial or predominantly peripheral involvement).

The purpose of these guidelines is to bring evidencebased information on clinical management of axial SpA patients, including, diagnosis, treatment and prognosis, for rheumatologists, general physicians, allied-specialists (dermatology, ophthalmology and gastroenterology), and other allied-professionals, such as physiotherapists. This version replaces the previous guidelines published on May 26, 2013 [3] and should be updated every 4 years.

\section{Methods}

${ }^{1}$ Universidade Federal de Minas Gerais (UFMG), Alameda Álvaro Celso, 175 /

$2^{\circ}$ Andar. Santa Efigênia. CEP 30.150-260, Belo Horizonte, MG, Brazil

Full list of author information is available at the end of the article
A systematic literature review was performed, with external review of an specialized group of the Brazilian 
Medical Association. It was used keywords defined according to the PICO (Patient | Intervention | Comparison | Outcome) strategy and searching for records in the following databases: MEDLINE, EMBASE, SciELO/ LILACS, and Cochrane Library, since March 1st, 2012 until December 31, 2018. The target population included patients with 3-month or more back pain and less than 45 years old, according to the ASAS classification criteria in 2009 [1, 2]. Two hundred thirty-seven studies were selected and used to formulate 29 recommendations answering 15 clinical questions, which were divided into four sections: diagnosis, non-pharmacological therapy, conventional drug therapy and biological therapy. For each recommendation the level of evidence supporting (highest available) and strength grade according to Oxford Centre for Evidence-based Medicine Levels of Evidence of 2001 [4] is informed. The methodological details of the bibliographic research and a table with the Oxford levels of evidence are available in the Additional file 1 . The degree of expert agreement (inter-rater reliability) was determined by the Delphi method through an online anonymous survey. Table 1 summarizes these recommendations and Fig. 1 shows a guide algorithm for axial SpA management.

Whenever possible, the results are presented as absolute values, followed by an effect size measure to highlight its clinical significance or practical relevance. In comparisons among treated and untreated (placebo) ratios, the number needed to treat (NNT) or the number needed to harm $(\mathrm{NNH})$, and the respective confidence intervals $(95 \% \mathrm{CI})$ were calculated using a normal approximation, the most statistically robust method. The data retrieved from each study used to define these intervals are available in Additional file 2. In comparisons between paired means (before and after treatment), the effect sizes were calculated using the Cohen method (difference between the means divided by the pooled standard deviation of the groups). Effect sizes were considered small ranging from 0.2 to 0.4 , medium ranging from 0.4 to 0.8 and large greater than 0.8 .

\section{Clinical questions}

1. What are the clinical criteria for considering someone affected by a spondyloarthritis?

In 2009, the ASAS group conducted a study based on the Delphi methodology, with the participation of all members, and selected all possible variables that should be evaluated in a patient with axial SpA. These variables were evaluated in a prospective study that included 647 patients who experienced back pain for more than three months without definite cause or known diagnosis, with or without peripheral symptoms, and an onset of symptoms before 45 years of age who were followed in 25 university centers from 16 countries.
The classification criteria based on two main variables were proposed (Table 2). The sensitivity based on these criteria was $82.9 \%$ and the specificity was $84.4 \%[1,2]$ (1B). Although some cases of axial SpA may start after 45 years of age, this age is set as a cut-off point to emphasize that many other causes of back pain after this age, particularly degenerative disorders, can mimic the imaging changes characteristic of axial SpA. Despite the specific criticisms directed to the method used to establish the classification criteria for SpA, proposed by ASAS, they represented a considerable advance in our understanding regarding the SpA spectrum and have been since widely adopted by the international community.

A study designed to assess the performance of the axial SpA classification criteria proposed by ASAS in Chinese individuals complaining of chronic back pain without radiological evidence of sacroiliitis found that the diagnostic concordance of the ASAS criteria was better than the criteria established by the European Spondyloarthropathy Study Group (ESSG) and by Bernard Amor. The sensitivity values of the ESSG, Amor and ASAS criteria were $81.5,87.7$ and $89.4 \%$, respectively, and the specificity values were $78.6,76.7$ and $86.4 \%$, respectively [5] (2B).

Another study, known as PROSpA (PRevalence Of axial $\mathrm{SpA}$ ), assessed the performance of the ASAS criteria in another population: American individuals over the age of 18 years and chronic back pain with onset before age 45 . In this study, the direct application of classification criteria proposed by the ASAS group enabled the diagnosis of $47 \%$ individuals with axial SpA. The specificity and sensitivity of the ASAS criteria were 79 and $81 \%$, respectively, which are slightly lower than the values reported in other, more "selected" populations and may be related to the lower prevalence of HLA-B27-positive individuals [6] (2B). In 2016, the long-term follow-up (mean of 4.4 years $)$ data regarding axial SpA cohort $(\mathrm{N}=394$ patients), based on ASAS classification criteria, showed that the positive predictive value was from 86 to $96 \%$ [7] (2B).

Despite the ASAS criteria has had a good performance, as shown above, their efficacy in diagnosing different populations varies, particularly in individuals with chronic back pain and whose pretest probability of axial SpA is low. Considering patients with back pain started after 45 years old, the ASAS axial criteria had also the best performance to classify as late-onset axial SpA in the clinical practice [8] (2B).

Recommendation

The 2009 ASAS criteria should be used to classify patients with axial spondyloarthritis. The diagnosis should be performed by an experienced physician or rheumatologist. Level of evidence: 1B; strength of recommendation: A (strong); Degree of agreement: 9.2. 


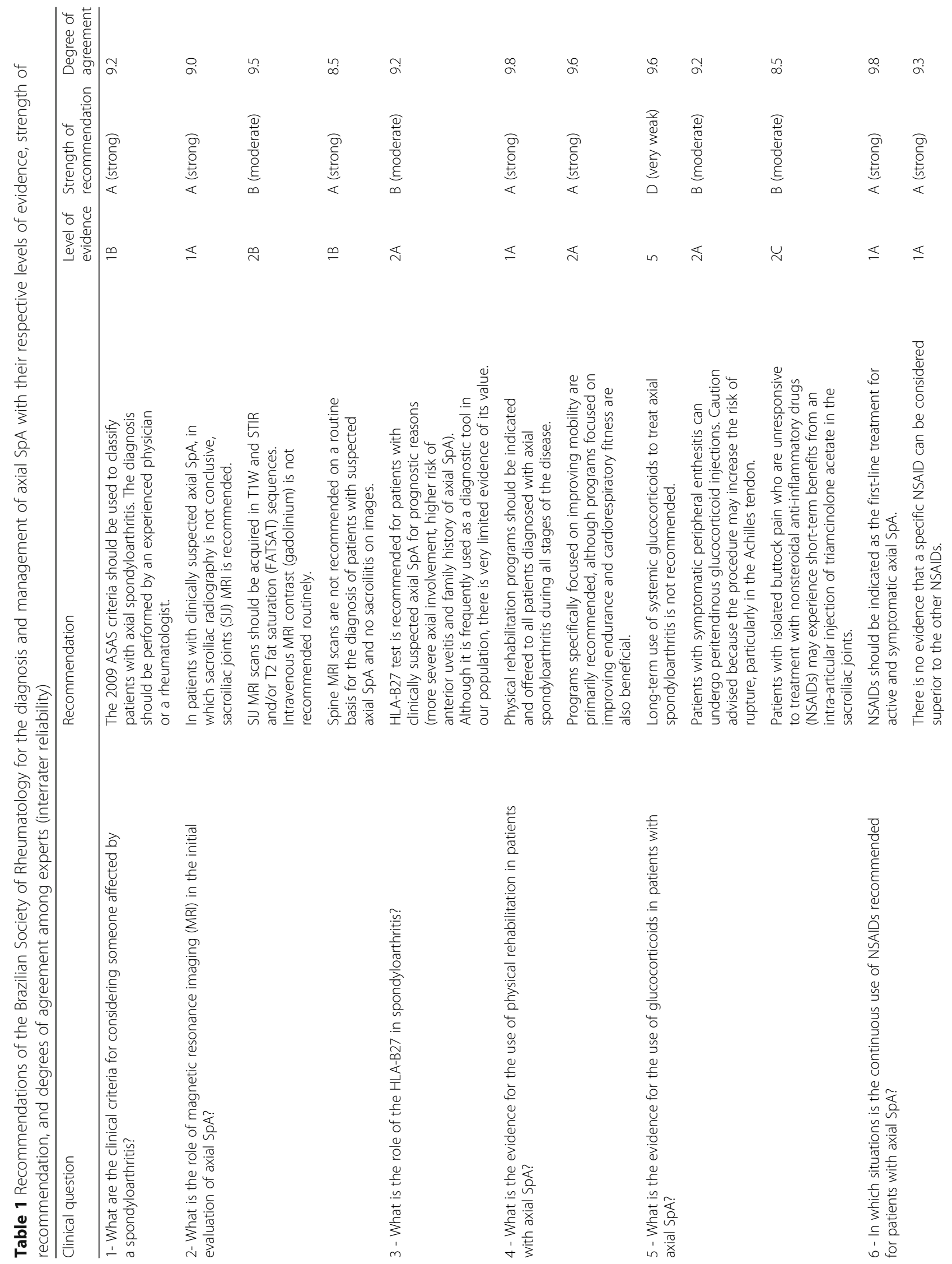




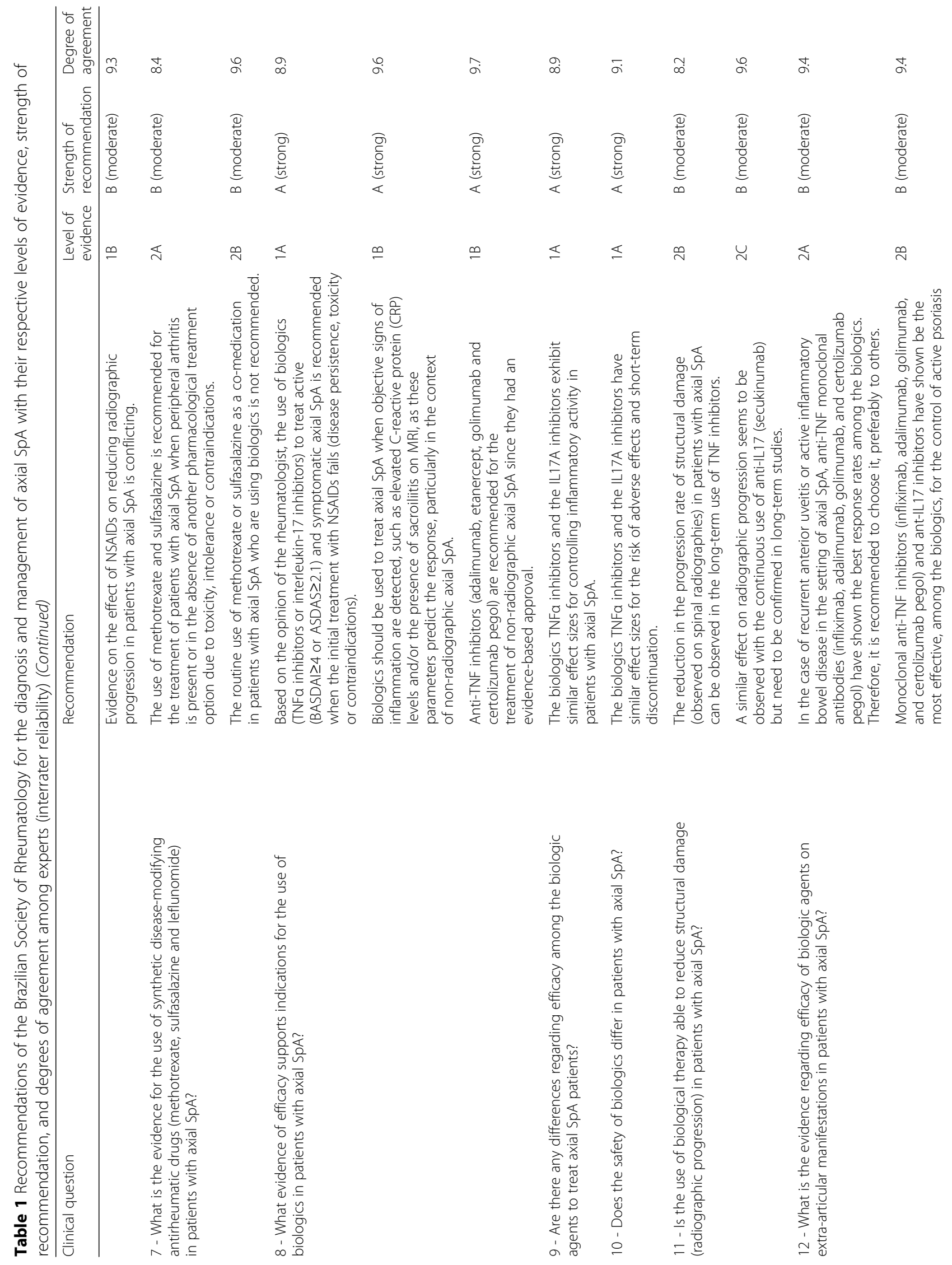


Resende et al. Advances in Rheumatology

(2020) 60:19

Page 5 of 35

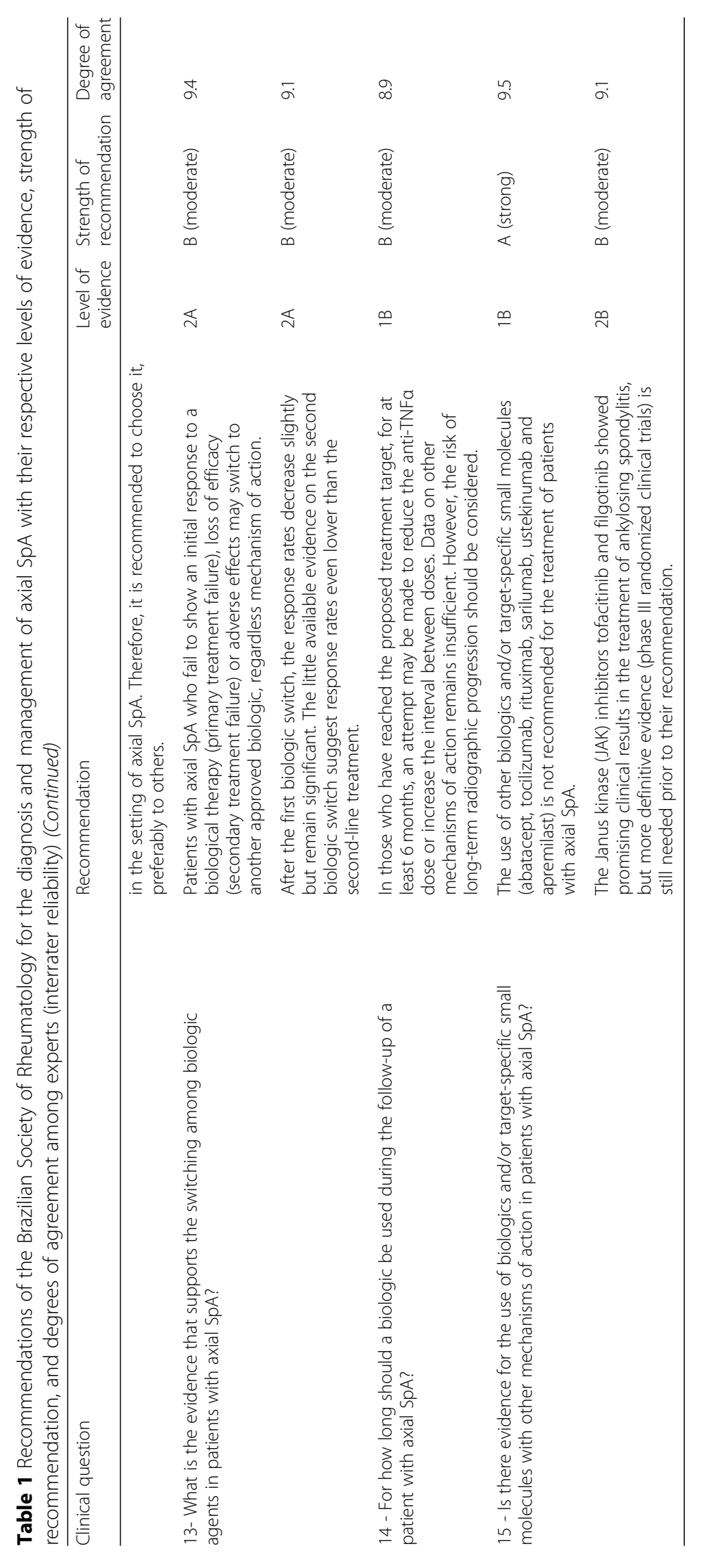




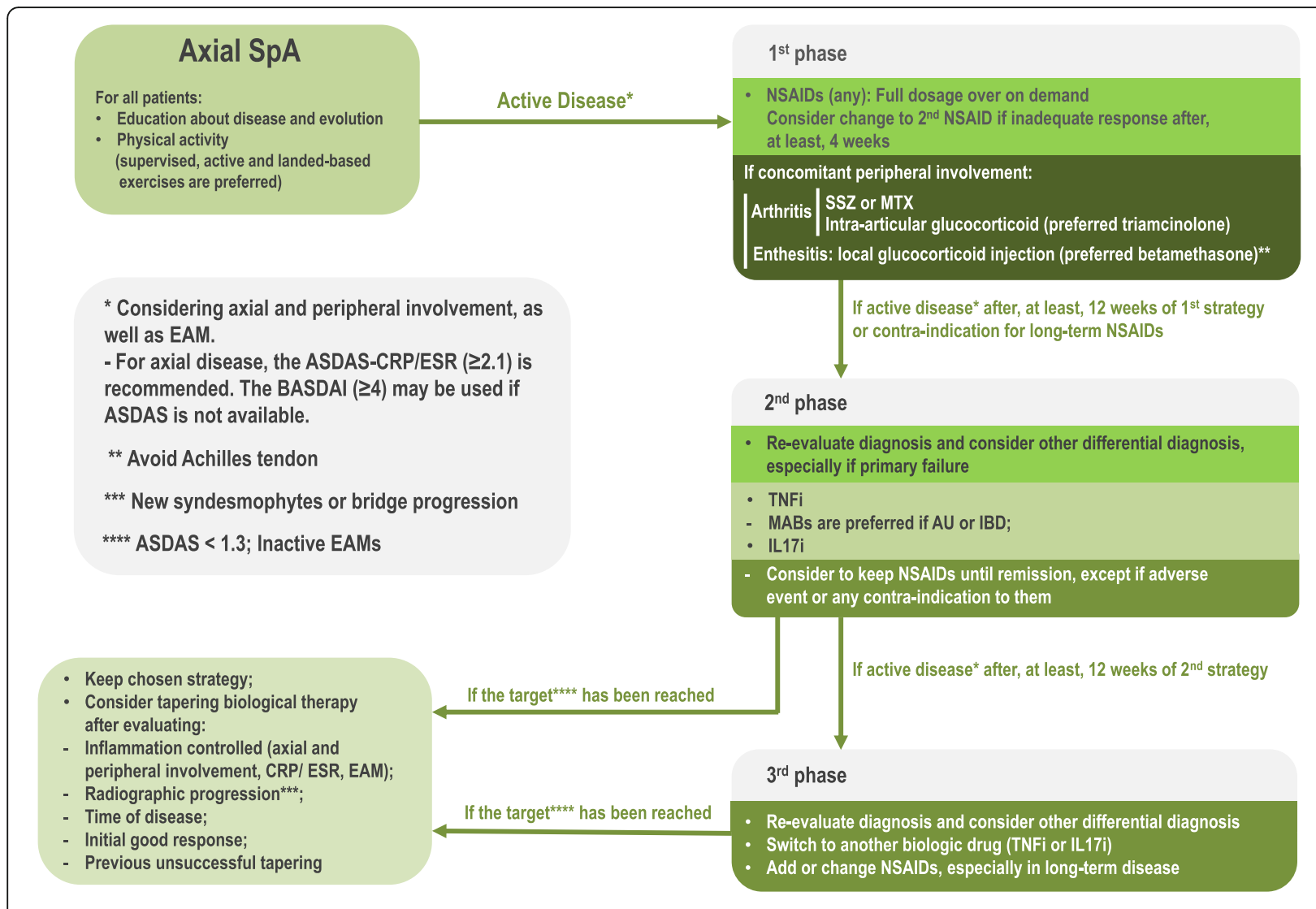

SSZ: sulfasalazine; MTX: methotrexate; TNFi: TNF inhibitors; IL-17i: LL-17 inhibitors; MABs: monoclonal antibodies; NSAIDs: non-steroidal anti-inflammatory drugs; EAM: extra-articular manifestations; AU: anterior uveitis; IBD: inflammatory bowel disease

Fig. 12019 Brazilian Society of Rheumatology algorithm for axial SpA management

2. What is the role of magnetic resonance imaging (MRI) for the initial evaluation of axial SpA?

Sacroiliac joints (SIJ) and spine imaging plays a key role for the diagnosis, classification, monitoring and prognosis of axial SpA patients. Bone structural changes, usually with a late onset, are clearly identified using conventional radiography [9] (2C), whereas inflammatory changes, often with an early onset, are better evaluated using MRI $[10,11](2 B)$.

\section{Diagnosis}

In 2009, the ASAS/Outcome Measures in Rheumatology (OMERACT) MRI working group published that the unequivocal presence of bone marrow edema and osteitis (in at least two sites in one slice or in one site in two consecutive slices) is essential to define active sacroiliitis for diagnostic purposes. Active inflammatory lesions have been visualized with both short tau inversion-recovery (STIR) images and T1weighted (T1W) sequences with fat suppression (FS) after administration of intravenous (IV) contrast (gadolinium) (T1 with FS post-Gd) [12] (5). In 2012, a study evaluated the baseline SIJ MRI scans of 29 patients with early inflammatory back pain (IBP) who were subsequently diagnosed with axial SpA according to the ASAS criteria, to validate the ASAS definition of active sacroiliitis. The study reported a $79 \%$ sensitivity, $89 \%$ specificity, a positive likelihood ratio $(\mathrm{LR}+)$ of 7.1 and a negative likelihood ratio (LR-) of 0.2 [13] (2B). In another study employing a retrospective design that analyzed 110 patients who were referred for SI) MRI (of whom 28 were later diagnosed with axial $\mathrm{SpA}$ ), the presence of bone marrow edema located in the sacral area and in both sacral and iliac areas was an independent predictor of diagnosis with odds ratios (ORs) of 7.07 (95\% CI 1.05-47.6) and 36 (95\% CI 5.61-23.1), respectively [14] (2B).

A multicenter study to evaluate the diagnostic utility of SIJ MRI scans from 187 people (75 patients with ankylosing spondylitis (AS), 27 patients with pre-radiographic IBP, 26 patients with non-specific back pain and 59 healthy controls) showed that bone marrow edema, erosion, fat metaplasia and ankylosis had 90\% of sensitivity and 97\% of specificity for diagnosis of axial SpA, with a $\mathrm{LR}+=30$ and, therefore, 97\% diagnostic certainty for positive axial SpA 
Table 22009 ASAS classification criteria for axial spondyloarthritis

\begin{tabular}{|c|c|c|}
\hline \multicolumn{3}{|c|}{ In patients with back pain $\geq 3$ months and age at onset $<45$ years } \\
\hline $\begin{array}{l}\text { Sacroiliitis on image } \\
\text { Active (acute) inflammation on MRI } \\
\text { highly suggestive of sacroiliitis } \\
\text { associated with SpA or definitive } \\
\text { radiographic sacroiliitis according to } \\
\text { mod. New York criteria }\end{array}$ & \multirow[t]{2}{*}{ or } & HLA-B27 positive \\
\hline plus $\geq 1 \mathrm{SpA}$ feature & & plus $\geq 2 \mathrm{SpA}$ features \\
\hline \multicolumn{3}{|c|}{ SpA features: } \\
\hline \multicolumn{3}{|c|}{$\begin{array}{c}\text { Inflammatory back pain } \\
\text { Arthritis } \\
\text { Enthesitis (heel) } \\
\text { Uveitis } \\
\text { Dactylitis } \\
\text { Psoriasis } \\
\text { Crohn's disease / ulcerative colitis } \\
\text { Good response to NSAID } \\
\text { Family history for SpA } \\
\text { HLA-B27 } \\
\text { Elevated CRP }\end{array}$} \\
\hline
\end{tabular}

and 91\% diagnostic certainty for negative axial SpA [11] (1A). The inclusion of erosions, but not fat metaplasia, for the definition of sacroiliitis (in addition to bone marrow edema) increased the sensitivity without a loss of specificity, according to three other studies [15-17] (2B). In the DESIR cohort that included patients with short-term axial SpA (IBP $\geq 3$ months and $\leq 3$ years), the structural lesions ( $\geq 5$ erosions or fat metaplasia) on SIJ MRI were reliably used instead of positive radiography [18] (2B). Conversely, in the SPACE cohort, any combination of 5 chronic lesions (erosions or fat metaplasia) ensured a specificity $>95 \%$ in discriminating patients with and without axial SpA [19] (2B). Regarding the SIJ MRI in the same cohort (SPACE), the use of an IV MRI contrast agent (gadolinium), which is essential for the detection of synovitis and/or capsulitis, failed to increase the sensitivity of the test compared with STIR alone, because these acute lesions were only observed in patients who also presented bone marrow edema (visible on STIR) [20] (2B). In addition, the acquisition of diffusionweighted images (DWI) is an alternative to the use of contrast agents, reducing the risk of nephrotoxicity, albeit without showing better performance than STIR imaging analyses [21, 22] (2B).

Regarding spine MRI scans, the value and the best definition for a positive MRI related to axial SpA remains open to debate, with rather data heterogeneity in different studies. In 2012, the ASAS/OMERACT MRI working group defined a positive spine MRI (inflammation) when there were the presence of bone marrow edema (BME) in 3 or more sites (corner inflammatory lesions) [23] (5). Some findings corroborate its use as a diagnostic tool, suggesting some value of spine MRI when sacroiliitis is absent. The findings include the observation of more than five corner fatty lesions (CFL) identified by hypersignals in T1W images in association with the diagnosis of axial SpA in patients with back pain, with $86 \%$ diagnostic certainty (LR of 12.6) [24] (2B); identification of lesions (both inflammatory and structural) in the spine MRI scans of $50 \%$ of the 20 patients without sacroiliitis (on XR or MRI) of a total of 60 patients with a confirmed diagnosis of axial 
SpA [25] (2B); and spinal inflammation in 53 of 109 (49\%) patients with non-radiographic axial SpA, without sacroiliitis, who were included in a clinical trial [26] (2B). Conversely, some evidence also questions the value of spine MRI in patients with suspected axial SpA, without sacroiliitis. In the SPACE and DESIR cohorts, the inclusion of spinal MRI as an imaging criterion into the ASAS criteria resulted in the reclassification of a very small percentage of patients (1-2\%) [27] (2B). In another study of 130 patients with chronic back pain who were younger than 50 years and 20 healthy controls, the combination of spine MRI (using the ASAS/OMERACT definition and several other alternatives) with SIJ MRI had little effect on the final accuracy, mainly due to the large number of false-positives (11-16\% of the patients were diagnosed with non-specific back pain and $17.5 \%$ of the healthy controls had spine lesions) [28] (2B). In the ASAS cohort, in which the 2009 criteria were validated, only $5.4 \%$ of 235 patients with SIJ and spine MRI exclusively had spinal inflammation [2] (2B).

\section{Prognosis}

For the evaluation of patients with recent-onset IBP $(<2$ years), the combination of MRI-evident severe sacroiliitis, according to the Leeds scoring system ( $>75 \%$ of any SIJ quadrant affected by bone marrow edema), added to positive HLA-B27 predicts the future development of radiographically evident AS at eight years with $62 \%$ sensitivity, $92 \%$ specificity, $80 \%$ positive post-test probability and $83 \%$ negative post-test probability. Severe sacroiliitis alone predicted this diagnosis with $50 \%$ positive post-test probability and $84 \%$ negative post-test probability [10] (2B). Based on 2 to 7 years of follow-up of axial SpA patients, the evaluation of SIJ MRI changes (Danish score: erosion, edema and fat infiltration) revealed that chronic changes at baseline are related to the future development of AS. At baseline, the SIJ MRI scans with activity scores $\geq 2$, total chronic scores $\geq 1$, erosion scores $\geq 1$ and fatty metaplasia scores $\geq 4$ had predictive ability for the radiographic sacroiliitis of 74 , 77, 79 and 68\% accuracy, respectively [29] (1B). In another study, radiographic progression (measured using the modified Stoke Ankylosing Spondylitis Spinal Score [mSASSS]) was significantly greater during the follow-up period in patients with fat metaplasia and ankylosis at baseline SIJ MRI scans than in patients without these lesions [30] (2B). Also regarding spine MRI, the presence of corner inflammatory lesions (CILs) in AS patients after 2 years of follow-up predicted a $14.9 \%$ increase for developing new syndesmophytes $(\mathrm{NNH}=7)$. After TNF inhibitors, this risk was $11.4 \%$ higher for vertebral corners with no inflammation than in those with inflammation $(\mathrm{NNH}=9)$ [31] (1B). Higher Bath Ankylosing Spondylitis Metrology Index (BASMI; an index of the degree of functional limitation in patients with AS) scores have already been associated with higher Ankylosing Spondylitis spine Magnetic Resonance Imaging-activity (ASspiMRI-a; an index of spinal inflammatory activity on
MRI) scores, particularly in patients who have suffered from the disease for $\leq 3$ years and with higher mSASSS scores (an index of radiographic progression). In conclusion, spinal mobility is independently determined by both reversible spinal inflammation (on MRI) and irreversible structural damage (on XR) [32] (2B).

Recommendation

\begin{abstract}
In patients with clinically suspected axial SpA, in which sacroiliac radiography is not conclusive, sacroiliac joints (SIJ) MRI is recommended. Level of evidence: $1 A$; Strength of recommendation: $A$ (strong); Degree of agreement: 9.0 .

SIJ MRI scans should be acquired in T1W and STIR and/or T2 fat saturation (FATSAT) sequences. Intravenous MRI contrast (gadolinium) is not recommended routinely. Level of evidence: $2 B$; Strength of recommendation: $B$ (moderate); Degree of agreement: 9.5 . Spine MRI scans are not recommended on a routine basis for the diagnosis of patients with suspected axial SpA and no sacroiliitis on images. Level of evidence: $1 B$; Strength of recommendation: $A$ (strong); Degree of agreement: 8.5.
\end{abstract}

3. What is the role of HLA-B27 in axial spondyloarthritis? Diagnosis

HLA-B27 represents an important arm (also known as clinical arm) of the ASAS classification criteria. When combined with other variables (such as imaging and other clinical criteria), HLA-B27 allows the classification of axial SpA [2] (2B). The presence of HLA-B27, when associated with sacroiliitis diagnosed on MRI, increases the diagnostic specificity for AS of the latter from 62 to $77 \%$ compared with MRI alone, without changing the sensitivity. A positive HLA-B27 test alone predicted the disease with $48 \%$ probability, and negative HLA-B27 test excluded the disease with $88 \%$ probability [10] (2B). The value of HLAB27 as a diagnostic tool in the Brazilian population remains unknown due to lack of evidence.

Genetic factors have already been associated with susceptibility to AS, as shown in a meta-analysis of studies that measured the risk of occurrence of AS in relatives of patients with AS. A 63\% risk was observed among monozygotic twins, an $8.2 \%$ risk was observed among first-degree relatives, and 1.0 and $0.7 \%$ risks were observed among second- and third-degree relatives, respectively [33] (2A). According to a study enrolled 348 blood donors of whom 20 were diagnosed with SpA, the relative risk (RR) of developing SpA was 20 (95\% CI 4.6-94) among HLA-B27-positive individuals. In the same study, 50\% of HLA-B27-positive individuals with IBP had sacroiliitis on SIJ MRI [34] (2B). The overall incidence and prevalence of AS and $\mathrm{SpA}$ strongly depend on and are directly correlated with the prevalence of HLA-B27 in a specific population. Indeed, in various countries, their prevalence rates vary widely: 0.14 1.4\% for AS; $0.30-1.73 \%$ for SpA; and $5.4-16 \%$ for HLAB27 [35, 36] (2B). Currently, more than 160 HLA-B27 subtypes have been identified (HLA-B*27:01 to HLA-B*27:161) 
and coded by 213 allelic variants, with wide variation related to ethnicity [37] (5).

Prognosis

In HLA-B27-positive AS patients, the data have shown longer disease duration (earlier onset of symptoms and diagnosis), higher frequency of NSAIDs intake, higher frequency of biologic agents therapy, higher disease severity (including extra-articular manifestations) and higher functional (Bath Ankylosing Spondylitis Functional Index BASFI) and disease activity (BASDAI) scores [38, 39] (2B). In another study, HLA-B27-positive AS patients showed significantly more axial and hip involvement; higher positive family history frequency; and higher percentage of men among HLA-B27-positive AS patients than among HLAB27-negative AS patients [40] (2B). There was significant association between HLA-B27 and BASMI (metrological index) in AS patients (worse prognosis) [41] (2B). In Chinese AS patients there was significant association between HLA-B27 positivity and severe SIJ involvement and earlieronset disease [42] (2B). In fact, when AS patients were classified according to onset-disease age $(<20$ years, $21-30$ years, $31-40$ years and $>40$ years), the positivity for HLAB27 was found in 94.6, 90.2, 74.1, and 61.2\%, respectively. The same pattern was also observed in non-radiographic axial SpA patients [43] (2B). A systematic literature review included almost 30,000 patients reported 4-times higher likely for uveitis in HLA-B27 positive AS patients [44] (2A). Recommendation

HLA-B27 test is recommended for patients with clinically suspected axial SpA for prognostic reasons (more severe axial involvement, higher risk of anterior uveitis and family history of axial SpA). Although it is frequently used as a diagnostic tool in our population, there is very limited evidence of its value. Level of evidence: $2 A$; Strength of recommendation: $B$ (moderate); Degree of agreement: 9.2.

4. What is the evidence for the use of physical rehabilitation in patients with axial SpA?

According to the Assessment of Spondyloarthritis International Society/ European League Against Rheumatism (ASAS/EULAR) group, the optimal management of patients with axial SpA requires a combination of nonpharmacological and pharmacological treatment modalities [45] (1A). Among non-pharmacological therapies, exercise is considered an important tool for maintaining or improving mobility and physical function and for preventing deformities [46-48] (1A).

Supervised exercise

A randomized controlled trial (RCT) compared the treatment of patients with AS $(n=40)$ using the Global Postural Reeducation (GPR) method or conventional exercise; both exercise interventions were conducted in weekly 1-h sessions in groups of 6-8 patients for 4 months. The outcomes were mobility, as assessed using the BASMI, activity assessed using the BASDAI and physical function scored with the BASFI. After 4 months (15 sessions), the BASFI (effect size of 0.32) and all BASMI parameters (effect sizes ranging from 0.36 to 1.1), but not the BASDAI, significantly improved in the GPR group. Only the tragus to wall distance and lumbar side flexion were significantly improved in the control group. The comparison between the two forms of treatment revealed better results in the group treated with postural rehabilitation using the GPR method than in the group treated with conventional training over a one-year follow-up period $[49,50](2 B)$. Similar results were obtained in another study in which patients with AS were subjected to a 16week supervised GPR program $(n=22)$ or unsupervised training $(\mathrm{n}=16)$. Morning stiffness, pain, spinal mobility, physical function (Health Assessment Questionnaire Spondyloarthropathies - HAQ-S), quality of life (Medical Outcomes Study 36 - Item Short-Form Health Survey SF-36) and disease activity (BASDAI) were evaluated, with significant improvements in all study parameters between the pre- and posttreatment periods in both groups. The GPR group reported significantly better results for morning stiffness, spinal mobility and the physical component of the SF-36 than the control group [51] (2B). Consistent with these findings, significant improvements in the BASDAI, BASMI and BASFI indices were observed in a group of patients with AS $(n=48)$ subjected to training combining the Pilates, McKenzie and Heckscher techniques compared to a group $(\mathrm{n}=48)$ subjected to conventional physical therapy (classical kinesiotherapy) [52] (2B).

In-patient exercise

Patients with AS ( $\mathrm{n}=107)$ who were subjected to 4-week, in-patient rehabilitation programs were assessed for health status (patient global assessment, pain, morning stiffness, spinal mobility, BASFI, BASDAI and fatigue) according to the Assessments in Ankylosing Spondylitis working group's Improvement Criteria (ASAS-IC; the response criterion most commonly used in clinical trials, consisting of four domains: physical function, spinal pain, patient global assessment and inflammation). The programs offered a personalized assessment of physical therapy, group exercise, passive therapy, relaxation and patient education, with a difference in two components - endurance training (centers located in Norway) or mobility (centers located in the Mediterranean). After 16 weeks, all variables (except question 2 of the BASDAI (spinal pain), thoracic expandability and erythrocyte sedimentation rate (ESR)) were significantly improved by both modalities. The numbers of patients who achieved ASAS20 and ASAS40 were 27\% (NNT =4) and $19 \%(\mathrm{NNT}=5)$ higher after mobility-focused rehabilitation than after endurance training-focused rehabilitation at week 16. This difference, although not significant, persisted until the final assessment (week 28) [53] (2B). Another randomized clinical trial also reported evidence favoring a 3-week 
in-patient rehabilitation program $(n=46)$ over the "usual treatment", without systematic rehabilitation $(\mathrm{n}=49)$. The results showed significant improvements of BASDAI (effect size $=1.38$ ) and physical, emotional and vitality and pain components of the SF-36 after 4months of follow-up. However, after 12 months, no significant differences were observed in any study outcome, thus indicating a transient effect of rehabilitation [54] (2B).

Education and home-based exercise

A non-randomized clinical trial $(n=66)$ compared patients with AS who underwent a home-based exercise program (after theoretical and practical counseling by a physical therapist) five times a week (at least $30 \mathrm{~min}$ per session) with patients who exercised less than five times a week (control group). After 3 months of follow-up, all assessed parameters, such as pain, morning stiffness, spinal mobility, BASFI, BASDAI, Ankylosing Spondylitis Quality of Life Questionnaire (ASQol) and the pulmonary function measures forced vital capacity (FVC) and forced expiratory volume in $1 \mathrm{~s}$ (FEV1) significantly improved in the treatment group compared to the baseline values, but not in the control group, which even showed worsening of some parameters (stiffness, mobility and ASQol). In the intergroup comparison, only the quality of life scores (ASQol) at 3 months differed significantly, in favor of the treatment group [55] (2B). Another RCT compared a short-term (5-day) education and exercise program, followed by unsupervised training, with conventional treatment (no exercise). This trial included 41 patients with AS and, after 3 months of follow-up, observed significant improvements (BASDAI, BASFI, ASQol and SF-36) compared to the baseline only in the education+exercise group. No improvements regarding BASMI or inflammatory markers were observed [56] (2B). The educational intervention effectiveness (a 2-h session, with guidance on the disease and an unsupervised physical activity program) was also investigated in another RCT $(\mathrm{n}=756)$ in which 381 patients were allocated to the experimental group and 375 to the control group (without any specific intervention). After 6 months, the experimental group showed significantly better quality of life (ASQoL), physical function (BASFI), global pain and disease activity scores (BASDAI) than the control group, even after adjusting for baseline values, sex, age and education. The effect sizes ranged from 0.20 to 0.28 [57] (2B). A 2015 meta-analysis included data from six studies including 1098 patients and concluded that exercise, even unsupervised, significantly improves physical function (measured using the BASFI), disease activity (measured using the BASDAI) and depression and pain scores [58] (2A).

Aerobic exercise

A RCT compared the effect of aerobic exercise (a 50min walk, 3 times per week for 3 months) followed by stretching exercises (intervention group) with stretching alone (control group) on 70 patients with AS (35 in each group). The BASMI, BASFI, HAQ-S, BASDAI and ASDAS scores improved in both groups, with no significant differences between groups. The 6-min walk test and aerobic capacity (as assessed using ergospirometry on a treadmill) were significantly improved in the intervention group compared with the control group [59] (2B). Another clinical trial included 106 patients with AS who were randomly allocated to the aerobic exercise group (3 times per week) or control group (both with a weekly session of stretching exercises). After 3 months, physical fitness (measured in watts) and the BASDAI peripheral pain component were significantly better in the aerobic exercise group than in the control group [60] (2B). In another nonrandomized trial, 46 patients with axial SpA were subjected to a 6-month physical exercise program, including aerobic training (60 min, twice a week), and compared with another 29 sex- and agematched patients with axial SpA (controls, without any intervention). In the final evaluation, the ASDAS-CRP and BASMI values were significantly improved in both groups and were better in the exercise group than in the control group [61] (2C). Another study also reported benefits from aerobic exercise (40-60 min, 3 times per week) in 28 patients with axial SpA who were randomly allocated to the exercise group or to the control group. After 12 weeks, the exercise group showed significant differences in disease activity (BASDAI), physical function (BASFI), cardiorespiratory fitness (peak oxygen volume $\left(\mathrm{VO}_{2}\right)$ ), body composition (\% total and abdominal fat) and arterial stiffness markers (augmentation index and pulse wave velocity). Therefore, cardiovascular risk factors were reduced by this type of intervention [62] (2B).

Aquatic exercise

A clinical trial compared aquatic exercise (20 sessions: 5 sessions per week for 4 weeks) with home-based exercise after a practical demonstration in 69 patients with AS. All study parameters (pain, BASMI, BASFI, BASDAI and SF-36) were significantly improved after 4 and 12 weeks in both groups. The intergroup comparison showed significant differences in pain and in six of the eight components of the SF-36, favoring aquatic exercise [63] (2B). In another RCT, 30 patients with axial SpA were allocated to an aquatic exercise and stretching program (24 sessions: 3 sessions per week for 8 weeks) or to the control group (no training). Quality of life (SF-12), physical function (BASFI) and disease activity (BASDAI) only significantly differed between the pre- and postintervention periods in the treatment group (effect sizes ranging from 0.44 to 0.66$)$ [64] (2B).

However, it is important to emphasize that an exercise test could be requested before recommending some 
physical activity for AS patients, regardless disease activity, functional or mobility impairment, as well as concomitant diseases or other medications [65] (2B). Recommendation

Physical rehabilitation programs should be indicated for and offered to all patients diagnosed with axial spondyloarthritis during all stages of the disease. Level of evidence: $1 A$; Strength of recommendation: $A$ (strong); Degree of agreement: 9.8 .

Programs specifically focused on improving mobility are primarily recommended, although programs focused on improving endurance and cardiorespiratory fitness are also beneficial. Level of evidence: $2 A$; Strength of recommendation: $B$ (moderate); Degree of agreement: 9.6.

5. What is the evidence for the use of glucocorticoids in patients with axial SpA?

Systemic glucocorticoids

A double-blind study compared a single pulse therapy with two doses of methylprednisolone (375 mg versus $1000 \mathrm{mg}$ in an IV injection for 3 days) in the treatment of 17 patients with AS who were unresponsive to NSAIDs with a 180-day follow-up. The study showed improvements in mobility, pain and morning stiffness following the administration of both doses, with less persistent effects on pain (the median time to requiring reintroduction of analgesics and/or NSAIDs was 8 days at the lowest dose and 25 days at the highest dose) than on morning stiffness (pretreatment levels were reached after 90 and 120 days of treatment with the lowest and highest dose, respectively) and mobility (improvement was observed throughout the follow-up period of 180 days). No significant difference in any outcome was observed between doses, but the very small sample size precluded this comparison. No serious adverse event was observed during the 180-day follow-up period [66] (2B). Another study with a retrospective design and a small sample size $(\mathrm{n}=15)$ observed BASDAI improvement $(7.4 \pm 1.5$ at baseline) after pulse therapy with methylprednisolone (250-500 mg per day for 3-5 days) from the first posttreatment evaluation (on the day after treatment, $3.9 \pm$ 2.4, $\mathrm{p}<0.001)$ to the 3-month $(5.3 \pm 1.8, \mathrm{p}<0.001)$ and 12-month (5.4, $\mathrm{p}<0.001$ ) evaluations [67] (2C). Conversely, the use of low-dose oral glucocorticoids $(5.0 \mathrm{mg} /$ day of modified-release prednisone) was evaluated in a 12-week uncontrolled study, which included 57 individuals with axial $\mathrm{SpA}$ who were refractory, intolerant to or contraindicated for NSAIDs. In the initial evaluation, $73.7 \%$ patients used a synthetic disease-modifying antirheumatic drug (DMARD; methotrexate (MTX), sulfasalazine (SSZ) or leflunomide (LFL)) and 7\% used a TNF $\alpha$ inhibitor; the doses remained stable throughout the study. The results showed a significant decrease in disease activity (from $5.5 \pm 2.6$ to $3.0 \pm 2.8$ on the BASDAI; $\mathrm{p}=0.001$ ), but not concerning mobility (BASMI) or enthesitis index (Maastricht Ankylosing Spondylitis Enthesitis Score - MASES). No serious adverse event was observed during the 12-week follow-up period [68] (2C). Another short-term randomized, placebocontrolled trial, which included 34 patients with AS, found that daily treatment with two oral doses of prednisolone $(20$ or $50 \mathrm{mg}$ ) for two weeks improved activity indices compared with the placebo. Although the treatment group showed no significant improvement in the primary outcome (BASDAI50), the $50 \mathrm{mg} /$ day dose led to significant decreases in BASDAI (2.39 [1.38-3.40], $\mathrm{p}=0.03)$ and ASDAS-CRP scores (1.56 [0.93-2.20], $\mathrm{p}=$ 0.01 ), whereas the dose of $20 \mathrm{mg} /$ day only produced a significant decrease in the ASDAS-CRP score (1.16 [0.45-1.88], $\mathrm{p}=0.004)$ [69] (2B). A cohort study $(\mathrm{n}=$ 830 ) evaluated the safety of low daily oral doses (prednisone up to $10 \mathrm{mg}$ or an equivalent dose) by comparing the incidence of adverse effects in AS patients users $(\mathrm{n}=$ $555)$ and nonusers $(\mathrm{n}=275)$. The study found higher incidence of skin adverse effects, such as acne, hematomas and infections (22.2 vs 6.6/1000 patient-years (PY); $\mathrm{p}=$ $0.003)$ among users. However, when considering a mean follow-up period of 1.6 years (0.5-15) and a total of 1801 PY of exposure to glucocorticoids, the study did not detect differences related to low bone mass or lipids and glucose serum levels changes [70] (2B).

Infiltration with glucocorticoids

In an open-label and uncontrolled study, an ultrasoundguided retro-calcaneal bursa injection of $20 \mathrm{mg}$ of methylprednisolone in 18 patients with SpA (27 cases of symptomatic Achilles enthesitis treated) improved pain (visual analog scale (VAS): 7 [4-10] vs 3 [0-7]; $\mathrm{p}<0.0001$ ) and ultrasound parameters (reduced tendon thickness and vascularity, peritendinous edema and bursitis and power Doppler signal intensity) after 6 weeks, without any complication documented until the last evaluation of each patient in the study (3 to 12 months) [71] (2C). A systematic literature review (which included only 5 studies, with only one RCT) questions the long-term effects of infiltration of glucocorticoids on the Achilles tendinopathy in general (not only in patients with $\mathrm{SpA}$ ) and highlights the risk of tendon injuries and rupture [72] (2A).

An uncontrolled trial included 66 patients with axial SpA who experienced inflammatory back pain for at least two months without an improvement after 4 weeks of NSAID use and were treated with a computed tomography (CT)-guided intraarticular injection of 40 $\mathrm{mg}$ of triamcinolone acetate into the sacroiliac joints. The results showed a significant reduction in pain intensity (as assessed using the VAS) from 2 weeks $( \pm 1$ ) to 10 months $( \pm 5)$ after the intervention. A reduction in the levels of serum inflammatory markers (ESR and CRP) and bone marrow edema on SIJ MRI were also observed [73] (2C). 
Recommendation

Long-term use of systemic glucocorticoids to treat axial spondyloarthritis is not recommended. Level of evidence: 5; Strength of recommendation: D (very weak); Degree of agreement: 9.6 .

Patients with symptomatic peripheral enthesitis can undergo peritendinous glucocorticoid injections. Caution is advised because the procedure may increase the risk of rupture, particularly in the Achilles tendon. Level of evidence: $2 A$; Strength of recommendation: $B$ (moderate); Degree of agreement: 9.2.

Patients with isolated buttock pain who are unresponsive to treatment with nonsteroidal anti-inflammatory drugs (NSAIDs) may experience short-term benefits from an intraarticular injection of triamcinolone acetate in the sacroiliac joints. Level of evidence: $2 C$; Strength of recommendation: B (moderate); Degree of agreement: 8.5.

6. In which situations is the continuous use of NSAIDs recommended for patients with axial SpA?

Based on evidence of high-to-moderate quality, an extensive systematic review and meta-analysis (Cochrane) published in 2015 (including 35 studies published until June 2014 and including 4356 patients with axial SpA) concluded that both traditional NSAIDs and cyclooxygenase-2 (COX2) inhibitors (coxibs) are more effective than the placebo for improving pain, disease activity (BASDAI) and physical function (BASFI) in 6-12 weeks), with no significant differences in benefits or damages between the two classes of NSAIDs [74] (1A). Another systematic review and Bayesian network meta-analysis included 26 studies with 3410 patients (of whom approximately $60 \%$ overlapped with the Cochrane review mentioned above) by limiting the diagnosis to AS and compared 20 different NSAIDs. The authors also concluded that the evidence was insufficient to consider that any NSAID is more effective in treating AS than the other drugs [75] (1A). Other studies published after these reviews corroborate the similarity between coxibs and non-selective NSAIDs. A comparison between two doses of celecoxib (200 mg and $400 \mathrm{mg}$ daily) and diclofenac (150 mg daily) did not detect differences in improving pain and adverse effects in 330 AS patients [76] (1B). The efficacy and tolerance/safety study of etoricoxib (daily doses of 60 and $90 \mathrm{mg}$ ) in AS patients had similar results to naproxen at dose of $1000 \mathrm{mg} /$ day [77] (1B).

Inhibition of radiographic progression

Based on the current evidence, the continuous use of NSAIDs by AS patients might reduce the radiographic progression of spinal damage (new bone formation), although no clinical trial comparing the use of NSAIDs with placebo for this outcome has been published to date. A RCT compared continuous and on-demand use of NSAIDs (celecoxib). At the end of the study (after 24 months of follow-up), although significant differences in activity levels (BASDAI) and physical function (BASFI) were not observed between the two groups, radiographic progression, as assessed using the mSASSS, was three times higher in patients treated with the on-demand regimen than in patients treated with the continuous regimen $(0.4 \pm 1.7$ vs $1.5 \pm 2.5 ; \mathrm{p}=0.002)$. The frequency of adverse events, namely, hypertension, abdominal pain and dyspepsia, was higher in the continuous regimen group but was not significantly different from the on-demand regimen group [78]. Subgroup and post hoc analyses of this trial suggested that the benefit is greater in or even exclusive to patients at greater risk of radiographic progression (patients with elevated inflammatory tests, high rates of disease activity, and pre-existing syndesmophytes) [79] (1B). Another (retrospective) study reported similar results. In 88 patients with AS of the German Spondyloarthritis Inception Cohort (GESPIC), more intense use of NSAIDs (defined by the intake of doses $\geq 50 \%$ of the recommended maximum dose for each NSAID) compared with less intense use (NSAID index $<50 \%$ of the maximum recommended dose) was associated with a lower likelihood of radiographic progression (defined as worsening $\geq 2$ units on the mSASSS), with an OR of 0.15 (95\% CI 0.02-0.96; $\mathrm{p}=$ 0.045), even after adjustment for baseline structural damage, CRP levels and smoking. Conversely, in 76 patients with non-radiographic axial SpA in the same cohort, the same difference in radiographic progression was not observed between intense or non-intense NSAID users, most likely due to the generally low frequency of new bone formation in this subgroup [80] (2C). However, opposite results were obtained in another prospective study known as ENRADAS (Effects of NSAIDs on Radiographic Damage in Ankylosing Spondylitis). In this randomized, multicenter trial, whose primary outcome was the difference in spinal radiographic progression measured using the mSASSS, patients with AS were randomly allocated to continuous treatment with diclofenac $(150 \mathrm{mg} /$ day $)$ or to on-demand treatment. At the end of the two-year follow-up period, both groups showed significant radiographic progression, with no differences between individuals from the continuous regimen and on-demand regimen groups $(\mathrm{OR}=1.3$ with a $95 \% \mathrm{CI}$ of $0.7-1.9$ versus $\mathrm{OR}=0.8$ with a $95 \% \mathrm{CI}$ of $0.2-1.4$, respectively). No differences regarding adverse events were observed between the two groups [81] (1B). The evident contradiction between these results, including two clinical trials with very similar designs, indicates that the possible beneficial effect of NSAIDs on new bone formation is not clearly established.

Recommendation

NSAIDs should be indicated as the first-line treatment for active and symptomatic axial SpA. Level of evidence: $1 A$; Strength of recommendation: A (strong); Degree of agreement: 9.8 .

There is no evidence that a specific NSAID can be considered superior to the other NSAIDs. Level of evidence: $1 A$; Strength of recommendation: A (strong); Degree of agreement: 9.3.

Evidence on the effect of NSAIDs on reducing radiographic progression in patients with axial SpA is conflicting. Level of evidence: $1 B$; Strength of recommendation: B (moderate); Degree of agreement: 9.3. 
7. What is the evidence for the use of synthetic diseasemodifying antirheumatic drugs (methotrexate, sulfasalazine and leflunomide) in patients with axial SpA?

Methotrexate

A systematic review and meta-analysis showed the evidence regarding the effects of methotrexate in AS patients was insufficient. However, it is important to highlight that only 5 clinical trials were included (256 patients), with heterogeneity related to outcomes and treatments, hampering the its validity [82] (2A). Of the studies included in the review, only one randomized, placebo-controlled trial showed positive results in 35 patients with AS who were treated with methotrexate at a dose of $7.5 \mathrm{mg} /$ week for 24 weeks. In this study, an improvement $\geq 20 \%$ in five of the eight following items was considered a response: a) morning stiffness intensity, b) physical well-being, c) BASDAI, d) BASFI, e) HAQ-S, f) physician global assessment (PGA), and g) patient-reported disease activity. The results showed a higher percentage of responsive patients in the treatment group than in the placebo group (53\% vs 11\%). In the intention-totreat (ITT) analysis, an NNT $=3$ was found, with BASDAI, BASFI and HAQ-S, and other PROs (patient-reported outcomes) improvements, with no differences in the reported frequency of adverse events [83] (2B). In a 1-year randomized clinical trial (RCT) with 51 AS patients, a weekly $7.5-\mathrm{mg}$ dose of methotrexate had no additional benefit in improving activity, mobility or physical function parameters compared to the use of naproxen alone, with the exception of the PGA [84] (2B). Another 24-week RCT with 30 AS patients showed no significant difference between the groups [85] (2B). When comparing the use of methotrexate with placebo in patients with AS using infliximab, the results were also conflicting. An open-label, non-randomized, small-scale $(n=19)$ trial with a high risk of bias (the compared groups were heterogeneous with respect to previous exposure to treatments) observed a better BASDAI50 and ASAS50 response in the methotrexate group than in the placebo group [86] (2C). In another trial, 123 patients were allocated to an ondemand regimen of infliximab after conventional infusion. Of these individuals, 62 patients were treated with methotrexate (at a maximum dose of $12.5 \mathrm{mg}$ per week) and 61 received anti-TNFa alone. After 52 weeks, no significant differences were found, according to the ASAS definition on improvement outcomes [87] (2B).

Thus, there is no agreement regarding the type of benefit or subpopulation in which the methotrexate could be used [88-90] (2C). Methotrexate also reduced the incidence of anterior uveitis (from 2.05/PY to 0.21/ PY, $\mathrm{p}<0.0001)$ in a small observational study that included 21 patients with recurrent acute anterior uveitis, 8 of whom (38\%) had a positive HLA-B27 test [91] (2C).

Sulfasalazine

Eleven clinical trials were included in a systematic literature review (Cochrane) published in 2005 and updated in 2014, and the effects of sulfasalazine in patients with AS $(n=895)$ were assessed. The authors concluded that the evidence did not support any beneficial effect of the drug on reducing pain, disease activity or radiographic progression or on improving physical function or mobility. ESR and spinal stiffness were the only significantly improved outcomes, although with very small effect sizes and without clinical significance $(-4.8 \mathrm{~mm} / \mathrm{h}[95 \% \mathrm{CI}-8.8$ to -0.8$]$ for ESR; and $-13.9 \mathrm{~mm}$ [ $95 \% \mathrm{CI}-22.5$ to -5.2$]$ in a $100-\mathrm{mm}$ visual scale for stiffness). In addition, the risk of treatment discontinuation due to adverse effects increased by $47 \%$, with reports of severe adverse reactions (erythematous rash, nausea, anorexia and, insomnia) [92, 93] (2A).

Another study that was not included in the aforementioned review also assessed "non-radiographic patients". This RCT included 230 patients who showed no improvement after 24 weeks of treatment with $2 \mathrm{~g}$ of sulfasalazine per day compared to the placebo-treated group. Surprisingly, in the subgroup without peripheral arthritis, the BASDAI score improved significantly (due to the exclusive improvement in the spinal pain and spinal stiffness components) [94] (2B).

Two studies with the TNF $\alpha$ inhibitor etanercept used sulfasalazine (2-3g per day) as an active comparator from which some evidence of efficacy was deduced. One trial allocated 187 patients with active AS to treatment with sulfasalazine. After 16 weeks, $52.9 \%$ of these patients achieved the ASAS20 response and 15.5\% showed partial remission according to the ASAS definition [95] (2C). In the other trial (ESTHER), 36 patients with active, non-radiographic axial SpA received sulfasalazine for 48 weeks. At the end of the study, $42 \%$ of the treated patients achieved the ASAS20 response, $31 \%$ achieved the ASAS40 response, 19\% achieved ASAS partial remission and $28 \%$ achieved the BASDAI50 response [96] (2C).

According to an observational study (NOR-DMARD), arthritis predicted the response (at 3 months) to sulfasalazine in 181 patients with axial SpA who received this drug as a first-line treatment ( $\triangle$ BASDAI -1.4 [1.9] when arthritis was present $v s-0.3$ [1.7] when absent; $\mathrm{p}=0.008$ ). In addition, the 3 -year drug survival rate was higher in patients with peripheral arthritis than in patients without arthritis (0.22 vs. 0.10 respectively, $\mathrm{p}=0.03)$ [97] (2C).

A RCT evaluated the efficacy of sulfasalazine $(2.0 \mathrm{~g} /$ day target dose) combined with $90 \mathrm{mg} /$ day etoricoxib compared with the NSAID alone in the treatment of 67 
individuals with axial SpA. After 6 months of follow-up, a significant difference was observed between the percentage of responsive patients (clinical improvement: $\triangle$ ASDAS $>1.1)$ in the sulfasalazine $(67.7 \%)$ and placebo (15.1\%) groups, signifying a NNT $=1.90(95 \% \mathrm{CI}=1.37-$ 3.12). The mean improvements in the BASDAI (3.29 \pm 0.97 vs $1.47 \pm 0.99)$ and BASMI ( $3.10 \pm 0.87$ vs $1.32 \pm$ 0.88 ) scores were also significantly higher in the sulfasalazine group than in the placebo group [98] (2B).

Another possible effect of sulfasalazine is to reduce the incidence of anterior uveitis flares in patients with axial SpA, according to data from two studies: an observational study $(\mathrm{n}=10)$ in which the annual incidence dropped from 3.4 to $0.9(\mathrm{p}=0.007)$ and a randomized clinical trial $(n=22)$ in which the relative risk of new episodes of acute anterior uveitis between the treatment $(0.47 /$ year $)$ and placebo $(1.06 /$ year) groups was 0.44 (95\% CI 0.30-0.64) $[99,100](2 \mathrm{C})$.

Leflunomide

Only one RCT has assessed the effects of leflunomide in patients with AS. After 24 weeks, the percentage of the 45 patients who responded to leflunomide was $27 \%$, according to the ASAS20 criterion, a value that is similar to that of the placebo group (20\%). Significant differences in the disease activity (BASDAI), functional (BASFI) and mobility (BASMI) indices, pain and joint edema were not observed. However, the risk of adverse events, such as gastrointestinal disorders, respiratory infections, dermatitis, fatigue, venous thrombosis and elevated liver enzyme levels increased by $20 \%(\mathrm{NNH}=5)$ [101] (2B). A 24-week open-label study with only 20 patients with AS was the only study to observe a significant $(\mathrm{p}=0.039)$ improvement exclusively in the peripheral component (mean joint counts were 1.7 at baseline and 0.2 after 6 months), but no significant improvements regarding BASDAI, BASMI, BASFI and other PROs [102] (2C).

Effect of combined synthetic DMARDs on biological therapy survival

Two observational studies aimed to answer the still open question of whether synthetic DMARDs affect the retention rates (drug survival) of TNF $\alpha$ inhibitors in patients with axial SpA. The Swedish biologics registry ARTIS (Antirheumatic Therapies in Sweden) found that co-medication during the use of the first TNF $\alpha$ inhibitor $(n=2420)$ exerted a beneficial effect, as shown by a lower 5 -year discontinuation rate in users than in nonusers (hazard ratio (HR) 0.71, 95\% CI $0.59-0.85, \mathrm{p}<0.001$ for AS; and HR $0.82,95 \%$ CI 0.69-0.97, $\mathrm{p}=0.020$ for undifferentiated SpA) [103] (2B). Conversely, the Portuguese Rheumatic Diseases Register $(\mathrm{n}=954)$ found no evidence of the same effect on retention after 13 years of follow-up (HR 1.07, 95\% CI 0.68-1.68) [104] (2B).
Recommendation

The use of methotrexate and sulfasalazine is recommended for the treatment of patients with axial SpA when peripheral arthritis is present or in the absence of another pharmacological treatment option due to toxicity, intolerance or contraindications. Level of evidence: $2 A$; Strength of recommendation: $B$ (moderate); Degree of agreement: 8.4.

The routine use of methotrexate or sulfasalazine as a co-medication in patients with axial SpA who are using biologics is not recommended. Level of evidence: $2 B$; Strength of recommendation: $B$ (moderate); Degree of agreement: 9.6.

8. What evidence of efficacy supports indications for the use of biologics in patients with axial SpA?

Five TNF $\alpha$ inhibitors (anti-TNF $\alpha$ ) are currently available as treatments for AS: the anti-TNF $\alpha$ monoclonal antibodies infliximab, adalimumab and golimumab; certolizumab pegol, which is only the fragment antigenbinding (Fab) portion of the antibody; and the TNFa receptor analog etanercept. The last four compounds are also approved for the treatment of non-radiographic axial SpA. The following interleukin-17 inhibitors (antiIL17A) are also available: secukinumab, which is approved for AS, and ixekizumab (anti-IL17A/F), which has not yet been approved for axial SpA.

Anti-TNF $\alpha$

A RCT including 69 patients with active AS (BASDAI $\geq 4$ and back pain $\geq 4 \mathrm{~mm}$ - VAS) who received IV infliximab therapy $(5.0 \mathrm{mg} / \mathrm{kg})$ or placebo at weeks 0,2 and 6 performed a primary outcome evaluation (BASDAI50) at week 12 . In this trial, $53 \%$ of patients in the treatment group showed this response, in contrast to $9 \%$ of patients in the placebo group $(\mathrm{P}<0.0001, \mathrm{NNT}=2.3)$ [105] (2B). The open-label phase of this study, using the same dose administered every 6 weeks, confirmed a sustained response until the third year, based on the ITT analysis. In addition, $47 \%$ patients maintained the initial BASDAI50 response until week 54, 41\% until week 102 and $47.1 \%$ until week 156 [106-108] (2C). Other publications from the same study (with data from 5 and 8 years of follow-up) confirmed the persistence of the long-term response, although without an ITT analysis, which tends to underestimate treatment effects within such long follow-up periods. Thirty-eight of the initial 69 patients (55\%) completed the fifth year and 33 (47\%) completed the eighth year. Of these patients, $25(66 \%)$ and $21(64 \%)$, respectively, maintained a BASDAI score $<50 \%$ of the initial BASDAI score [109, 110] (2C).

A much larger RCT (ASSERT study) evaluated 357 AS patients for 24 weeks using the same disease activity criteria, and patients were treated with infliximab $(5.0 \mathrm{mg} /$ $\mathrm{kg}$ ) or placebo at weeks $0,2,6,12$ and 18. The drug effectively reduced the disease activity (ASAS20 responders: $61.2 \%$ vs. $19.2 \%$ in the placebo group, $\mathrm{NNT}=$ 
2.4; ASAS40 responders: $47 \%$ vs. $12 \%, \mathrm{NNT}=2.8$, ASAS partial remission: $22.4 \%$ vs $1.3 \%, \quad \mathrm{NNT}=4.7$, and BASDAI50: $51 \%$ vs. $10.7 \%$, NNT $=2.5$ ). Physical function also improved (reduction of $\geq 2$ units of the BASFI score: $47.5 \%$ vs $13.3 \%$, NNT $=2.9)$, as well as BASMI $(-1.0$ vs $0.0, \mathrm{p}=0.019$ ), and the quality of life (physical component SF-36: -10.2 vs. $0.8, \mathrm{p}<0.001)$. No difference of the Mander enthesitis index (MEI) score was observed [111] (1B).

The first study assessing the efficacy of etanercept was an American study, in which 40 patients with active AS, defined as the presence of inflammatory back pain with morning stiffness for at least $45 \mathrm{~min}$ and PROs with moderate disease activity, were randomized to treatment with $25 \mathrm{mg}$ of etanercept twice per week or placebo. At the end of the 4-month follow-up, there was a $50 \%$ increase $(\mathrm{NNT}=2)$ in the response to treatment, as defined by a composite index that is very similar to ASAS20: improvement $\geq 20 \%$ in three of five measures of disease activity (duration of morning stiffness, intensity of night pain, BASFI, patient global assessment and joint edema score) [112] (2B). Another multinational 24-week RCT included 277 patients with active AS (score $\geq 30$ $\mathrm{mm}$ for morning stiffness, as measured using a VAS, and greater than two of three parameters: patient global assessment, back pain and BASFI) who were treated with $25 \mathrm{mg}$ of etanercept twice per week for 24 weeks or placebo. The results showed a $31 \%$ increase $(\mathrm{NNT}=3.2)$ of ASAS20 after 12 weeks and a $35 \%$ increase $(\mathrm{NNT}=2.9)$ of ASAS20 and a $13 \%$ increase $(\mathrm{NNT}=7.7)$ of ASAS partial remission, as well as BASDAI, BASFI and BASMI [113] (1B). The open-label extension of this trial included 200 of the initially included patients (72\%), who were followed until week 96 . All patients who were initially treated with placebo started receiving etanercept. After 24 weeks, $70 \%$ of these patients also achieved ASAS20. At the end of two years, 74, 61 , and $46 \%$ of patients who received the active drug (treatment group) for 96 weeks and 78, 54, and 38\% of patients who received the drug for 72 weeks (placebo-treated group) achieved ASAS20, ASAS50 and ASAS70, respectively, suggesting a sustained response [114] (2C). Finally, the follow-up for up to week 192 consisted of 126 individuals of the 277 included in the original trial (45.5\%). The percentages of patients who achieved ASAS20, ASAS40 and ASAS partial remission responses were 81, 69 and $44 \%$ in the treatment group (etanercept administered from the beginning of the trial) and 82, 68 and 28\% in the placebo-treated group (etanercept administered after week 24) [115] (2C).

A small trial performed in four German centers included 30 patients, of whom 14 were randomly allocated to the treatment group (25 $\mathrm{mg}$ of etanercept twice per week) and 16 to the placebo group in a double-blind phase (6 weeks). After this phase, all patients received etanercept for 12 weeks and then discontinued this medication and were followed for another 12 weeks. The 6 -week treatment resulted in a $51 \%$ improvement in BASDAI50 response $(\mathrm{NNT}=2.0)$. The mean time (standard deviation) until reactivation (BAS$\mathrm{DAI} \geq 4$ and global assessment by the physician $\geq 4$ in a $0-10$-point VAS) was $6( \pm 3)$ weeks. Twenty-six of the 30 initial patients were included in the extension, of which all patients resumed the medication. In week $54,58 \%$ patients had achieved a BASDAI50 response and 31\% achieved ASAS partial remission. In addition, 21 of 26 (81\%) patients completed 2 years of follow-up treatment, and $16(62 \%)$ completed 7 years. Of these 16 patients, $31 \%$ achieved ASAS partial remission and $44 \%$ patients achieved the inactive disease criteria according to the ASDAS [116-118] (2B). Another RCT was conducted at 14 European centers and included 84 patients with active AS who received $25 \mathrm{mg}$ of etanercept twice per week $(\mathrm{n}=45)$ or placebo $(\mathrm{n}=39)$ for 12 weeks. The results showed a $37 \%$ increase $(\mathrm{NNT}=2.7)$ of ASAS20 response and a $50 \%$ increase $(\mathrm{NNT}=2.0)$ of ASAS50 response, but no significant difference concerning ASAS70 response, despite the numerical difference favoring the drug group (24.4\% vs 10.3\%) [119] (1B). The effect of etanercept was also assessed on a subpopulation of patients with advanced and severe AS (namely, two intervertebral adjacent bridges and/or fusion at the lumbar spine, three intervertebral adjacent bridges and/or fusion at the thoracic spine, or two intervertebral adjacent bridges and/or fusion at the cervical spine). The patients were treated with $50 \mathrm{mg}$ of etanercept per week $(\mathrm{n}=39)$ or the placebo $(n=43)$ for 12 weeks. There was improved in the following parameters: $34 \%$ increase $(\mathrm{NNT}=2.9)$ of ASAS20, $21 \%$ increase $(\mathrm{NNT}=4.8)$ of ASAS40, $23 \%$ increase $(\mathrm{NNT}=4.4)$ of BASDAI50 response, and $13 \%$ increase $(\mathrm{NNT}=7.7)$ of ASAS partial remission. After 12 weeks, the results also showed significant BASDAI (-2.6), BASFI (-2.2), BASMI $(-0.57)$ improvement. In addition, some lung function parameters were also improved: vital capacity (VC) of $2.88 \%$ (effect size $=0.17$ ) and forced $\mathrm{VC}(\mathrm{FVC})$ of $3.75 \%$ (effect size $=0.24)$ [120] $(\mathbf{1 B})$. The ESTHER trial included patients with axial SpA (AS and non-radiographic axial SpA) who had experienced symptoms for less than five years and active inflammation in the axial skeleton on MRI. Patients were randomly allocated to treatment with $50 \mathrm{mg}$ of etanercept/week $(\mathrm{n}=40)$ or sulfasalazine $(\mathrm{n}=$ 36) for 12 months. At the end of this period, nonremitted patients continued in an open-label extension of the study, receiving long-term treatment with etanercept. Remitted patients discontinued the medication, resuming etanercept upon exacerbation. A significantly greater improvement in inflammation scores (SIJ and spinal MRI) was observed in the anti-TNFo-treated 
group than in the sulfasalazine-treated group. Significantly greater improvements were also observed regarding BASDAI, BASFI, MASES, EQ-5D and ASQoL. The efficacy and safety data from the two groups were similar. A similar long-term response level was also observed (3-year follow-up) [96, 121, 122] (2C). Another RCT (EMBARK) recruited 215 individuals with nonradiographic axial SpA who had experienced symptoms for up to five years. These individuals were randomly allocated to etanercept (50 mg/week) or placebo. After 12 weeks, the improvement of ASAS40 response was 16\% better $(\mathrm{NNT}=6.0)$ in the treatment group than placebo. The disease activity scores on SIJ and spinal MRI were also better in the treatment group than in the placebo group. A subgroup analysis observed correlations between CRP levels and sacroiliac inflammation on MRI (Spondyloarthritis Research Consortium of Canada (SPARCC) MRI scoring system) with an improved response. After 12 weeks, all patients received etanercept and were followed in an open-label extension study for another 36 weeks. The percentages of patients achieving the ASAS40 response who were initially allocated to etanercept and to placebo in week 48 were 52 and $53 \%$, respectively [123, 124] (1B).

A systematic review with a meta-analysis involving 1570 participants compared the efficacy of etanercept in Caucasians with the Chinese population by calculating the relative risk $(R R)$ of achieving ASAS20 $(R R=2.36$, 95\% CI 2.03-2.74) and ASAS40 ( $R R=2.81,95 \% \mathrm{CI}$ 2.01-3.92) responses and ASAS partial remission $(R R=$ 4.31, 95\% CI 2.52-7.37) with treatment versus placebo [125] (1A).

The ATLAS study, a 24-week RCT with primary outcomes measured at week 12 and a 5-year open-label extension, included 315 patients with AS who were unresponsive to NSAIDs and treated with adalimumab at a dose of 40 mg every other week $(n=208)$ or placebo $(n=107)$. After 12 weeks, the results showed a $37.6 \%$ increase of the ASAS20 response $(\mathrm{NNT}=2.7)$, a $26.8 \%$ increase of ASAS40 response $(\mathrm{NNT}=3.7)$, and a $17 \%$ increase of ASAS partial remission $(\mathrm{NNT}=5.9)$. In weeks 12 and 24, the treatment and control groups showed significant differences in improvement (BASDAI, BASFI, BASMI and MASES. The ASAS20 and ASAS40 responses and ASAS partial remission persisted for two years after treatment and were 64.5, 50.6 and $33.5 \%$, respectively. A 3-year follow-up of these patients revealed a sustained response that was measured using the BASDAI, BASFI, SF-36 (summary of physical components) and ASQoL, and 125/208 (60\%) patients of the group that was initially allocated to the adalimumab arm completed the 5th year of follow-up. Of these patients, 70 and $77 \%$ achieved ASDAS40 and BASDAI50 responses, whereas 51 and $56 \%$ met the ASAS partial remission and ASDAS inactive disease criteria [126-129], respectively
(1B). A RCT published in 2008, even before the publication of the ASAS criteria (2009), which defined the concept of non-radiographic axial SpA, included patients $(n=46)$ with inflammatory back pain and a positive HLA-B27 test or inflammation on SIJ or spinal MRI and the absence of radiographic sacroiliitis. After 12 weeks, the use of adalimumab ( $40 \mathrm{mg}$ every other week) led to a higher percentage of patients achieving the ASAS40 response compared to individuals treated with placebo $(54.5 \%$ vs $12.5 \%$, NNT $=2.4)$. The same level of response was observed in the placebo group after the switch to treatment and was maintained until week 52 of the open-label phase [130] (1B). Another large study $(\mathrm{n}=185)$, which was already using the 2009 ASAS criteria, also evaluated the efficacy of $40 \mathrm{mg}$ of adalimumab every two weeks for the treatment of active nonradiographic axial $\operatorname{SpA}$ (BASDAI $\geq 4$, axial pain $\operatorname{VAS} \geq 4$, and an inappropriate response, intolerance or contraindications to NSAIDs). Similar results were observed after 12 weeks. Compared with the placebo group, a significant $21 \%$ increase of ASAS40 response (NNT $=4.8), 11 \%$ increase of ASAS partial remission $(\mathrm{NNT}=9)$, and $20 \%$ increase of remission according to ASDAS inactive disease $(\mathrm{NNT}=5)$ were observed. Significant differences were also observed in the improvements in the BASDAI, ASDAS, HAQ-S, SF-36 and SPARCC activity scores on SIJ and spinal MRI. No differences in improvements regarding BASFI, BASMI and MASES were observed between the adalimumab and placebo groups. Elevated CRP levels at baseline and objective inflammation intensity on SIJ MRI were associated with an improved response [131] (1B). A metaanalysis included 8 clinical trials assessing the effects of adalimumab in AS. In the week 12, the risk ratio (or $\mathrm{RR}$ ) of achieving ASAS20 and BASDAI50 was $\mathrm{RR}=2.26$ (95\% CI 1.85-2.75) and RR $=2.82$ (95\% CI 2.14-3.71), respectively [132] (1A).

When subcutaneously treated with golimumab $(50 \mathrm{mg} /$ 4 weeks), patients with active AS (BASDAI $\geq 4$, spinal pain VAS $\geq 4$ and inadequate response to prior use of NSAIDs or synthetic DMARDs) achieved the following results compared with placebo: $37.6 \%$ increase of ASAS20 response $(\mathrm{NNT}=2.7)$ and $30.5 \%$ increase in BASDAI50 $(\mathrm{NNT}=3.3)$ as early as week 14 ; a $28.1 \%$ increase of ASAS40 response $(\mathrm{NNT}=3.6)$ and $36.1 \%$ increase of BASDAI50 $(\mathrm{NNT}=2.8)$ in week 24. Patients who received golimumab also showed significantly greater BASDAI, BASFI, SF-36 improvements, as well as sleep quality (Jenkins Sleep Evaluation Questionnaire (JSEQ). However, no improvement regarding the BASMI [133] (1B). The 5-year follow-up of those patients showed a sustained response $[134,135](2 C)$. Similar results were observed in a Chinese trial $(\mathrm{n}=213)$ in which the treatment with golimumab increased the ASAS20 response by $24.3 \%(\mathrm{NNT}=4.1)$ after 14 weeks and by $27.1 \%(\mathrm{NNT}=3.7)$ after 24 weeks in a 1 year follow-up [136] (2B). The efficacy of golimumab in 
patients with non-radiographic axial SpA was also assessed in 198 patients (GO-AHEAD study RCT) with the disease for up to five years who were randomly allocated to treatment with golimumab (50 mg/4 weeks) or placebo. At week 16 of follow-up, more patients treated with golimumab achieved clinical responses than patients treated with placebo, with significant differences of $31.1 \%$ of ASAS20 $(\mathrm{NNT}=3.2)$ and $33.7 \%$ of ASAS40 $(\mathrm{NNT}=3)$ responses. Consistent with the results from other clinical trials analyzing this population of patients with nonradiographic axial $\mathrm{SpA}$, no significant difference in ASAS20 or ASAS40 responses was observed between the golimumab and placebo treatments in the subgroup of patients without objective sings of inflammation (with normal CRP levels and without sacroiliitis on MRI) [137] (1B). Another route of administration of golimumab (IV injection) was tested in a 28-week RCT (40 centers from 8 countries) that included 208 patients with active AS (BAS$\mathrm{DAI} \geq 4$; axial pain $\mathrm{VAS} \geq 4$; ultrasensitive $\mathrm{CRP} \geq 0.3 \mathrm{mg} / \mathrm{dl}$ ) who were randomly allocated to treatment with $2 \mathrm{mg} / \mathrm{kg}$ golimumab at weeks $0,4,12$ and every 8 weeks thereafter or with placebo. In this trial, $14.4 \%$ [30] of the individuals had already used another anti-TNF $\alpha$ antibody without primary treatment failure, and $5.8 \%$ (12) patients already showed complete spinal ankylosis at baseline. At week 16, the ASAS20, ASAS40 and BASDAI50 responses were achieved in the golimumab group, but not the placebo group: $73.3 \%$ vs $26.2 \%(\mathrm{NNT}=2.1), 47.6 \%$ vs $8.7 \%(\mathrm{NNT}=$ $2.6)$, and $41 \%$ vs $14.6 \%(\mathrm{NNT}=3.8)$, respectively. Remission according to the ASDAS inactive disease criteria occurred in $17.1 \%$ patients $(\mathrm{NNT}=5.8)$, as well as ASAS partial remission in $12.3 \%$ patients $(\mathrm{NNT}=8.1)$. The BASFI score also improved to a significantly greater extent in the treatment group $(-2.4$ vs $-0.5 ; p<$ 0.001) [138] (1B).

The efficacy of certolizumab pegol was assessed in the RAPID-axial SpA, which included 325 patients with active axial SpA, of whom $\backslash 147$ with non-radiographic axial SpA and they were randomly allocated to treatment with two certolizumab pegol dosing regimens (doses of $200 \mathrm{mg}$ every two weeks and $400 \mathrm{mg}$ every four weeks) or placebo. At baseline, $16 \%$ had already used another anti-TNF $\alpha$ antibody, without discontinuation due to primary treatment failures. At week 12, the ASAS20 response was achieved by 57.7 and $63.6 \%$ patients receiving doses of 400 and $200 \mathrm{mg}$ of certolizumab pegol, respectively, compared with $38.3 \%$ patients treated with placebo (NNT $=5.2$ and 3.95 for the two dosing regimens, respectively). Significant increases in ASAS40 responses of $25.4 \%(\mathrm{NNT}=3.9)$ and $31 \%(\mathrm{NNT}=$ 3.2) were observed for patients receiving both dosing regimens, respectively. ASAS partial remission increased by $19.7 \%(\mathrm{NNT}=5.1)$ and $20.6 \%(\mathrm{NNT}=4.8)$ with the two certolizumab pegol dosing regimens compared to the placebo. In addition, the ASDAS inactive disease status was achieved by 25.2 and $20.6 \%$ patients receiving the two dosing regimens compared with $0 \%$ in the placebo group $(\mathrm{NNT}=4$ and 4.8$)$. Altogether, the two arms of the treatment resulted in significant improvements of BASFI, BASDAI, BASMI and ASDAS compared with placebo, at both weeks 12 and 24 [139] (1B). A sustained response was assessed at the 96th week and up to the 4th year of followup, when $67 \%(218 / 325)$ participants continued receiving the drug in the study, of whom $31.4 \%$ met the ASDAS inactive disease criteria $[140,141](2 \mathrm{C})$.

Anti-IL17

In the MEASURE 1 and MEASURE 2 phase III trials, the anti-IL17A monoclonal antibody induced a significant reduction in signs and symptoms attributed to active AS (BASDAI $\geq 4$; axial pain VAS $\geq 4$ ), at week 16 of follow-up. In the MEASURE 1 trial $(n=371)$, the patients in the treatment group received IV injections of $10 \mathrm{mg} / \mathrm{kg}$ secukinumab at weeks 0,2 and 4, followed by maintenance therapy with 75 or $150 \mathrm{mg}$ every 4 weeks. In the MEASURE 2 trial $(n=219)$, the antibody was subcutaneously (SC) injected (with 75 or $150 \mathrm{mg}$ secukinumab) at weeks $0,1,2$ and 3, followed by SC maintenance therapy every 4 weeks. In the MEASURE 1 trial, the ASAS20 response was reached at week 16 by 61,60 and $29 \%$ patients treated with $150 \mathrm{mg}, 75 \mathrm{mg}$ and placebo, respectively $(\mathrm{p}<0.001$ for both comparisons with placebo [NNT $=3.1$ for $150 \mathrm{mg}$ and NNT $=3.2$ for $75 \mathrm{mg}]$ ). Conversely, in the MEASURE 2 trial, these rates were 61,41 and $28 \%(\mathrm{p}<0.001$ for 150 $\mathrm{mg}$ vs placebo [NNT $=3$ ] and $\mathrm{p}=0.10$ for $75 \mathrm{mg}$ vs placebo). Therefore, SC injections (less intense and equally effective) and a 150-mg maintenance dose, but not a 75mg dose (ineffective), were chosen as the best treatment. These response levels were maintained until week 52 in both studies ( $63 \%$ for both). In terms of the most clinically relevant secondary outcomes and considering only individuals who received the maintenance dose of $150 \mathrm{mg}$ (which is the dose approved in Brazil for AS), 42 and 36\% patients achieved ASAS40 at week 16 and 51 and 49\% patients achieved this response at week 52 in the MEASURE 1 and MEASURE 2 trials, respectively. In terms of ASAS partial remission, 15\% (MEASURE 1) and 14\% (MEASURE 2) of patients achieved this condition at week 16 and 22\% (in both studies) at week 52 [142] (1B). Comparing bio-naive $(n=134)$ and anti-TNF $\alpha$ failure $(n=85)$ patients, it was shown good efficacy in both scenarios, although with smaller effect size $(\mathrm{NNT}=2.7$ for ASAS20 in the first group and $\mathrm{NNT}=3.9$ in the second group) [143] (1B). The levels of total spinal pain, night pain and fatigue (measured using the FACIT-fatigue scale) in individuals with or without elevated CRP levels at baseline and in patients who had or had not been treated with an anti-TNF $\alpha$ antibody were significantly decreased compared with patients treated with the placebo at week 16, with a sustained response until week 104 [144] (1B). The 
clinical responses observed at week 24 were sustained until the third year of follow-up [145-147] (2C).

Ixekizumab, another anti-IL17 antibody (specific for the IL17A homodimer and IL17A/F heterodimer), showed efficacy in treating AS in two published phase 3 trials, COAST-V and COAST-W. The former included 341 patients with an inadequate response or intolerance to NSAIDs who were randomly allocated (1:1:1:1) to receive $80 \mathrm{mg}$ of ixekizumab SC every 2 or 4 weeks, $40 \mathrm{mg}$ of adalimumab SC every 2 weeks or the placebo. The latter group included only patients with prior exposure (inadequate response or intolerance) to one or two antiTNF $\alpha$ therapies $(n=316)$ and therefore the active comparator arm for this mechanism was not established. The NNTs for ASAS40 at week 16 were 3.2 (95\% CI $2.3-4.9)$ in the bio-naïve subpopulation, with no significant difference for adalimumab, and 6.5 (95\% CI 4.2$15.2)$ in the subpopulation that was previously exposed to anti-TNF $\alpha$ therapy $[148,149]$ (1B). This drug is not yet approved for the treatment of axial SpA.

\section{Recommendation}

Based on the opinion of the rheumatologist, the use of biologics (TNFa inhibitors or anti-IL17 antibodies) to treat active (BASDAI $\geq 4$ or ASDAS $\geq 2.1$ ) and symptomatic axial SpA is recommended when the initial treatment with NSAIDs fails (disease persistence, toxicity or contraindications). Level of evidence: 1A; Strength of recommendation: $A$ (strong); Degree of agreement: 8.9.

Biologics should be used to treat axial SpA when objective signs of inflammation are detected, such as elevated CRP levels and/or the presence of sacroiliitis on MRI, as these parameters predict the response, particularly in the context of non-radiographic axial SpA. Level of evidence: $1 B$; Strength of recommendation: $A$ (strong); Degree of agreement: 9.6.

Anti-TNF inhibitors (adalimumab, etanercept, golimumab and certolizumab pegol) are recommended for the treatment of nonradiographic axial SpA since had received an evidence-based approval. Level of evidence: 1B; Strength of recommendation: A (strong); Degree of agreement: 9.7 .
9. Do differences in efficacy exist among biologics used to treat axial $\mathrm{SpA}$ patients?

To date, only three trials have performed head-to-head comparisons between biological therapies in patients with axial SpA.

An open-label RCT analyzed 55 AS patients who were randomly allocated to treatment with infliximab or etanercept. At 12 weeks of follow-up, significant differences of BASDAI (3.5 versus 5.6, $\mathrm{p}<0.005)$ and BASFI (3.5 versus $5.0, \mathrm{p}<0.005)$ in favor to infliximab. However, this difference was not sustained over time (104 weeks of follow-up). No difference of ASAS20 or ASAS40 responses was identified between groups at the 2nd, 12th or 104th weeks of follow-up [150] (2B).

A phase I (the primary endpoint was to show pharmacokinetic equivalence) randomized, double-blind, multicenter clinical trial (PLANETAS study) compared the efficacy of infliximab with one of its bio-similar (CTP13) in patients with AS $(n=250,125$ in each treatment arm) for 30 weeks. The ASAS20 and ASAS40 responses observed at week 30 in the biosimilar and original groups, were: $70.5 \%$ vs $72.4 \%(\mathrm{OR}=0.91,95 \% \mathrm{CI} 0.51-1.62)$ and $51.8 \%$ vs $47.4 \%$ (OR $=1.19,95 \%$ CI $0.70-2.00)$, respectively, with no significant differences between treatment groups [151] (2B).

Another open-label RCT compared the survival of patients receiving each drug and the disease activity, according to ASDAS-CRP, in patients with AS who were treated with etanercept $(n=163)$ or adalimumab $(n=82)$ in a real-life scenario (routine care). In a two-year follow-up period, no difference was observed between mean ASDAS-CRP $(2.0 \pm 0.9$ for etanercept and $1.9 \pm 1.1$ for adalimumab, $\mathrm{p}=0.624)$. However, the survival rate of patients treated with etanercept was significantly better than patients treated with adalimumab. The

Table 3 Increase in the relative frequency (\%) of different outcomes and the number needed to treat (NNT) with respective 95\% Cls calculated using a normal approximation compared to the placebo. - Data were not reported in the studies. Data from different studies were pooled when the same outcomes from the same treatments were available and when they referred to doses and/or regimens approved in Brazil

\begin{tabular}{|c|c|c|c|c|c|c|c|c|c|c|c|c|}
\hline \multirow{4}{*}{$\begin{array}{l}\text { Outcome } \\
\text { Drug }\end{array}$} & \multirow{2}{*}{\multicolumn{4}{|c|}{$\begin{array}{l}\text { ASAS20 } \\
\text { Follow-up time (weeks) }\end{array}$}} & \multicolumn{4}{|c|}{ ASAS40 } & \multicolumn{4}{|c|}{ ASAS PR } \\
\hline & & & & & & & & & & & & \\
\hline & \multicolumn{2}{|c|}{12 to 16} & \multicolumn{2}{|l|}{24} & \multicolumn{2}{|c|}{12 to 16} & \multicolumn{2}{|l|}{24} & \multicolumn{2}{|c|}{12 to 16} & \multicolumn{2}{|l|}{24} \\
\hline & $\%$ & NNT $(95 \%$ Cl) & $\%$ & NNT $(95 \% \mathrm{Cl})$ & $\%$ & NNT $(95 \% \mathrm{Cl})$ & $\%$ & NNT $(95 \% \mathrm{Cl})$ & $\%$ & NNT $(95 \% \mathrm{Cl})$ & $\overline{\%}$ & NNT $(95 \% \mathrm{Cl})$ \\
\hline Infliximab [111] & - & - & 42 & $2.4(1.9-3.2)$ & - & - & 35 & $2.9(2.2-4.0)$ & - & - & 21 & $4.7(3.7-6.7)$ \\
\hline Etanercept [113, 119, 120, 123] & 27 & $3.7(2.9-5.1)$ & 34 & $2.9(2.2-4.3)$ & 18 & $5.5(3.6-11.7)$ & - & - & 13 & $7.5(3.7-\infty)$ & 13 & $7.6(4.9-16.9)$ \\
\hline Adalimumab $[126,130,131]$ & 27 & $3.7(2.8-5.2)$ & - & - & 26 & $3.8(3.0-5.2)$ & 26 & $3.8(2.8-5.8)$ & 16 & $6.4(4.8-9.5)$ & 17 & $6.1(4.2-10.7)$ \\
\hline Golimumab [133, 137, 138] & 37 & $2.7(2.3-3.4)$ & - & - & 40 & $2.5(2.1-3.2)$ & 28 & $3.6(2.5-6.0)$ & - & $7.5(4.8-16.3)$ & - & - \\
\hline Certolizumab pegol [139] & 22 & $4.5(3.0-9.1)$ & - & - & 28 & $3.6(2.6-5.5)$ & - & - & 20 & $5.0(3.7-7.5)$ & - & - \\
\hline Secukinumab [142] & 36 & $2.8(2.2-3.8)$ & - & - & 30 & $3.3(2.5-4.6)$ & - & - & 12 & $8.1(5.4-16.0)$ & - & - \\
\hline
\end{tabular}


HR of adalimumab discontinuation compared with etanercept discontinuation was 2.5 (95\% CI 1.3-4.5, $\mathrm{p}=0.006)[152](2 \mathrm{~B})$.

The Table 3 outlines the relative frequencies (relative to the placebo group) of specific efficacy outcomes during treatment with different drugs. Although different studies with different populations are unable to be compared so simply, interestingly, all confidence intervals available for the same outcome overlap, at least in the short-term follow-up of the controlled period.

Another way to infer differences regarding efficacy among different agents is indirect comparisons metaanalysis, using the Bayesian network or Bayesian mixed treatment comparison (MTC). Recently, one of this methodology was used for analysis of data from 2574 AS patients from 16 RCTs wit adalimumab, etanercept, golimumab and infliximab, concluding that no evidence supported any difference in efficacy among these drugs concerning the following outcomes: ASAS20, ASAS40 and BASDAI50 responses [153] (1A). Another systematic review (28 eligible RCTs), including patients with non-radiographic axial $\mathrm{SpA}$, also found no evidence of efficacy differences among different TNFa inhibitors [154] (1A). More recently, 18 RCTs (2971 AS patients), using secukinumab database and ASAS20 as main outcome, were indirectly compared (Bucher's method) and no differences were found [155] (1A).

Recommendation

The TNFa inhibitors and the IL17A inhibitors exhibit similar effect sizes for controlling inflammatory activity in patients with axial SpA. Level of evidence: $1 A$; Strength of recommendation: $A$ (strong); Degree of agreement: 8.9.

10. Does the safety of biologics differ in patients with axial SpA?

Similar to the efficacy comparison, safety differences among agents have been inferred using indirect comparisons and meta-analyses. Table 4 outlines the RRs of serious adverse events and treatment discontinuation (both in comparison with the placebo group) reported for different drugs. Interestingly, the confidence intervals of the RRs overlap in short-term, suggesting similar safety profiles.

Indirect comparisons and different meta-analyses (albeit with considerable data overlap) concluded that the data are similar among different biologics. Moreover, the rates of serious adverse events, including serious infections and malignancies associated with biological treatments, showed no significant differences from controls $[153,156,157](\mathbf{1 A})$. The main limitation of the safety analysis, as shown in Table 4 and in the meta-analyses cited, is the low frequency of events due to the short follow-up (short exposure time) and to the selection of the exposed population according to the restrictive inclusion/exclusion criteria of RCTs. Long-term safety evidence and data that are closer to real-life scenarios are provided by registry studies and cohort studies. However, few of these studies have been performed specifically with patients with axial SpA, and in some studies presented below, other diagnoses, such as psoriatic arthritis (PsA) and rheumatoid arthritis (RA), were grouped in risk analyses.

A Canadian cohort study followed 440 patients with axial SpA for 1712 PY of observation. Two hundred sixtyfour $(60 \%)$ patients used some TNFo inhibitor in the study period, 124 (28.2\%) used a DMARD (methotrexate-15\%, sulfasalazine- $10.9 \%$, leflunomide- $1.1 \%$, and others-1.1\%) and $42(9.5 \%)$ used glucocorticoids, with a mean dose of $14 \mathrm{mg} /$ day. The use of an anti-TNF $\alpha$ inhibitor did not exert significant effect on the incidence of infections in general compared with the lack of use of an anti-TNF $\alpha$ inhibitor. The incidence rates in the exposed and control groups were 19/100 PY vs 14/100 PY, respectively, with an OR adjusted for several cofactors (comorbidities, use of glucocorticoids and synthetic DMARDs) of 1.25 (95\% CI

Table 4 Relative risks of different safety outcomes and respective 95\% Cls calculated using a normal approximation. Data from different studies were pooled when the same outcomes from the same treatments were available and when they referred to doses and/or regimens approved in Brazil

\begin{tabular}{|c|c|c|c|c|}
\hline \multirow[t]{3}{*}{ Outcome } & \multicolumn{2}{|c|}{ Serious adverse effects } & \multicolumn{2}{|c|}{ Discontinuation for any cause } \\
\hline & \multicolumn{4}{|c|}{ Follow-up time (weeks) } \\
\hline & \multicolumn{4}{|l|}{12 to 24} \\
\hline Drug & Relative risk & $95 \% \mathrm{Cl}$ & Relative risk & $95 \% \mathrm{Cl}$ \\
\hline Infliximab [111] & 1.30 & $0.28-6.12$ & 0.78 & $0.14-4.15$ \\
\hline Etanercept $[113,119,120,123]$ & 0.84 & $0.37-1.91$ & 0.81 & $0.47-1.42$ \\
\hline Adalimumab $[126,130,131]$ & 1.59 & $0.49-5.06$ & 1.49 & $0.65-3.39$ \\
\hline Golimumab $[133,137,138]$ & 0.94 & $0.35-2.56$ & 1.19 & $0.52-2.75$ \\
\hline Certolizumab pegol [139] & 1.18 & $0.43-3.36$ & 0.74 & $0.34-1.58$ \\
\hline Secukinumab [142] & 0.81 & $0.34-1.92$ & 0.55 & $0.26-1.16$ \\
\hline
\end{tabular}


0.90-1.73). In the multivariate analysis, only the use of DMARDs increased the risk of infections with an OR of 1.73 (95\% CI 1.21-2.48, p=0.003) [158] (2B). A systematic review included 10 RCTs and 51 observational studies to compare the risk of adverse effects of 13 immunomodulators (biologics and target-specific molecules). The rates of adverse effects, discontinuation due to adverse effects, serious adverse effects, death, serious infections, tuberculosis, herpes zoster and malignancies were analyzed as outcomes of interest. However, $70 \%$ of the studies were conducted with patients diagnosed with RA, thus limiting the power of the analysis for axial SpA patients. Nevertheless, the outcome of discontinuation due to adverse effects was higher for infliximab than for adalimumab and etanercept in patients with AS, RA and PsA [159] (2A).

Two South Korean studies on the risk of tuberculosis (TB; South Korea is considered a country with an intermediate TB burden) have shown contradictory results regarding the effect of exposure to anti-TNF $\alpha$ therapy on the risk of TB. One of the studies calculated the TB incidence rates in patients with AS from a single center who were exposed $(n=354)$ or were not exposed $(n=919)$ to anti-TNF $\alpha$ therapy, with 308/100 thousand PY among nonusers and 168/100 thousand PY among users. A significant difference was not observed and the $\mathrm{RR}=0.53$ (95\% CI $0.14-1.91$ ), thus suggesting that exposure does not increase the risk [160] (2B). The other study also calculated the incidence of TB in 1322 patients with AS (336 users and 986 unexposed controls), finding an incidence of $600.2 / 100,000$ PY among users and RR $=4.87$ (95\% CI 1.50-15.39) compared to nonusers [161] (2B). Two other observational studies, both of which were conducted in Turkey (a country with a high prevalence of TB), aimed to identify factors associated with an increased risk of developing TB among anti-TNF $\alpha$ drug users (in both studies, adalimumab, etanercept and infliximab alone were evaluated). The first study evaluated the medical records of 1887 patients receiving anti-TNF $\alpha$ therapy, 705 of whom (37.3\%) had been diagnosed with AS. The overall incidence (all diagnoses) was 423/100,000 PY. The use of adalimumab (9.5-fold increase), male gender (15.6-fold increase) and a history of TB (11.5fold increase) were indicated as risk factors for $\mathrm{TB}$ in the multivariate analysis [162] (2B). The other study is a casecontrol study in which 73 (52.1\% patients with AS) cases of TB among anti-TNFa drug users were compared with 7695 (50.6\% patients with AS) controls, namely, anti-TNF $\alpha$ drug users without TB. The prevalence of TB among patients with AS undergoing anti-TNF $\alpha$ therapy was $0.97 \%$. The frequency of TB among infliximab users (considering all diagnoses) was $1.27 \%$, which was significantly higher $(\mathrm{OR}=3.4,95 \%$ CI $1.88-6.10, \mathrm{p}=0.001)$ than adalimumab $(0.57 \%)$ and etanercept (0.3\%) [163] (3B).

Despite the limited data, the risk of tuberculosis in patients exposed to IL-17 inhibition seems to be low, as there are no cases described in clinical trials. In contrast, there is an increased risk of candida infections in patients treated with anti-IL-17 [142, 147-149] (1B). These small differences should be considered in the management of axial SpA patients.

Three publications with data from four registries did not detect increase in the risk of malignancies with the use of anti-TNFa therapy in patients with SpA. The BIOBADASER registry (761 Spanish patients with AS, among other diagnoses, who were undergoing anti-TNF $\alpha$ therapy and followed from 2001 to 2008) calculated a standardized incidence ratio of 0.92 (95\% CI $0.44-1.70$ ). The BIOSPAR registry (231 Belgian patients with SpA undergoing anti-TNFa therapy who were followed from 2000 to 2010) identified a nonsignificant increase in incidence among women, $\mathrm{R}=1.99$ (95\% CI 0.54-3.82), but not in men, $\mathrm{RR}=0.69$ (95\% CI 0.29-1.66), compared with the general population. The DANBIO registry (3255 Danish patients with SpA who were followed from 2001 to 2011) and ARTIS registry (5448 Swedish patients with SpA who were followed from 2001 to 2011) obtained a similar risk between patients undergoing anti-TNF $\alpha$ therapy and untreated patients, $\mathrm{RR}=0.8$ (95\% CI $0.7-$ 1.0) $[164-166](2 B)$.

Recommendation

The biologics TNFa inhibitors and the anti-IL17A inhibitors exhibit similar effect sizes for the short-term risks of serious adverse effects and discontinuation. Level of evidence: $1 A$; Strength of recommendation: $A$ (strong); Degree of agreement: 9.1.

11. Is the use of biological therapy able to reduce structural damage (radiographic progression) in patients with axial SpA?

Table 5 Mean mSASSS variations and respective 95\% Cls calculated using a normal approximation (except for certolizumab pegol, whose $95 \% \mathrm{Cl}$ was reported by the authors of the original study). Data from different studies were pooled when the same outcomes from the same treatments were available and when they referred to doses and/or regimens approved in Brazil

\begin{tabular}{|c|c|c|c|c|}
\hline \multirow{4}{*}{$\begin{array}{l}\text { Outcome } \\
\text { Drug }\end{array}$} & \multicolumn{4}{|c|}{ mSASSS variation (units) } \\
\hline & \multicolumn{4}{|c|}{ Follow-up time (years) } \\
\hline & \multicolumn{2}{|l|}{0 to 2} & \multicolumn{2}{|l|}{0 to 4} \\
\hline & $\Delta$ mSASSS & $95 \% \mathrm{Cl}$ & $\Delta \mathrm{mSASSS}$ & $95 \% \mathrm{Cl}$ \\
\hline Infliximab [171, 172] & 0.9 & $0.54-1.26$ & 1.60 & $1.1-2.1$ \\
\hline Etanercept [173] & 0.91 & $0.62-1.21$ & & \\
\hline Adalimumab [174] & 0.9 & $0.51-1.09$ & & \\
\hline Golimumab [175] & 0.9 & $0.38-1.40$ & 1.30 & $0.9-1.7$ \\
\hline Certolizumab pegol [176] & 0.67 & $0.21-1.13$ & 0.98 & $0.34-1.63$ \\
\hline Secukinumab $[145,177]$ & 0.5 & $0.11-0.89$ & 1.2 & $0.29-2.11$ \\
\hline
\end{tabular}


The reduction or even prevention of structural damage in patients with axial SpA is an important goal in the treatment of these diseases because, in addition to inflammation, the damage caused by bone new formation contributes to impaired mobility and function, particularly after the early phase (3 years of symptoms) [32] (2B). Observational studies have indicated a protective effect of anti-TNF $\alpha$ therapy on radiographic progression, particularly if it had been started early or extended for long periods ( $\geq 4$ years) [167-170] (2B). However, a definitive demonstration that these agents are able to prevent or at least reduce progression is still expected, mainly because experimental studies (outlined in Table 5) have not yet provided definitive evidence of this property.

Infliximab

In the ASSERT study, the spinal radiographs of 201 patients with AS who received $5.0 \mathrm{mg} / \mathrm{kg}$ infliximab every 6 weeks after the induction dose for 96 weeks were analyzed (baseline and after week 96) for structural damage using the mSASSS. The radiographic progression (difference between mSASSS at weeks 0 and 96) of these patients was compared with patients with AS who had not been treated with biologics from a historical cohort (OASIS), with all the limitations of this type of comparison. No significant difference ( $\mathrm{p}=0.541$ ) was observed between mean 2-year progression values in the ASSERT and OASIS cohorts, which were $0.9 \pm 2.6$ and $1.0 \pm 3.2$, respectively [171] (2C). Another cohort, in which 33 of the 69 patients with AS were initially included in the DIKAS (Deutsche Infliximab Kohorte für AS) study, also assessed radiographic progression using the mSASSS, but in two intervals: baseline- 2 years; and 2-4 years. In this population, the mSASSS varied by $1.6 \pm 2.6 / 4$ years (lower than the variation in the OASIS cohort of $4.4 / 4$ years). However, this study had notable limitations, including differences in baseline disease activity and methods for reading radiographs between the two groups. At the end of eight years of follow-up, 22 patients remained in the open-label extension using infliximab. The progression from baseline of these patients was then compared with 34 "controls" from another historic cohort (Herne) of patients with AS who had never undergone anti-TNF $\alpha$ therapy. Interestingly, although no difference in mean progression rates was observed between the two groups during the first 4 years $(p=0.18)$, a significant difference was detected in the last 4 years of follow-up $(p=0.01)$ favoring the infliximab group $[172,178](2 \mathrm{C})$.

\section{Etanercept}

Similarly, the effect of etanercept treatment on the progression of spinal structural damage was assessed by comparing 257 patients who were treated for up to two years (patients from the placebo-treated group were grouped with patients from the treatment group) with 175 patients from the OASIS cohort. Again, changes in radiological scores (mSASSS) of the cervical and lumbar spine after 96 weeks of treatment with etanercept were similar to the changes observed in patients from the historical cohort who were not treated with biological therapy $(0.91 \pm 2.45$ vs $0.95 \pm 3.18)$, thus suggesting a lack of a "disease-modifying" effect of etanercept [173] (2C).

Adalimumab

Using a similar study design, the ATLAS and M03-606 trials compared the radiographic progression of 307 patients with AS who were treated with adalimumab for two years with data from 169 patients of the historical OASIS cohort treated with non-biological drugs. Importantly, the patients enrolled in both RCTs who were initially allocated to the placebo group and started to receive adalimumab in the open-label phase were analyzed together with patients who were allocated to receiving biologics at the beginning of the trial. No difference in mSASSS variations was detected between groups, suggesting similar radiographic progression. The mean variation of the mSASSS from the start to the 2nd year of follow-up was $0.9 \pm 3.3$ and $0.8 \pm 2.6$ for patients from the historical OASIS cohort and for patients undergoing treatment with adalimumab, respectively $(\mathrm{p}=0.771)$ [174] $(2 \mathrm{C})$.

Golimumab

The GO-RAISE study also led to the publication of an analysis of the 4-year radiographic progression of the 356 AS patients. Radiographs of 111 of the 138 (80\%) patients initially allocated to the $50 \mathrm{mg}$ golimumab group (the only subcutaneous dose approved in Brazil) were available for mSASSS analysis. The radiographic progression, as measured by calculating mSASSS variations, of the $50 \mathrm{mg}$ golimumab group was, on average, $0.9 \pm 2.7$ in the first biennium and $1.3 \pm 4.1$ in the 4-year follow-up period. The 2-year analysis was performed using observed data, and the longer (4-year) analysis relied on $9 \%(26 / 299)$ of missing data that were completed by linear extrapolation. This difference in analyses considerably impairs the comparison between the two biennia. Nevertheless, the stability in mean rates of change in the two intervals (0-2 and 0-4 years) merely suggests that no acceleration in progression occurred [175] (2C). Certolizumab pegol

A study of the effect of certolizumab pegol on the radiographic progression of axial SpA (one arm of the RAPID-axial SpA trial) included 174 patients with AS and 141 patients with non-radiographic axial SpA, whose radiographs of the cervical and lumbar spine were analyzed using the mSASSS at baseline and at weeks 96 and 204. In patients with non-radiographic axial SpA, damage progression was slow $(0.06,95 \%$ CI $-0.17-0.28)$ during the 4 years of the study. In patients with AS, the mean change in mSASSS from week 0 to week 204 was 0.98 (95\% CI 0.34-163). This change was greater in the first biennium $(0.67,95 \%$ CI $0.21-1.13)$ than in the second $(0.31,95 \%$ CI $0.02-0.60)$ biennium. This reduction 
in the progression rate between the two intervals suggests that long-term anti-TNF $\alpha$ therapy may inhibit the progression of structural damage [176] (2C).

Secukinumab

The MEASURE 1 trial also provided radiographic progression data for AS patients who were originally randomly allocated to secukinumab $(75$ and $150 \mathrm{mg}$ ) in 2 years. Eighty-six of the 97 patients included in the 150 mg group (88.7\%) had radiographs available for mSASSS assessment. The mean change in this score from start to week 104 was $0.3 \pm 2.53$ units. Although this study reported the lowest mean radiographic progression among patients with AS treated with biologics and followed for 2 years differences in study design and populations preclude the comparison of these findings with results from other studies [145] (2C). In addition, 4-year data have already been published. seventy-one of the patients in the $150 \mathrm{mg}$ group $(73,2 \%)$ had at least baseline and week 208 radiographs. The rates of progression in the $0-2,2-$ 4 , and $0-4$ years intervals were, respectively, $0.5 \pm 1.69$; $0.7 \pm 3.32$; and $1.2 \pm 3.91$, respectively [177] $(2 \mathrm{C})$.

\section{Recommendation}

The reduction in the progression rate of structural damage (observed on spinal radiographies) in patients with axial SpA can be observed in the long-term use of TNF inhibitors. Level of evidence: $2 B$; Strength of recommendation: $B$ (moderate); Degree of agreement: 8.2.

A similar effect on radiographic progression seems to be observed with the continuous use of anti-IL17 (secukinumab) but need to be confirmed in long-term studies. Level of evidence: $2 C$; Strength of recommendation: B (moderate); Degree of agreement: 9.6.

12. What is the evidence for the efficacy of biologics regarding the treatment of extra-articular manifestations in patients with axial SpA?

\section{Uveitis}

Despite the lack of RCTs addressed to assess the efficacy of biologics on uveitis associated with axial SpA, some observational, open-label and uncontrolled studies and subanalyses of RCTs reasonably bridges the gap of evidence regarding the efficacy of these treatments.

A subanalysis of data from seven studies including 397 patients with AS, whose cumulative exposure to placebo, infliximab and etanercept was 70, 147 and 430 PY, respectively, calculated the incidence of new episodes of uveitis in the three groups. The combined incidence of uveitis among patients treated with anti-TNF $\alpha$ drugs was $6.8 / 100 \mathrm{PY}$, in contrast to $15.6 / 100 \mathrm{PY}$ in patients treated with placebo, which accounts for a $57 \%$ reduction in risk $(\mathrm{RR}=0.43,95 \% \mathrm{CI} 0.23-0.81)$. The incidence of uveitis in patients treated with infliximab (3.4/100 PY) differed from patients treated with etanercept (7.9/100 PY), although the difference was not significant [179] (2A). An open-label, non-randomized clinical trial included 1250 patients with active AS who were treated with adalimumab for 20 weeks. The incidence of acute anterior uveitis in the year prior to treatment with adalimumab was 15/100 PY. Treatment with adalimumab decreased the short-term incidence (mean exposure of 106 days) to $7.4 / 100 \mathrm{PY}$, a $50 \%$ reduction in risk $(\mathrm{RR}=0.50$, 95\% CI 0.34-0.73) [180] (2C). In a population with AS selected for an increased frequency of uveitis (77 patients with 52 attacks in the year before baseline), the reduction in risk was, as expected, even higher, from 68/ 100 to $14 / 100$ PY after treatment with adalimumab for at least 12 weeks ( $R R=0.20,95 \%$ CI $0.13-0.32)$ [181] (2C). Another post hoc analysis of eight clinical trials of etanercept in patients with AS found a 55\% lower incidence of uveitis in the etanercept group (8.6/100 PY) than in the placebo group (19.3/100 PY). In the long term, considering all patients treated with etanercept in the placebo-controlled period and in open-label extension studies, the incidence was 12/100 PY [182] (2C). Smaller $(\mathrm{n} \leq 15)$ open-label and uncontrolled studies also reported the efficacy of the newer anti-TNF $\alpha$ drugs, golimumab and certolizumab pegol in the treatment of anterior uveitis associated with SpA, including in patients previously exposed to another anti-TNFa drugs [183185] (2C). During the double-blind phase of the RAPIDaxial SpA trial, the incidence of uveitis was lower in patients who received certolizumab pegol than in patients treated with the placebo (3/100 PY versus 10.3/100 PY). In the long-term follow-up period, the rate of uveitis remained low for up to week $96(4.9 / 100 \mathrm{PY})$ and was similar between individuals with AS and nonradiographic axial SpA [186] (2B). An open-label, nonrandomized trial included 93 patients with AS who were treated with golimumab for 12 months. The incidence of anterior uveitis was compared between the 12-month period prior to treatment and the treatment period. Treatment with golimumab reduced the risk of uveitis by $80 \%$ from 11.1 to $2.2 / 100$ PY ( $R R=0.20,95 \% \mathrm{CI}$ 0.04-0.91) [187] (2C). Finally, a meta-analysis published in 2015 used the inclusion criteria of RCTs of at least 12 weeks comparing anti-TNF $\alpha$ therapy with placebo and describing the rates of uveitis in both groups, and concluded that short-term anti-TNF $\alpha$ therapy was associated with fewer uveitis episodes in patients with AS $(\mathrm{OR}=0.35,95 \% \mathrm{CI} 0.15-0.81)$. According to the results of a subgroup analysis, the effects of treatment with etanercept significantly differed from placebo, but not from monoclonal antibodies. Importantly, the statistical power $(1-\beta)$ of this subanalysis in comparing etanercept with placebo, calculated a posteriori, was $99.8 \%$. Conversely, in the comparison between monoclonal antibodies and placebo, the smaller sample size provided a statistical power of only $65.5 \%$ because only one trial of certolizumab pegol and two trials of infliximab met the inclusion criteria of the study [188] (2A). The incidence rates of 
Table 6 Incidence (mean) of acute anterior uveitis (AAU) and inflammatory bowel disease (IBD) and respective 95\% Cls calculated using a normal approximation. Data from different studies were pooled when the same outcomes from the same treatments were available and when they referred to doses and/or regimens approved in Brazil. * 95\% Cl reported by the authors of the original study. ${ }^{* *}$ No new case or reactivation was reported in the study with golimumab IV. The incidence of this event was not described in studies with SC golimumab injections

\begin{tabular}{|c|c|c|c|c|}
\hline \multirow{2}{*}{$\begin{array}{l}\text { Outcome } \\
\text { Drug }\end{array}$} & \multicolumn{4}{|c|}{ Incidence (events/100 PY) } \\
\hline & AAU Incidence & $95 \% \mathrm{Cl}$ & IBD Incidence & $95 \% \mathrm{Cl}$ \\
\hline Infliximab [179, 189] & 3.4 & $0.5-6.4$ & 0.2 & $0-0.9^{*}$ \\
\hline Etanercept $[179,189]$ & 7.9 & $5.4-10.5$ & 1.3 & $0-4.2^{*}$ \\
\hline Adalimumab $[180,189]$ & 7.4 & $4.7-10.1$ & 0.8 & $0.6-2.5^{*}$ \\
\hline Golimumab [133, 138, 187] & 2.2 & $0-5.2$ & $0^{* *}$ & - \\
\hline Certolizumab pegol $[141,186]$ & 4.9 & $3.0-6.9$ & 0.1 & $0-0.3$ \\
\hline Secukinumab [142] & 1.0 & $0.3-1.8$ & 0.7 & $0.1-1.3$ \\
\hline
\end{tabular}

uveitis reported in the clinical trials analyzing the various biologics are outlined in Table 6.

The publication of a case series of paradoxical uveitis induced by anti-TNF $\alpha$ therapy highlighted possible differences in efficacy (or even safety) in the treatment of axial SpA-related uveitis between a fusion protein (etanercept) and monoclonal antibodies (including the antibody fraction certolizumab pegol) by suggesting that the incidence of new cases of uveitis increased following etanercept treatment [190] (4). Subsequently, evidence from several observational studies confirmed these findings. A study analyzed a large US health service claims database covering approximately 100 third-party payers and 170 million covered individuals. Of the more than 52,000 patients diagnosed with AS in the study period, 2115 initiated anti-TNF $\alpha$ therapy, with no prior history of uveitis. The incidence rates of (new) uveitis cases in patients receiving treatment with adalimumab, infliximab and etanercept were $2.4,3.2$ and $4.5 \%$, respectively, with a significance difference only observed between adalimumab and etanercept, favoring the monoclonal antibody [191] (2C). A retrospective Chinese cohort study included 182 patients with AS and a previous history of uveitis. The treatments with the three anti-TNF $\alpha$ drugs available at that time (adalimumab, infliximab or etanercept) were equally effective, but the relapse rate with the soluble receptor $(38 \%)$ was much higher than with the monoclonal antibodies (6 and 11\% for adalimumab and infliximab, respectively). The combination of methotrexate with anti-TNF $\alpha$ therapy nullified the difference in efficacy observed between monotherapies [192] (2B). The Swedish registry also analyzed the incidence of anterior uveitis in more than 1600 patients with AS treated with adalimumab, infliximab and etanercept. The comparison of the incidence rates of uveitis before starting and in the first two years of treatment with each TNFa inhibitor showed a decrease in total rates for the treatments with adalimumab and infliximab. Conversely, the use of etanercept increased the incidence of anterior uveitis. The adjusted HR of uveitis in patients previously free of the disease (last two years before starting treatment with a TNF $\alpha$ inhibitor) were significantly higher for etanercept than adalimumab $(\mathrm{HR}=3.86,95 \% \mathrm{CI} 1.85-8.06)$ and for etanercept than infliximab $(\mathrm{HR}=1.99,95 \% \mathrm{CI}$ 1.23-3.22), with no differences between infliximab and adalimumab [193] (2B). A Korean cohort study of 1055 patients with AS analyzed the incidence of uveitis among users of an anti-TNF $\alpha$ antibody (adalimumab, infliximab or golimumab), soluble TNF $\alpha$ receptor (etanercept) and nonsteroidal anti-inflammatory drugs (NSAIDs). Compared with the group treated with NSAIDs alone, uveitis was less common in the group treated with anti-TNF $\alpha$ monoclonal antibodies $(\mathrm{HR}=$ 0.53, 95\% CI 0.29-0.96), but more common in the group treated with etanercept $(\mathrm{HR}=2.25,95 \% \mathrm{CI}$ 1.43-3.53) [194] (2B). Based on these data, among the anti-TNFa antibodies, monoclonal antibodies are more effective in preventing new episodes of uveitis than etanercept.

The data on secukinumab are insufficient to analyze its efficacy regarding this outcome. In the MEASURE 1 and 2 trials, no difference regarding uveitis incidence was observed between the treatment (regardless of dose or administration route) and placebo ( $R R=1.20,95 \% \mathrm{CI}$ 0.25-5.73) groups [142] (2B).

Psoriasis and inflammatory bowel disease (IBD)

Among the biologics approved for the treatment of axial SpA in Brazil, the on-label use of adalimumab and infliximab is also approved for the treatment of psoriasis, Crohn's disease and ulcerative colitis; etanercept and secukinumab for plaque psoriasis; certolizumab pegol for Crohn's disease; and golimumab for ulcerative colitis. The incidence rates of cases of IBD reported in clinical trials of various biologics are outlined in Table 6 .

No clinical trials have specifically assessed the efficacy of these drugs in treating psoriasis associated with axial 
Table 7 Increase in the relative frequency (\%), relative to placebo, in different outcomes, the corresponding number needed to treat (NNT) and 95\% Cls calculated using a normal approximation. - Data were not available. Data from different studies were pooled when the same outcomes from the same treatments were available and when they referred to doses and/or regimens approved in Brazil

\begin{tabular}{|c|c|c|c|c|c|c|}
\hline \multirow{4}{*}{$\begin{array}{l}\text { Outcome } \\
\text { Drug }\end{array}$} & \multirow{2}{*}{\multicolumn{2}{|c|}{$\frac{\text { PASI50 }}{\text { Follow-up time (weeks) }}$}} & \multicolumn{2}{|c|}{ PASI75 } & \multicolumn{2}{|c|}{ PASI90 } \\
\hline & & & & & & \\
\hline & \multicolumn{2}{|l|}{24} & \multicolumn{2}{|l|}{24} & \multicolumn{2}{|l|}{24} \\
\hline & $\%$ & NNT $(95 \%$ Cl) & $\%$ & NNT $(95 \%$ Cl) & $\%$ & NNT $(95 \%$ Cl) \\
\hline Infliximab [195] & 66.7 & $1.5(1.3-1.8)$ & 58.8 & $1.7(1.4-2.1)$ & 38.4 & $2.6(2.0-3.6)$ \\
\hline Etanercept $[196,197]$ & 27.0 & $3.7(2.6-6.3)$ & 20.8 & $4.8(3.5-7.8)$ & - & - \\
\hline Adalimumab [198] & 62.5 & $1.5(1.2-1.8)$ & 58.8 & $1.7(1.4-2.2)$ & 41.7 & $2.4(1.9-3.3)$ \\
\hline Golimumab [199] & 66.7 & $1.5(1.3-1.8)$ & 55.5 & $1.8(1.6-2.2)$ & 32.2 & $3.1(2.4-4.3)$ \\
\hline Certolizumab pegol [200] & 45.5 & $2.2(1.7-2.9)$ & 45.5 & $2.2(1.8-2.8)$ & 35.7 & $2.8(2.2-3.7)$ \\
\hline Secukinumab $[201,202]$ & - & - & 37.0 & $2.1(1.8-2.6)$ & 35.7 & $2.7(2.2-3.4)$ \\
\hline
\end{tabular}

SpA. However, the effects of these drugs are reasonably inferred, as surrogate markers, from the efficacy analysis of a clinical response known as the Psoriasis Area and Severity Index (PASI), which was 50, 75 and 90 in the respective studies of psoriatic arthritis. Table 7 outlines the relative frequencies (relative to the placebo group) of these responses in patients receiving treatment with different drugs. Again, despite differences between populations and even between profiles of prior exposure to treatment, the confidence intervals of the various studies available for the same outcome overlap, except for the etanercept results, suggesting that it is less effective in controlling psoriasis than monoclonal TNF $\alpha$ inhibitors and secukinumab (2B).

A meta-analysis of 9 RCTs and two open-label studies analyzed the incidence of IBD (Crohn's disease or ulcerative colitis) in patients with AS undergoing anti-TNF $\alpha$ therapy (infliximab, adalimumab or etanercept, $n=1130)$, of whom $6.7 \%(n=76)$ had a history of one of these diseases. The treatment of these patients was associated with the incidence rates of reactivation and/or a new case of Crohn's disease or ulcerative colitis in $0.2 / 100$ PY for infliximab, 2.3/100 PY for adalimumab and 2.2/100 PY for etanercept, whereas the incidence in the placebo group was 1.3/100 PY. Regarding flare-up prevention in patients with a history of IBD, infliximab was the most effective drug in this study. Regarding the onset of new cases, no differences were observed among the three drugs [189] (2A). In the MEASURE 1 and 2 trials, the pooled exposure-adjusted incidence rate of Crohn's disease alone in secukinumabtreated patients was $0.7 / 100$ PY [142] (1B). In phase 2 clinical trials, etanercept and secukinumab showed no efficacy in treating Crohn's disease [203, 204] (2B).

\section{Recommendation}

In the case of recurrent anterior uveitis or active inflammatory bowel disease in the setting of axial SpA, anti-TNF monoclonal antibodies (infliximab, adalimumab, golimumab, and certolizumab pegol) have shown the best response rates among the biologics. Therefore, it is recommended to choose it, preferably to others. Level of evidence: $2 A$; Strength of recommendation: $B$ (moderate); Degree of agreement: 9.4 .

Monoclonal anti-TNF inhibitors (infliximab, adalimumab, golimumab, and certolizumab pegol) and ant-IL17 inhibitors have shown be the most effective, among the biologics, for the control of active psoriasis in the setting of axial SpA. Therefore, it is recommended to choose it, preferably to others. Level of evidence: $2 B$; Strength of recommendation: $B$ (moderate); Degree of agreement: 9.4.

13. What evidence supports switching biologics in patients with axial SpA?

Switching biologics in patients with axial SpA either due to primary failure (those unresponsive since treatment initiation), secondary failure (those who stopped responding to treatment over time), or even toxicity, is frequently needed in the long-term use of biologic drugs in axial SpA. There are a limited number of studies with high-quality designs, particularly studies investigating more recently developed drugs, regarding this issue.

One uncontrolled trial included 23 patients with AS who were previously treated with infliximab (minimum 6 doses) and did not achieve the ASAS20 response. These patients were switched to treatment with etanercept $50 \mathrm{mg} /$ week for 54 weeks. By week 24, 78, 52 and $39 \%$ of patients had achieved ASAS20, ASAS50 and ASAS70, respectively. By week 54, 74\% maintained at least the ASAS20 response, 61\% maintained the ASAS50 response and 39\% maintained the ASAS70 response [205] (2C). A retrospective analysis of a cohort of patients with AS who were treated with an anti-TNF $\alpha$ 
drug (infliximab, etanercept or adalimumab) reported a clinical response (BASDAI50) to a second anti-TNFa drug in $93 \%$ of 15 patients in whom the first anti-TNFa drug was switched due to primary or secondary treatment failure, adverse effects or patient preference [206] (2C). In another cohort, 16 patients with AS (15\% of 108 users of anti-TNF $\alpha$ drugs) undergoing treatment with infliximab, etanercept or adalimumab switched to a different TNF $\alpha$ inhibitor due to inefficacy $(67 \%)$ or to adverse events (28\%). Of these patients, 67 and $86 \%$ achieved BASDAI50 response within six and 12 months, respectively. Patients who switched TNF $\alpha$ inhibitors due to adverse effects were more likely to show clinical responses than patients who switched due to a lack of efficacy [207] (2C). In a similar study, 11 (24\%) of 46 patients with AS undergoing anti-TNF $\alpha$ therapy showed no clinical response or presented adverse effects. An adequate response was observed in $46 \%(n=5)$ of patients treated with a second TNF $\alpha$ inhibitor and in 100\% ( $\mathrm{n}=$ 5) of patients treated with a third inhibitor [208] (2C). The Norwegian registry (NOR-DMARD) compared 437 patients with AS using a first anti-TNFa drug with another 77 patients with AS who switched to a second anti-TNFa drug. After 3 months, $50 \%$ and of $38 \%$ patients undergoing first-line treatment achieved BASDAI50 and ASAS40 responses, respectively, whereas the same response rates of patients undergoing second-line treatments (switchers) were $28 \%(\mathrm{p}=0.007$ for intergroup difference) and $31 \%(\mathrm{p}=0.41)$, respectively. No significant efficacy difference of the second anti-TNF $\alpha$ drug was observed between switches due to inefficacy or to adverse effects [209] (2B). The Danish registry (DAN$\mathrm{BIO})$ also revealed worse responses to the second and third anti-TNF $\alpha$ drugs than the responses observed in naïve patients who were using an anti-TNFa drug for the first time, although half of the switches resulted in good responses. In addition, 432 patients with AS who switched once and 137 who switched twice were compared with 773 non-switchers. After 2 years of treatment, $79 \%$ patients who underwent first-line treatment and $54 \%$ of patients who underwent second- or third-line treatment maintained low disease activity with BAS$\mathrm{DAI}<4 \quad(\mathrm{p}<0.0001)$ and 71 and $37 \%$ has an ASDAS $<2.1$ $(\mathrm{p}<0.001)$, respectively [210] $(\mathbf{2 B})$. Data on AS patients treated with an anti-TNF $\alpha$ drug (adalimumab, etanercept, infliximab or golimumab) were retrospectively analyzed, and 77 of the 175 patients included in the analysis received at least two anti-TNFo drugs (switchers). The main reason for switching the first medication was inefficacy. The BASDAI50 response 12 months after treatment initiation was achieved at a lower frequency among switchers than among non-switchers (47\% vs $71 \%)$, corresponding to an OR of 0.37 (95\% CI 0.26-0.52). Other evidence of a loss of response is the difference between the survival times of the first and second anti-TNF $\alpha$ therapy lines: 63 months (95\% CI 57-69) and 39 months (95\% CI 31-47), respectively, $\mathrm{p}=0.05$ [211] (2B).

More recently, two systematic literature reviews (SLRs) published results supporting the strategy of using a second anti-TNFo drug when treatment failure or adverse effects occur $[212,213](2 \mathrm{~A})$. According to one of the reviews based on data from 21 studies, the NNT to achieve BASDAI50 response in patients undergoing first-line treatment with an anti-TNF $\alpha$ drug ranged from 1.6 to 2.0. Conversely, patients undergoing second-line treatment (with a second anti-TNF $\alpha$ drug) showed higher (worse) NNTs, although still significant, ranging from 2.5 to 4.0 [213] (2A).

In the phase 3 trials of the two most recently launched anti-TNFa drugs (golimumab and certolizumab pegol) in patients with axial $\mathrm{SpA}$, a small portion of patients with prior exposure to anti-TNFo therapy, 16\% in the RAPIDaxial SpA trial of certolizumab pegol and $14.4 \%$ in the GO-ALIVE trial of IV administered golimumab, were analyzed. However, separate response data for this subpopulation were not reported in either case [138, 139] (2C).

In the MEASURE 2 trial of secukinumab for AS, $38.8 \%$ of the participants already used some anti-TNFa drug before starting the study. A subsequent publication compared the efficacy results between the two groups (anti-TNF $\alpha$-naive and anti-TNF $\alpha$-inadequate response/ intolerance), and, not surprisingly, the clinical responses were also slightly worse in the group with prior exposure than in the group receiving the first-line biological therapy. The NNTs were calculated for first- and secondline treatments and were $2.7(95 \%$ CI $1.8-5.6)$ and 3.9 (95\% CI 2.0-60) for ASAS20; 3.9 (95\% CI 2.3-14.3) and 4.0 (95\% CI 2.4-11.2) for ASAS40; and 8.7 (95\% CI 4.0$49)$ and 14 (95\% CI 6.0-41) for ASAS partial remission, respectively [143] (2B). To date, no data on the efficacy of second- or third-line treatments after treatment failure or toxic response to secukinumab are available.

\section{Recommendation}

Patients with axial SpA who fail to show an initial response to a biological therapy (primary treatment failure), loss of efficacy (secondary treatment failure) or adverse effects should switch to another approved biologic, regardless of the mechanism of action. Level of evidence: $2 A$; Strength of recommendation: $B$ (moderate); Degree of agreement: 9.4.

After the first biologic switch, the response rates decrease slightly but remain significant. The little available evidence on the second biologic switch suggest response rates even lower than the second-line treatment. Level of evidence: $2 A$; Strength of recommendation: $B$ (moderate); Degree of agreement: 9.1.

14. For how long should a biologic be used during the follow-up of patients with axial SpA?

Considering the prevalence of axial SpA, the portion of patients who will require biologics and the costs 
involved (both financial and related to individual health), strategies for the reduction and/or discontinuation of these drugs in patients who are considered to have an inactive disease must be discussed. The lack of studies with adequate methodology and sufficient follow-up time further complicates the difficult task of defining remission in patients with axial SpA and the minimum time a patient should remain in this presumed inactive status before drug withdrawal begins.

Biological therapy discontinuation

A systematic review of biological therapy discontinuation in patients with axial SpA included 4 RCT extensions and an uncontrolled trial $(n=220)$ that were highly heterogeneous regarding the length of antiTNF $\alpha$ therapy before discontinuation, use of comedication in the post-discontinuation period and the definition of reactivation (flare-up). After 1-year followup, $76-100 \%$ (79\% median) patients exhibited disease reactivation after a mean period ranging from 6 to 24 weeks after discontinuation. Importantly, in these studies, the probability of achieving a good clinical response similar to the response observed before discontinuation after resuming treatment with these drugs was high [214] (2A). A retrospective Polish study reported similar results. In that study, $74 \%$ of patients with axial SpA presenting low disease activity (LDA) and having completed anti-TNF $\alpha$ therapy withdrawal showed disease reactivation, which required a resumption of therapy, on average, after 14 weeks during an observation period ranging from 9 to 48 months [215] (2C). Conversely, the ABILITY-3 trial included 305 patients exclusively diagnosed with non-radiographic axial SpA axial who were using adalimumab and considered inactive $($ ASDAS $<1.3$ ) for at least 12 weeks in a randomized, double-blind controlled extension in which 152 of those patients continued to receive adalimumab and 153 received the placebo. After 40 weeks of follow-up, $70 \%$ of patients in the adalimumab group and $47 \%$ of patients in the placebo group remained without disease reactivation (defined as ASDAS $\geq 2.1$ ). The difference of $23 \%$ in the incidence of flare-ups at 40 weeks corresponds to a number needed to harm $(\mathrm{NNH})$ of reactivation after withdrawal of 4.3 (95\% CI 2.9-7.9) [216] (1B).

Dose reduction in biological therapy

The aforementioned systematic review also included data on gradual anti-TNF $\alpha$ dose reduction strategies from eight studies, mostly with low-grade evidence (six observational studies, one controlled but nonrandomized trial and only one RCT) including $436 \mathrm{pa-}$ tients with AS who were followed for a median time of 12 months. The inclusion criteria, which were highly heterogeneous among the studies, ranged from three to six months in remission or LDA before starting antiTNF $\alpha$ dose reduction. In most studies, remission was defined as $\mathrm{BASDAI}<2$, normal CRP levels and LDA or as $\mathrm{BASDAI}<4$ and normal CRP levels. The percentage of patients who maintained LDA or remission following the anti-TNF $\alpha$ dose reduction was reported in five studies and ranged from 53 to $100 \%$. The remaining three studies reported mean changes in BASDAI and CRP levels after anti-TNF $\alpha$ dose reduction and found no relevant increase in these parameters. Patients with a longer remission time before dose reduction and patients without peripheral or extra-articular manifestations had higher success rates with anti-TNF $\alpha$ dose reduction [214] (2A). The Dutch cohort GLAS followed 58 patients with AS undergoing anti-TNFa therapy with LDA (BASDAI $<4$ ) for at least 6 months and for whom the treatment dose was reduced for 24 months. The etanercept dose was reduced from $50 \mathrm{mg} /$ week to $25 \mathrm{mg} / 2$ weeks in 4 reduction steps, infliximab was reduced from $5 \mathrm{mg} / \mathrm{kg} / 8$ weeks to $3 \mathrm{mg} / \mathrm{kg} / 10$ weeks in two steps and adalimumab was reduced from $40 \mathrm{mg} / 2$ weeks to $40 \mathrm{mg} / 4$ weeks in two steps. Dose reduction only continued if BASDAI remained $<4$ and the attending physician and patient agreed to the subsequent reduction. After 2 years, 53\% patients remained on a reduced dose regimen (mean: $62 \pm 11 \%$ of the standard dose) [217] (2B). Consistent with these findings, other studies reported success rates in anti-TNF $\alpha$ dose reduction (ranging from 50 to $75 \%$ of the standard dose) in patients with axial SpA who were in remission or LDA, ranging from 55 to $96 \%$ after one year of follow-up [218-221] and from 56 to $84 \%$ after 3 years [220, 222, 223].

Better results were observed among patients undergoing the same therapy and patients in remission for longer periods [219, 221] (2C). The drug survival remained unchanged during the four years $(\mathrm{HR}=$ 0.472, 95\% CI 0.155-1.435) among 100 patients with AS for whom the dose of etanercept was reduced from $50 \mathrm{mg} /$ week to $25 \mathrm{mg} /$ week (or $50 \mathrm{mg} / 2$ weeks) and among 34 controls who maintained the standard dose, thus supporting the efficacy of the reduced dose in patients in remission/LDA during the longest followup period [224] (2B). A South Korean study compared radiographic progression, using the mSASSS 2 and 4 years after the baseline between 116 patients with AS using a reduced anti-TNF $\alpha$ (etanercept or adalimumab) dose and 49 treated with a standard dose. The mean dose used by the reduction group was $68 \%$ of the standard dose, with no difference observed between groups. Only a small but significant difference was observed in patients at higher risk of progression (those with syndesmophytes since the baseline) in favor of the standard dose group (1.23 vs 1.72 units/year; $\mathrm{p}=$ 0.023) [225] (2B). No studies have examined a secukinumab dose reduction or withdrawal in patients with axial SpA. 
Recommendation

In those who have reached the proposed treatment target, for at least 6 months, an attempt may be made to reduce the anti-TNFa dose or increase the interval between doses. Data on other mechanisms of action remains insufficient. However, the risk of long-term radiographic progression should be considered. Level of evidence: 1B; Strength of recommendation: B (moderate); Degree of agreement: 8.9.

15. Is there evidence for the use of biologics and/or target-specific small molecules with other mechanisms of action (non-TNF $\alpha$ i and non-IL17i) in patients with axial SpA?

A non-negligible portion of patients with axial SpA will not achieve the desired activity control target, remission or at least LDA, despite the use of conventional drugs and biologicals approved for this indication. Here, we compile the currently available evidence for the efficacy of drugs with other action mechanisms, including target-specific small molecules.

Anti-CD20, anti-IL6R and CTLA4-Ig

A small $(n=20)$, open-label and uncontrolled trial reported a favorable response to rituximab $(1000 \mathrm{mg}$ IV combined with $100 \mathrm{mg}$ methylprednisolone IV at weeks 0 and 2) in patients with AS and a history of anti-TNF $\alpha$ therapy failure (ASAS20, ASAS40, BASDAI50 and ASAS partial remission were only achieved by $30,10,0$ and $0 \%$ patients, respectively). A modest response (ASAS20, ASAS40, BASDAI50 and ASAS partial remission were achieved by $50,40,50$ and $30 \%$ patients, respectively) was observed only in bio-naïve individuals [226] $(\mathbf{2 C})$. The responsive patients $(n=9)$ were followed until week 48. Four maintained the response until the end of the study and five showed disease reactivation (defined by a worsening of the BASDAI corresponding to $1.5 \mathrm{x}$ the lowest value reached until week 24) and were retreated with the same dose, recovering their response within 48 weeks after retreatment [227] (2C). Negative results were also observed in two open-label and uncontrolled studies of abatacept in patients with active axial SpA, in which no difference was observed in any activity parameter assessed from baseline to week 24 [228, 229] (2C). Therapeutic blockade of the IL6 receptor (IL6R) was analyzed in the BUILDER-1 study, a phase II-III placebo-controlled randomized trial, which compared the efficacy of tocilizumab IV ( $\mathrm{n}=$ $48)$ with placebo $(n=51)$ in the treatment of patients with AS in 24 weeks of follow-up. After 12 weeks, ASAS20 was achieved by 37.3 and $27.5 \%$ patients in the treatment and control groups $(\mathrm{p}=0.28)$, respectively, and the study was discontinued [230] (2B). Another IL6R inhibitor, sarilumab, also failed to produce a clinical response in patients with AS in the ALIGN study, a randomized clinical trial with 301 patients.
No differences in the ASAS20 response at week 12 were observed between the placebo group and the groups treated any dose of sarilumab tested in the trial [231] (2B).

Inhibitors of the IL23/IL17 axis

Despite the promising results of a phase II trial [232], ustekinumab, an antibody that specifically binds the p40 subunit of IL12 and IL23, three phase III studies ( $\mathrm{n}=$ 1017) were interrupted early, after week 24 , when the results showed no difference in the proportion of patients showing ASAS20, ASAS40 and BASDAI50 responses between the placebo and treatment groups or changes in ASDAS-CRP or BASFI scores [233] (1B).

Target-specific small molecules

The specific phosphodiesterase-4 (PDE-4) inhibitor apremilast did not induce significant differences in changes in BASDAI, BASFI and BASMI scores from baseline to week 12 compared with the placebo in a phase II study. Additionally, no difference in the frequency of the ASAS20 response was observed between the treatment and placebo groups [234] (2B). In turn, therapeutic blockade of Janus kinases (JAK), a family of non-receptor tyrosine kinases that transduce the intracellular signals of various cytokines, produced promising results in patients with AS. Tofacitinib, a JAK inhibitor selective for JAK-1 and JAK-3, was tested in a phase II trial with 207 patients randomly allocated to three treatment doses (2, 5 and $10 \mathrm{mg}, 2$ times per day) and placebo, whose primary outcome was the ASAS20 response at week 12. The groups of patients treated with $5 \mathrm{mg}$ and $10 \mathrm{mg}$ of tofacitinib differed significantly from the placebo group in the ASAS20, ASAS40 and BASDAI50 responses and non-significantly in the ASAS partial remission and ASDAS inactive disease responses. In addition, approximately one-third of the patients treated with tofacitinib showed reduced inflammation on sacroiliac joint and spinal MRI, which was the most common clinical response among those patients [235, 236] (2B). Another JAK inhibitor, filgotinib, which is selective for JAK-1, was also tested in the TORTUGA trial, a phase II clinical trial that included 116 patients with AS. At week 12, the change in the ASDAS from baseline was greater in the treatment group than in the placebo group: $-1.47( \pm 1.04)$ and $-0.57(0.82)$, respectively, with a mean difference of -0.85 (95\% CI -1.17 to $-0.53, \mathrm{p}<0.0001)$. At week 12 , significantly greater proportions of patients in the treatment group achieved ASAS20 and ASAS40 responses, decreases in BASDAI, BASMI and BASFI scores and decreases in ultrasensitive CRP levels. Higher percentages of patients with ASDAS inactive disease and ASAS partial remission were observed in the treatment group than in the placebo group, but the differences were not significant [237] (2B). 


\section{Recommendation}

The use of other biologics and/or target-specific small molecules (abatacept, tocilizumab, rituximab, sarilumab, ustekinumab and apremilast) is not recommended for the treatment of patients with axial SpA. Level of evidence: $1 B$; Strength of recommendation: $A$ (strong); Degree of agreement: 9.5 .

The Janus kinase (JAK) inhibitors tofacitinib and filgotinib showed promising clinical results in the treatment of ankylosing spondylitis, but more definitive evidence (phase III randomized clinical trials) is still needed prior to their recommendation. Level of evidence: $2 B$; Strength of recommendation: B (moderate); Degree of agreement: 9.1.

\section{Conclusions}

The recommendations presented herein seek to provide scientific evidence to rheumatologists and other agents involved in the care of patients with axial spondyloarthritis. In each situation chosen for response, were considered aspects as the therapeutic efficacy, safety, and costs, together with the critical assessment and experience of a panel of experts to standardize the management of these conditions in the national socioeconomic context but maintaining the autonomy of the physician in choosing different therapeutic options. These recommendations should be updated periodically because of the rapid development of this field of knowledge.

\section{Supplementary information}

Supplementary information accompanies this paper at https://doi.org/10. 1186/s42358-020-0116-2.

Additional file 1. Bibliographic Research details.

Additional file 2. Data used in the Confidence Intervals.

\section{Acknowledgements}

Not applicable.

\section{Authors' contributions}

All authors made contributions to the acquisition of data, have been involved in drafting the manuscript or revising it critically for important intellectual content, participated in the voting rounds, gave final approval of the version to be published and have participated sufficiently in the work to take public responsibility for appropriate portions of the content.

\section{Authors' information}

Not applicable.

\section{Funding}

Brazilian Society of Rheumatology. The funding body had no role in the design of the study and collection, analysis, and interpretation of data and in writing the manuscript.

Availability of data and materials

Online supplements 1 and 2 .

Ethics approval and consent to participate

Not applicable.

Consent for publication

Not applicable.

\section{Competing interests}

Gustavo Gomes Resende received lecture fees from Abbvie, Janssen, Novartis, Pfizer, and UCB; advisory board from Abbvie, Janssen, and Novartis; Research support from Brazilian Society of Rheumatology, FAPEMIG and UCB; clinical research payments from Abbvie and Pfizer; sponsorship for scientific events from Abbvie, Janssen, Lilly, Novartis, Pfizer, and UCB.

Eduardo de Souza Meirelles received payments as a speaker from Novartis, Abbvie, Abbott and Marjan; research grants from Novartis and Pfizer; support for conferences and courses from Aché, Pfizer, Novartis, Janssen, Abbvie, Roche, and Lilly; Advisory board fee from Novartis and Marjan. Cláudia Diniz Lopes Marques received lecture fees from Abbvie, Janssen, Pfizer and Novartis; advisory board from Novartis and Abbvie; sponsorship for events from Abbvie, Janssen, Pfizer, Novartis, and Lilly.

Adriano Chiereghin received honoraria as a speaker from Janssen, Novartis, UCB, and Pfizer; support to courses and congresses from Abbvie, Janssen, Novartis, UCB, and Pfizer; advisory board from Novartis and Janssen. Andre Marun Lyrio received payments from Speaker of Janssen and UCB; support to courses/congresses from Janssen, Abbvie, Pfizer, UBC, Novartis, and Lily.

Antônio Carlos Ximenes received payments for participation in clinical research from Abbvvie, Pfizer, Roche, BMS, and Amgen; on scientific board of Pfizer, and Abbivie; as a lecturer from AbbVie, Pfizer, and Abbott.

Carla Gonçalves Saad has no conflicts of interest.

Célio Roberto Gonçalves has no conflicts of interest.

Charles Lubianca Kohen received financial support for advisory board participation from Novartis; speaker fee from Janssen, Abbvie, Novartis, Pfizer, UCB; support to events from Janssen, Abbvie, Roche, Astra-Zeneca, Novartis. Cláudia Goldenstein Schainberg has participated in the pharmaceutical advisory board of AbbVie, Janssen, Lilly, Novartis, and Pfizer; is a speaker invited by AbbVie, Janssen, Lilly, Novartis, Pfizer; has no stock of these pharmaceutical industries.

Cristiano Barbosa Campanholo received financial support for advisory board participation from Janssen, Abbvie, Bristol, Lilly, Novartis, Pfizer, UCB; speaker fee from Janssen, Abbvie, Lilly, Novartis, and Pfizer, UCB; support to events from Janssen, Abbvie, Bristol, Novartis, and Pfizer.

Júlio Silvio de Sousa Bueno Filho has no conflicts of interest. Lenise Brandao Pieruccetti has no conflicts of interest. Mauro Waldemar Keiserman received financial support for lectures, advisory bord and clinical research from Abbvie, Actelion, Biogen, Bristol, Celltrion, Lilly, Human Genome Sceiences, Janssen, Pfizer, Novartis, Roche, Sanofi, and UCB. Michel Alexandre Yazbek received financial support from Abbvie, UCB, Novartis and Lilly.

Penelope Esther Palominos has no conflicts of interest.

Rafaela Silva Guimarães Goncalves received fees for lectures from Janssen, Novertis, Abbvie, Apsen, Bristol, and Pfizer; advisory board from Janssen. Ricardo da Cruz Lage received speakers fee from Abbvie and Novartis; support to scientific events from Janssen, Novartis, Pfizer and Abbvie; clinical research payments from Abbvie.

Rodrigo Luppino Assad received fees for lectures and advisory board from Abbvie, Novartis, Janssen, UCB, Lilly, and Bristol; research support from Abbvie and UCB.

Rubens Bonfiglioli received financial support for clinical research from Roche, Pfizer, Amgen, and Novartis; for scientific advisory from Lilly, Abbvie, Roche, and UCB; for support to events from Roche, Pfizer, Abbvie and Novartis; for symposia and sponsored meetings from Roche, Pfizer, and Janssen. Sônia Maria Alvarenga Anti received financial support from Abbvie, Jansen, Novartis, Lilly, and UCB.

Sueli Coelho da Silva Carneiro received honorary speaker from Abbvie, Janssen, Lilly, Novartis and Pfizer; support to research from CNPq and FAPERJ; support for congresses from Abbvie, Janssen, Novartis, Pfizer, CNPq and FAPERJ; advisory board from Janssen, Lilly, and Novartis.

Thauana Luíza Oliveira received lecturer fees from Abbvie, Novartis and Janssen; support to congresses from Abbvie and Janssen.

Valderílio Feijó Azevedo is GRAPPA member; Medical diretor of Edumed Biotech; received for clinical research from Pfizer, Roche, Janssen, Bristol, Abbvie, Medimmune, Boehringer, GSK, USB, Sanofi, Takeda, Bird Rock Bio, and NovoNordisk; financial support to events and lectures from Pfizer, Hospira, Roche, MSD, BMS, Merck Senoro, Janssen, Novertis, Celltrion, UCB, and AztraZeneca.

Washington Alves Bianchi has no conflicts of interest.

Wanderley Marques Bernardo has no conflicts of interest. 
Marcelo de Medeiros Pinheiro received financial support for advisory board from Novartis and Janssen; by lectures from Novartis, Janssen, Abbvie. Percival Degrava Sampaio-Barros received for participation in lectures, boards or scientific events from laboratories Abbvie, Janssen, Novartis, Pfizer and UCB.

\section{Author details}

'Universidade Federal de Minas Gerais (UFMG), Alameda Álvaro Celso, 175 /

$2^{\circ}$ Andar. Santa Efigênia. CEP 30.150-260, Belo Horizonte, MG, Brazil. ${ }^{2}$ Universidade De São Paulo (USP), São Paulo, Brazil. ${ }^{3}$ Universidade Federal de Pernambuco (UFPE), Recife, Brazil. ${ }^{4}$ Pontifície Universidade Católica (PUC) de Sorocaba, Sorocaba, Brazil. ${ }^{5}$ Pontifície Universidade Católica (PUC) de Campinas, Campinas, Brazil. ${ }^{6}$ Hospital Estadual Geral de Goiania (HGG), Goiânia, Brazil. ' Universidade Federal do Rio Grande do Sul (UFRS), Porto Alegre, Brazil. ${ }^{8}$ Santa Casa de Misericórdia (SCM) de São Paulo, São Paulo, Brazil. ${ }^{9}$ Departmento de Estatística, Universidade Federal de Lavras (UFLA) Lavras, Brazil. ${ }^{10}$ Hospital Heliópolis, São Paulo, Brazil. ${ }^{11}$ Pontifície Universidade Católica (PUC) de Porto Alegre, Porto Alegre, Brazil. ${ }^{12}$ Universidade Estadual de Campinas (UNICAMP), Campinas, Brazil. ${ }^{13}$ USP Ribeirão Preto, Ribeirão Preto, Brazil. ${ }^{14}$ Hospital do Servidor Público do Estado de São Paulo, São Paulo, Brazil. ${ }^{15}$ Universidade Federal do Rio De Janeiro (UFRJ), Rio de Janeiro, Brazil. ${ }^{16}$ Universidade Federal de São Paulo (UNIFESP), São Paulo, Brazil. ${ }^{17}$ Universidade Federal do Paraná (UFPR), Curitiba, Brazil. ${ }^{18}$ Santa Casa de Misericórdia (SCM) do Rio De Janeiro, Rio de Janeiro, Brazil. ${ }^{19}$ Universidade de São Paulo (USP), São Paulo, Brazil.

Received: 7 July 2019 Accepted: 22 January 2020

Published online: 21 February 2020

\section{References}

1. Rudwaleit M, Landewe R, van der Heijde D, Listing J, Brandt J, Braun J, et al. The development of Assessment of SpondyloArthritis international Society classification criteria for axial spondyloarthritis (part I): classification of paper patients by expert opinion including uncertainty appraisal. Ann Rheum Dis. 2009;68(6):770-6.

2. Rudwaleit M, van der Heijde D, Landewe R, Listing J, Akkoc N, Brandt J, et al. The development of Assessment of SpondyloArthritis international Society classification criteria for axial spondyloarthritis (part II): validation and final selection. Ann Rheum Dis. 2009;68(6):777-83.

3. Sampaio-Barros PD, Keiserman M, Meirelles Ede S, Pinheiro Mde M, Ximenes AC, Azevedo VF, et al. Recommendations for the management and treatment of ankylosing spondylitis. Rev Bras Reumatol. 2013;53(3):242-57.

4. Phillips B, Ball C, Sackett D, Badenoch D, Straus S, Haynes B, et al. Levels of Evidence. BJU Int. 2010; 106: 1424.

5. Lin Z, Liao Z, Huang J, Jin O, Li Q, Li T, et al. Evaluation of Assessment of Spondyloarthritis International Society classification criteria for axial spondyloarthritis in Chinese patients with chronic back pain: results of a $2-$ year follow-up study. Int J Rheum Dis. 2014;17(7):782-9.

6. Deodhar A, Mease PJ, Reveille JD, Curtis JR, Chen S, Malhotra K, et al. Frequency of Axial Spondyloarthritis Diagnosis Among Patients Seen by US Rheumatologists for Evaluation of Chronic Back Pain. Arthritis Rheumatol. 2016;68(7):1669-76.

7. Sepriano A, Landewe R, van der Heijde D, Sieper J, Akkoc N, Brandt J, et al. Predictive validity of the ASAS classification criteria for axial and peripheral spondyloarthritis after follow-up in the ASAS cohort: a final analysis. Ann Rheum Dis. 2016;75(6):1034-42

8. Bendahan LT, Machado NP, Mendes JG, Oliveira TL, Pinheiro MM Performance of the classification criteria in patients with late-onset axial spondyloarthritis. Mod Rheumatol. 2018;28(1):174-81.

9. Mau W, Zeidler H, Mau R, Majewski A, Freyschmidt J, Stangel W, et al. Clinical features and prognosis of patients with possible ankylosing spondylitis. Results of a 10-year followup. J Rheumatol. 1988;15(7):1109-14.

10. Bennett AN, McGonagle D, O'Connor P, Hensor EM, Sivera F, Coates LC, et al. Severity of baseline magnetic resonance imaging-evident sacroiliitis and HLA-B27 status in early inflammatory back pain predict radiographically evident ankylosing spondylitis at eight years. Arthritis Rheum. 2008;58(11): 3413-8

11. Weber U, Lambert RG, Ostergaard M, Hodler J, Pedersen SJ, Maksymowych WP. The diagnostic utility of magnetic resonance imaging in spondylarthritis: an international multicenter evaluation of one hundred eighty-seven subjects. Arthritis Rheum. 2010;62(10):3048-58.
12. Rudwaleit M, Jurik AG, Hermann KG, Landewe $R$, van der Heijde $D$, Baraliakos $X$, et al. Defining active sacroiliitis on magnetic resonance imaging (MRI) for classification of axial spondyloarthritis: a consensual approach by the ASAS/OMERACT MRI group. Ann Rheum Dis. 2009;68(10): 1520-7.

13. Aydin SZ, Maksymowych WP, Bennett AN, McGonagle D, Emery P, MarzoOrtega $\mathrm{H}$. Validation of the ASAS criteria and definition of a positive MRI of the sacroiliac joint in an inception cohort of axial spondyloarthritis followed up for 8 years. Ann Rheum Dis. 2012;71(1):56-60.

14. Larbi A, Viala P, Molinari N, Lukas C, Baron MP, Taourel P, et al. Assessment of MRI abnormalities of the sacroiliac joints and their ability to predict axial spondyloarthritis: a retrospective pilot study on 110 patients. Skelet Radiol. 2014:43(3):351-8.

15. Weber U, Zubler V, Pedersen SJ, Rufibach K, Lambert RG, Chan SM, et al. Development and validation of a magnetic resonance imaging reference criterion for defining a positive sacroiliac joint magnetic resonance imaging finding in spondyloarthritis. Arthritis Care Res. 2013;65(6):977-85.

16. Weber U, Pedersen SJ, Zubler V, Rufibach K, Chan SM, Lambert RG, et al. Fat infiltration on magnetic resonance imaging of the sacroiliac joints has limited diagnostic utility in nonradiographic axial spondyloarthritis. J Rheumatol. 2014;41(1):75-83.

17. Weber U, Ostergaard M, Lambert RG, Pedersen SJ, Chan SM, Zubler V, et al. Candidate lesion-based criteria for defining a positive sacroiliac joint MRI in two cohorts of patients with axial spondyloarthritis. Ann Rheum Dis. 2015; 74(11):1976-82.

18. Bakker PA, van den Berg R, Lenczner $G$, Thevenin F, Reijnierse M, Claudepierre $P$, et al. Can we use structural lesions seen on MRI of the sacroiliac joints reliably for the classification of patients according to the ASAS axial spondyloarthritis criteria? Data from the DESIR cohort. Ann Rheum Dis. 2017;76(2):392-8.

19. de Hooge M, van den Berg R, Navarro-Compan V, Reijnierse M, van Gaalen F, Fagerli K, et al. Patients with chronic back pain of short duration from the SPACE cohort: which MRI structural lesions in the sacroiliac joints and inflammatory and structural lesions in the spine are most specific for axial spondyloarthritis? Ann Rheumatic Dis. 2016;75:1308-1314.

20. de Hooge $M$, van den Berg $R$, Navarro-Compan V, van Gaalen F, van der Heijde D, Huizinga T, et al. Magnetic resonance imaging of the sacroiliac joints in the early detection of spondyloarthritis: no added value of gadolinium compared with short tau inversion recovery sequence. Rheumatology. 2013;52(7):1220-4.

21. Zhao YH, Cao YY, Zhang Q, Mei YJ, Xiao JJ, Hu SY, et al. Role of Diffusionweighted and Contrast-enhanced Magnetic Resonance Imaging in Differentiating Activity of Ankylosing Spondylitis. Chin Med J. 2017;130(11):1303-8.

22. Bradbury LA, Hollis KA, Gautier B, Shankaranarayana S, Robinson PC, Saad N, et al. Diffusion-weighted Imaging Is a Sensitive and Specific Magnetic Resonance Sequence in the Diagnosis of Ankylosing Spondylitis. J Rheumatol. 2018;45(6):771-8.

23. Hermann KG, Baraliakos $X$, van der Heijde DM, Jurik AG, Landewe $R$, Marzo-Ortega $H$, et al. Descriptions of spinal MRI lesions and definition of a positive MRI of the spine in axial spondyloarthritis: a consensual approach by the ASAS/OMERACT MRI study group. Ann Rheum Dis. 2012;71(8):1278-88.

24. Bennett AN, Rehman A, Hensor EM, Marzo-Ortega H, Emery P, McGonagle D. The fatty Romanus lesion: a non-inflammatory spinal MRI lesion specific for axial spondyloarthropathy. Ann Rheum Dis. 2010;69(5):891-4.

25. Lorenzin M, Ortolan A, Frallonardo P, Vio S, Lacognata C, Oliviero F, et al. Spine and sacroiliac joints on magnetic resonance imaging in patients with early axial spondyloarthritis: prevalence of lesions and association with clinical and disease activity indices from the Italian group of the SPACE study. Reumatismo. 2016;68(2):72-82.

26. van der Heijde D, Sieper J, Maksymowych WP, Brown MA, Lambert RG, Rathmann SS, et al. Spinal inflammation in the absence of sacroiliac joint inflammation on magnetic resonance imaging in patients with active nonradiographic axial spondyloarthritis. Arthritis Rheumatol. 2014;66(3):667-73.

27. Ez-Zaitouni Z, Bakker PA, van Lunteren $M$, de Hooge $M$, van den Berg $R$, Reijnierse $M$, et al. The yield of a positive MRI of the spine as imaging criterion in the ASAS classification criteria for axial spondyloarthritis: results from the SPACE and DESIR cohorts. Ann Rheum Dis. 2017;76(10):1731-6.

28. Weber U, Zubler V, Zhao Z, Lambert RG, Chan SM, Pedersen SJ, et al. Does spinal MRI add incremental diagnostic value to MRI of the sacroiliac joints 
alone in patients with non-radiographic axial spondyloarthritis? Ann Rheum Dis. 2015;74(6):985-92

29. Madsen KB, Schiottz-Christensen B, Jurik AG. Prognostic significance of magnetic resonance imaging changes of the sacroiliac joints in spondyloarthritis--a followup study. J Rheumatol. 2010;37(8):1718-27.

30. Maksymowych WP, Wichuk S, Chiowchanwisawakit P, Lambert RG, Pedersen SJ. Fat metaplasia on MRI of the sacroiliac joints increases the propensity for disease progression in the spine of patients with spondyloarthritis. RMD open. 2017;3(1):e000399.

31. Maksymowych WP, Chiowchanwisawakit P, Clare T, Pedersen SJ, Ostergaard M, Lambert RG. Inflammatory lesions of the spine on magnetic resonance imaging predict the development of new syndesmophytes in ankylosing spondylitis: evidence of a relationship between inflammation and new bone formation. Arthritis Rheum. 2009;60(1):93-102.

32. Machado P, Landewe R, Braun J, Hermann KG, Baker D, van der Heijde D. Both structural damage and inflammation of the spine contribute to impairment of spinal mobility in patients with ankylosing spondylitis. Ann Rheum Dis. 2010;69(8):1465-70.

33. Brown MA, Laval SH, Brophy S, Calin A. Recurrence risk modelling of the genetic susceptibility to ankylosing spondylitis. Ann Rheum Dis. 2000;59(11):883-6.

34. Braun J, Bollow M, Remlinger $G$, Eggens U, Rudwaleit M, Distler $A$, et al. Prevalence of spondylarthropathies in HLA-B27 positive and negative blood donors. Arthritis Rheum. 1998;41 (1):58-67.

35. Schlosstein L, Terasaki PI, Bluestone R, Pearson CM. High association of an HL-A antigen, W27, with ankylosing spondylitis. N Engl J Med. 1973;288(14): 704-6.

36. Sieper J, Rudwaleit M, Khan MA, Braun J. Concepts and epidemiology of spondyloarthritis. Best Pract Res Clin Rheumatol. 2006;20(3):401-17.

37. Khan MA. An Update on the Genetic Polymorphism of HLA-B*27 With 213 Alleles Encompassing 160 Subtypes (and Still Counting). Curr Rheumatol Rep. 2017;19(2):9.

38. Freeston J, Barkham N, Hensor E, Emery P, Fraser A. Ankylosing spondylitis, HLA-B27 positivity and the need for biologic therapies. Joint Bone Spine. 2007;74(2):140-3.

39. Popescu C, Trandafir M, Badica A, Morar F, Predeteanu D. Ankylosing spondylitis functional and activity indices in clinical practice. J Med Life. 2014;7(1):78-83.

40. Yang M, Xu M, Pan X, Hu Z, Li Q, Wei Y, et al. Epidemiological comparison of clinical manifestations according to HLA-B*27 carrier status of Chinese ankylosing spondylitis patients. Tissue Antigens. 2013;82(5):338-43.

41. Fallahi S, Mahmoudi M, Nicknam MH, Gharibdoost F, Farhadi E, Saei A, et al. Effect of HLA-B*27 and its subtypes on clinical manifestations and severity of ankylosing spondylitis in Iranian patients. Iranian J Allergy Asthma Immunology. 2013;12(4):321-30.

42. Xiong J, Chen J, Tu J, Ye W, Zhang Z, Liu Q, et al. Association of HLA-B27 status and gender with sacroiliitis in patients with ankylosing spondylitis. Pakistan J Med Sciences. 2014;30(1):22-7.

43. Rudwaleit M, Haibel H, Baraliakos X, Listing J, Marker-Hermann E, Zeidler H, et al. The early disease stage in axial spondylarthritis: results from the German Spondyloarthritis Inception Cohort. Arthritis Rheum. 2009;60(3):717-27.

44. Zeboulon N, Dougados M, Gossec L. Prevalence and characteristics of uveitis in the spondyloarthropathies: a systematic literature review. Ann Rheum Dis. 2008;67(7):955-9.

45. van der Heijde D, Ramiro S, Landewé R, Baraliakos X, Van den Bosch F, Sepriano A, et al. 2016 update of the ASAS-EULAR management recommendations for axial spondyloarthritis. Ann Rheum Dis. 2017;76(6):978-91.

46. van den Berg R, Baraliakos X, Braun J, van der Heijde D. First update of the current evidence for the management of ankylosing spondylitis with nonpharmacological treatment and non-biologic drugs: a systematic literature review for the ASAS/EULAR management recommendations in ankylosing spondylitis. Rheumatology. 2012;51(8):1388-96.

47. Dagfinrud H, Kvien TK, Hagen KB. Physiotherapy interventions for ankylosing spondylitis. Cochrane Database Syst Rev. 2008;1:CD002822.

48. Regel A, Sepriano A, Baraliakos X, van der Heijde D, Braun J, Landewe R, et al. Efficacy and safety of non-pharmacological and non-biological pharmacological treatment: a systematic literature review informing the 2016 update of the ASAS/EULAR recommendations for the management of axial spondyloarthritis. RMD open. 2017;3(1):e000397.

49. Fernandez-de-Las-Penas C, Alonso-Blanco C, Morales-Cabezas M, Miangolarra-Page JC. Two exercise interventions for the management of patients with ankylosing spondylitis: a randomized controlled trial. Am J Physical Med Rehabilitation. 2005;84(6):407-19.
50. Fernandez-de-Las-Penas C, Alonso-Blanco C, Alguacil-Diego IM, MiangolarraPage JC. One-year follow-up of two exercise interventions for the management of patients with ankylosing spondylitis: a randomized controlled trial. Am J Physical Med Rehabilitation. 2006;85(7):559-67.

51. Silva EM, Andrade SC, Vilar MJ. Evaluation of the effects of Global Postural Reeducation in patients with ankylosing spondylitis. Rheumatol Int. 2012; 32(7):2155-63.

52. Rosu MO, Topa I, Chirieac R, Ancuta C. Effects of Pilates, McKenzie and Heckscher training on disease activity, spinal motility and pulmonary function in patients with ankylosing spondylitis: a randomized controlled trial. Rheumatol Int. 2014;34(3):367-72.

53. Staalesen Strumse YA, Nordvag BY, Stanghelle JK, Roisland M, Winther A, Pajunen PA, et al. Efficacy of rehabilitation for patients with ankylosing spondylitis: comparison of a four-week rehabilitation programme in a Mediterranean and a Norwegian setting. J Rehabil Med. 2011;43(6):534-42.

54. Kjeken I, Bo I, Ronningen A, Spada C, Mowinckel P, Hagen KB, et al. A threeweek multidisciplinary in-patient rehabilitation programme had positive long-term effects in patients with ankylosing spondylitis: randomized controlled trial. J Rehabil Med. 2013;45(3):260-7.

55. Aytekin E, Caglar NS, Ozgonenel L, Tutun S, Demiryontar DY, Demir SE. Home-based exercise therapy in patients with ankylosing spondylitis: effects on pain, mobility, disease activity, quality of life, and respiratory functions. Clin Rheumatol. 2012;31(1):91-7.

56. Kasapoglu Aksoy M, Birtane M, Tastekin N, Ekuklu G. The Effectiveness of Structured Group Education on Ankylosing Spondylitis Patients. J Clinical Rheumatol. 2017;23(3):138-43.

57. Rodriguez-Lozano C, Juanola X, Cruz-Martinez J, Pena-Arrebola A, Mulero J, Gratacos J, et al. Outcome of an education and home-based exercise programme for patients with ankylosing spondylitis: a nationwide randomized study. Clin Exp Rheumatol. 2013;31(5):739-48.

58. Liang $\mathrm{H}$, Zhang $\mathrm{H}$, Ji H, Wang $\mathrm{C}$. Effects of home-based exercise intervention on health-related quality of life for patients with ankylosing spondylitis: a meta-analysis. Clin Rheumatol. 2015;34(10):1737-44.

59. Jennings F, Oliveira HA, de Souza MC, Cruz Vda G, Natour J. Effects of Aerobic Training in Patients with Ankylosing Spondylitis. J Rheumatol. 2015;42(12):2347-53.

60. Niedermann K, Sidelnikov E, Muggli C, Dagfinrud H, Hermann M, Tamborrini $\mathrm{G}$, et al. Effect of cardiovascular training on fitness and perceived disease activity in people with ankylosing spondylitis. Arthritis Care Research. 2013; 65(11):1844-52.

61. Levitova A, Hulejova H, Spiritovic M, Pavelka K, Senolt L, Husakova M. Clinical improvement and reduction in serum calprotectin levels after an intensive exercise programme for patients with ankylosing spondylitis and non-radiographic axial spondyloarthritis. Arthritis Res Therapy. 2016;18(1):275.

62. Sveaas SH, Berg IJ, Provan SA, Semb AG, Hagen KB, Vollestad N, et al. Efficacy of high intensity exercise on disease activity and cardiovascular risk in active axial spondyloarthritis: a randomized controlled pilot study. PLoS One. 2014;9(9):e108688.

63. Dundar U, Solak O, Toktas H, Demirdal US, Subasi V, Kavuncu V, et al. Effect of aquatic exercise on ankylosing spondylitis: a randomized controlled trial. Rheumatol Int. 2014;34(11):1505-11.

64. Fernandez Garcia R, Sanchez Sanchez Lde C, Lopez Rodriguez Mdel M, Sanchez Granados G. [Effects of an exercise and relaxation aquatic program in patients with spondyloarthritis: A randomized trial]. Medicina Clinica 2015;145(9):380-384.

65. Klemz BN, Reis-Neto ET, Jennings F, Siqueira US, Klemz FK, Pinheiro HH, et al. The relevance of performing exercise test before starting supervised physical exercise in asymptomatic cardiovascular patients with rheumatic diseases. Rheumatology (Oxford). 2016;55(11):1978-86.

66. Peters ND, Ejstrup L. Intravenous methylprednisolone pulse therapy in ankylosing spondylitis. Scand J Rheumatol. 1992;21(3):134-8.

67. Rihl MBN, Wiese B, Schmidt RE, Zeidler H. Intravenous Glucocorticoid Pulse Therapy in Active, NSAID Refractory Axial Ankylosing Spondylitis: A Retrospective Analysis Spanning 12 Months. J Arthritis. 2018;7(1):266-9.

68. Bandinelli F, Scazzariello F, Pimenta da Fonseca E, Barreto Santiago M, Marcassa C, Nacci F, et al. Low-dose modified-release prednisone in axial spondyloarthritis: 3-month efficacy and tolerability. Drug Design Development Therapy. 2016;10:3717-24.

69. Haibel H, Fendler C, Listing J, Callhoff J, Braun J, Sieper J. Efficacy of oral prednisolone in active ankylosing spondylitis: results of a double-blind, randomised, placebo-controlled short-term trial. Ann Rheum Dis. 2014;73(1):243-6. 
70. Zhang YP, Gong Y, Zeng QY, Hou ZD, Xiao ZY. A long-term, observational cohort study on the safety of low-dose glucocorticoids in ankylosing spondylitis: adverse events and effects on bone mineral density, blood lipid and glucose levels and body mass index. BMJ Open. 2015;5(6):e006957.

71. Srivastava P, Aggarwal A. Ultrasound-guided retro-calcaneal bursa corticosteroid injection for refractory Achilles tendinitis in patients with seronegative spondyloarthropathy: efficacy and follow-up study. Rheumatol Int. 2016;36(6):875-80.

72. Metcalfe D, Achten J, Costa ML. Glucocorticoid injections in lesions of the achilles tendon. Foot Ankle International. 2009;30(7):661-5.

73. Bollow M, Braun J, Taupitz M, Haberle J, Reibhauer BH, Paris S, et al. CTguided intraarticular corticosteroid injection into the sacroiliac joints in patients with spondyloarthropathy: indication and follow-up with contrastenhanced MRI. J Comput Assist Tomogr. 1996;20(4):512-21.

74. Kroon FPB, van der Burg LRA, Ramiro S, Landewé RBM, Buchbinder R, Falzon $L$, et al. Non-steroidal anti-inflammatory drugs (NSAIDs) for axial spondyloarthritis (ankylosing spondylitis and non-radiographic axial spondyloarthritis) (Review). Cochrane Libr. 2015;7.

75. Wang R, Dasgupta A, Ward MM. Comparative efficacy of non-steroidal antiinflammatory drugs in ankylosing spondylitis: a Bayesian network metaanalysis of clinical trials. Ann Rheum Dis. 2015.

76. Walker C, Essex MN, Li C, Park PW. Celecoxib versus diclofenac for the treatment of ankylosing spondylitis: 12-week randomized study in Norwegian patients. J Int Med Res. 2016;44(3):483-95.

77. Balazcs E, Sieper J, Bickham K, Mehta A, Frontera N, Stryszak P, et al. A randomized, clinical trial to assess the relative efficacy and tolerability of two doses of etoricoxib versus naproxen in patients with ankylosing spondylitis. BMC Musculoskelet Disord. 2016;17(1):426.

78. Wanders A, Heijde D, Landewe R, Behier JM, Calin A, Olivieri I, et al. Nonsteroidal antiinflammatory drugs reduce radiographic progression in patients with ankylosing spondylitis: a randomized clinical trial. Arthritis Rheum. 2005;52(6):1756-65.

79. Kroon F, Landewe R, Dougados M, van der Heijde D. Continuous NSAID use reverts the effects of inflammation on radiographic progression in patients with ankylosing spondylitis. Ann Rheum Dis. 2012;71(10):1623-9.

80. Poddubnyy D, Rudwaleit M, Haibel H, Listing J, Marker-Hermann E, Zeidler H, et al. Effect of non-steroidal anti-inflammatory drugs on radiographic spinal progression in patients with axial spondyloarthritis: results from the German Spondyloarthritis Inception Cohort. Ann Rheum Dis. 2012;71(10):1616-22.

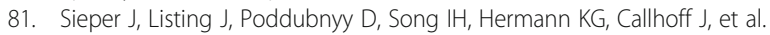
Effect of continuous versus on-demand treatment of ankylosing spondylitis with diclofenac over 2 years on radiographic progression of the spine: results from a randomised multicentre trial (ENRADAS). Ann Rheum Dis. 2015.

82. Yang Z, Zhao W, Liu W, Lv Q, Dong X. Efficacy evaluation of methotrexate in the treatment of ankylosing spondylitis using meta-analysis. Int J Clin Pharmacol Ther. 2014;52(5):346-51.

83. Gonzalez-Lopez L, Garcia-Gonzalez A, Vazquez-Del-Mercado M, Munoz-Valle JF, Gamez-Nava JI. Efficacy of methotrexate in ankylosing spondylitis: a randomized, double blind, placebo controlled trial. J Rheumatol. 2004;31(8): 1568-74.

84. Altan L, Bingol U, Karakoc Y, Aydiner S, Yurtkuran M, Yurtkuran M. Clinical investigation of methotrexate in the treatment of ankylosing spondylitis. Scand J Rheumatol. 2001;30(5):255-9.

85. Roychowdhury B, Bintley-Bagot S, Bulgen DY, Thompson RN, Tunn EJ, Moots RJ. Is methotrexate effective in ankylosing spondylitis? Rheumatology. 2002;41(11):1330-2.

86. Perez-Guijo VC, Cravo AR, Castro Mdel C, Font P, Munoz-Gomariz E, Collantes-Estevez E. Increased efficacy of infliximab associated with methotrexate in ankylosing spondylitis. Joint Bone Spine. 2007;74(3):254-8.

87. Breban M, Ravaud P, Claudepierre P, Baron G, Henry YD, Hudry C, et al. Maintenance of infliximab treatment in ankylosing spondylitis: results of a one-year randomized controlled trial comparing systematic versus ondemand treatment. Arthritis Rheum. 2008;58(1):88-97.

88. Creemers MC, Franssen MJ, van de Putte LB, Gribnau FW, van Riel PL. Methotrexate in severe ankylosing spondylitis: an open study. J Rheumatol. 1995;22(6):1104-7.

89. Biasi D, Carletto A, Caramaschi P, Pacor ML, Maleknia T, Bambara LM Efficacy of methotrexate in the treatment of ankylosing spondylitis: a threeyear open study. Clin Rheumatol. 2000;19(2):114-7.
90. Sampaio-Barros PD, Costallat LT, Bertolo MB, Neto JF, Samara AM. Methotrexate in the treatment of ankylosing spondylitis. Scand J Rheumatol. 2000;29(3):160-2.

91. Bachta A, Kisiel B, Tłustochowicz M, Raczkiewicz A, Rękas M, Tłustochowicz W. High Efficacy of Methotrexate in Patients with Recurrent Idiopathic Acute Anterior Uveitis: a Prospective Study. Arch Immunol Ther Exp. 2017;65(1):93-7.

92. Chen J, Liu C. Sulfasalazine for ankylosing spondylitis. Cochrane Database Syst Rev. 2005;2:CD004800.

93. Chen J, Lin S, Liu C. Sulfasalazine for ankylosing spondylitis. Cochrane Database Syst Rev. 2014;11:CD004800.

94. Braun J, Zochling J, Baraliakos X, Alten R, Burmester G, Grasedyck K, et al. Efficacy of sulfasalazine in patients with inflammatory back pain due to undifferentiated spondyloarthritis and early ankylosing spondylitis: a multicentre randomised controlled trial. Ann Rheum Dis. 2006;65(9):1147-53.

95. Braun J, van der Horst-Bruinsma IE, Huang F, Burgos-Vargas R, Vlahos B, Koenig AS, et al. Clinical efficacy and safety of etanercept versus sulfasalazine in patients with ankylosing spondylitis: a randomized, doubleblind trial. Arthritis Rheum. 2011;63(6):1543-51.

96. Song $\mathrm{IH}$, Hermann K, Haibel H, Althoff CE, Listing J, Burmester G, et al. Effects of etanercept versus sulfasalazine in early axial spondyloarthritis on active inflammatory lesions as detected by whole-body MRI (ESTHER): a 48week randomised controlled trial. Ann Rheum Dis. 2011;70(4):590-6.

97. Fagerli KM, van der Heijde D, Heiberg MS, Wierod A, Kalstad S, Rodevand E, et al. Is there a role for sulphasalazine in axial spondyloarthritis in the era of TNF inhibition? Data from the NOR-DMARD longitudinal observational study. Rheumatology. 2014;53(6):1087-94.

98. Khanna Sharma S, Kadiyala V, Naidu G, Dhir V. A randomized controlled trial to study the efficacy of sulfasalazine for axial disease in ankylosing spondylitis. Int J Rheum Dis. 2018;21(1):308-14.

99. Muñoz-Fernández S, Hidalgo V, Fernández-Melón J, Schlincker A, Bonilla G, Ruiz-Sancho D, et al. Sulfasalazine reduces the number of flares of acute anterior uveitis over a one-year period. J Rheumatol. 2003:30(6):1277-9.

100. Benitez-Del-Castillo JM, Garcia-Sanchez J, Iradier T, Bañares A. Sulfasalazine in the prevention of anterior uveitis associated with ankylosing spondylitis. Eye (Lond). 2000;14(Pt 3A):340-3.

101. van Denderen JC, van der Paardt M, Nurmohamed MT, de Ryck YM, Dijkmans BA, van der Horst-Bruinsma IE. Double blind, randomised, placebo controlled study of leflunomide in the treatment of active ankylosing spondylitis. Ann Rheum Dis. 2005;64(12):1761-4.

102. Haibel H, Rudwaleit M, Braun J, Sieper J. Six months open label trial of leflunomide in active ankylosing spondylitis. Ann Rheum Dis. 2005;64(1): $124-6$.

103. Lie E, Kristensen LE, Forsblad-d'Elia H, Zverkova-Sandstrom T, Askling J, Jacobsson LT, et al. The effect of comedication with conventional synthetic disease modifying antirheumatic drugs on TNF inhibitor drug survival in patients with ankylosing spondylitis and undifferentiated spondyloarthritis: results from a nationwide prospective study. Ann Rheum Dis. 2015;74(6):970-8.

104. Sepriano A, Ramiro S, van der Heijde D, Avila-Ribeiro P, Fonseca R, Borges J, et al. Effect of Comedication With Conventional Synthetic DiseaseModifying Antirheumatic Drugs on Retention of Tumor Necrosis Factor Inhibitors in Patients With Spondyloarthritis: A Prospective Cohort Study. Arthritis Rheumatol. 2016;68(11):2671-9.

105. Braun J, Brandt J, Listing J, Zink A, Alten R, Golder W, et al. Treatment of active ankylosing spondylitis with infliximab: a randomised controlled multicentre trial. Lancet. 2002;359(9313):1187-93.

106. Braun J, Brandt J, Listing J, Zink A, Alten R, Burmester G, et al. Long-term efficacy and safety of infliximab in the treatment of ankylosing spondylitis: an open, observational, extension study of a three-month, randomized, placebo-controlled trial. Arthritis Rheum. 2003;48(8):2224-33.

107. Braun J, Brandt J, Listing J, Zink A, Alten R, Burmester G, et al. Two year maintenance of efficacy and safety of infliximab in the treatment of ankylosing spondylitis. Ann Rheum Dis. 2005;64(2):229-34.

108. Braun J, Baraliakos X, Brandt J, Listing J, Zink A, Alten R, et al. Persistent clinical response to the anti-TNF-alpha antibody infliximab in patients with ankylosing spondylitis over 3 years. Rheumatology. 2005;44(5):670-6.

109. Braun J, Baraliakos X, Listing J, Fritz C, Alten R, Burmester G, et al. Persistent clinical efficacy and safety of anti-tumour necrosis factor alpha therapy with infliximab in patients with ankylosing spondylitis over 5 years: evidence for different types of response. Ann Rheum Dis. 2008;67(3):340-5.

110. Baraliakos X, Listing J, Fritz C, Haibel H, Alten R, Burmester GR, et al. Persistent clinical efficacy and safety of infliximab in ankylosing spondylitis 
after 8 years--early clinical response predicts long-term outcome. Rheumatology. 2011;50(9):1690-9.

111. van der Heijde D, Dijkmans B, Geusens P, Sieper J, DeWoody K, Williamson $P$, et al. Efficacy and safety of infliximab in patients with ankylosing spondylitis: results of a randomized, placebo-controlled trial (ASSERT). Arthritis Rheum. 2005;52(2):582-91.

112. Gorman JD, Sack KE, Davis JC Jr. Treatment of ankylosing spondylitis by inhibition of tumor necrosis factor alpha. N Engl J Med. 2002;346(18):1349-56.

113. Davis JC Jr, Van Der Heijde D, Braun J, Dougados M, Cush J, Clegg DO, et al. Recombinant human tumor necrosis factor receptor (etanercept) for treating ankylosing spondylitis: a randomized, controlled trial. Arthritis Rheum. 2003;48(11):3230-6.

114. Davis JC, van der Heijde DM, Braun J, Dougados M, Cush J, Clegg D, et al. Sustained durability and tolerability of etanercept in ankylosing spondylitis for 96 weeks. Ann Rheum Dis. 2005;64(11):1557-62.

115. Davis JC Jr, van der Heijde DM, Braun J, Dougados M, Clegg DO, Kivitz AJ, et al. Efficacy and safety of up to 192 weeks of etanercept therapy in patients with ankylosing spondylitis. Ann Rheum Dis. 2008;67(3):346-52.

116. Brandt J, Khariouzov A, Listing J, Haibel H, Sorensen H, Grassnickel L, et al. Six-month results of a double-blind, placebo-controlled trial of etanercept treatment in patients with active ankylosing spondylitis. Arthritis Rheum. 2003;48(6):1667-75.

117. Brandt J, Listing J, Haibel $H$, Sorensen $H$, Schwebig A, Rudwaleit M, et al. Long-term efficacy and safety of etanercept after readministration in patients with active ankylosing spondylitis. Rheumatology. 2005;44(3):342-8.

118. Baraliakos X, Haibel H, Fritz C, Listing J, Heldmann F, Braun J, et al. Longterm outcome of patients with active ankylosing spondylitis with etanercept-sustained efficacy and safety after seven years. Arthritis Research Therapy. 2013;15(3):R67.

119. Calin A, Dijkmans BA, Emery P, Hakala M, Kalden J, Leirisalo-Repo M, et al. Outcomes of a multicentre randomised clinical trial of etanercept to treat ankylosing spondylitis. Ann Rheum Dis. 2004;63(12):1594-600.

120. Dougados M, Braun J, Szanto S, Combe B, Elbaz M, Geher P, et al. Efficacy of etanercept on rheumatic signs and pulmonary function tests in advanced ankylosing spondylitis: results of a randomised doubleblind placebo-controlled study (SPINE). Ann Rheum Dis. 2011;70(5): 799-804.

121. Song $I H$, Weiss $A$, Hermann $K G$, Haibel $H$, Althoff $C E$, Poddubnyy $D$, et al. Similar response rates in patients with ankylosing spondylitis and non-radiographic axial spondyloarthritis after 1 year of treatment with etanercept: results from the ESTHER trial. Ann Rheum Dis. 2013;72(6): 823-5.

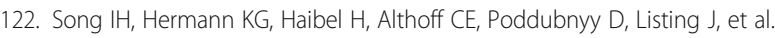
Consistently Good clinical response in patients with early axial spondyloarthritis after 3 years of continuous treatment with etanercept: longterm data of the ESTHER trial. J Rheumatol. 2014;41(10):2034-40.

123. Dougados M, van der Heijde D, Sieper J, Braun J, Maksymowych WP, Citera $\mathrm{G}$, et al. Symptomatic efficacy of etanercept and its effects on objective signs of inflammation in early nonradiographic axial spondyloarthritis: a multicenter, randomized, double-blind, placebo-controlled trial. Arthritis Rheumatol. 2014;66(8):2091-102.

124. Maksymowych WP, Dougados M, van der Heijde D, Sieper J, Braun J, Citera $\mathrm{G}$, et al. Clinical and MRI responses to etanercept in early non-radiographic axial spondyloarthritis: 48-week results from the EMBARK study. Ann Rheum Dis. 2016;75(7):1328-35.

125. Li ZH, Zhang Y, Wang J, Shi ZJ. Etanercept in the treatment of ankylosing spondylitis: a meta-analysis of randomized, double-blind, placebo-controlled clinical trials, and the comparison of the Caucasian and Chinese population. Eur J Orthopaedic Surg Traumatol. 2013;23(5):497-506.

126. van der Heijde D, Kivitz A, Schiff MH, Sieper J, Dijkmans BA, Braun J, et al. Efficacy and safety of adalimumab in patients with ankylosing spondylitis: results of a multicenter, randomized, double-blind, placebo-controlled trial. Arthritis Rheum. 2006;54(7):2136-46

127. van der Heijde D, Schiff MH, Sieper J, Kivitz AJ, Wong RL, Kupper H, et al. Adalimumab effectiveness for the treatment of ankylosing spondylitis is maintained for up to 2 years: long-term results from the ATLAS trial. Ann Rheum Dis. 2009;68(6):922-9.

128. van der Heijde DM, Revicki DA, Gooch KL, Wong RL, Kupper H, Harnam N, et al. Physical function, disease activity, and health-related quality-of-life outcomes after 3 years of adalimumab treatment in patients with ankylosing spondylitis. Arthritis Res Therapy. 2009;11(4):R124.
129. Sieper J, van der Heijde D, Dougados M, Brown LS, Lavie F, Pangan AL. Early response to adalimumab predicts long-term remission through 5 years of treatment in patients with ankylosing spondylitis. Ann Rheum Dis. 2012; 71(5):700-6.

130. Haibel H, Rudwaleit M, Listing J, Heldmann F, Wong RL, Kupper $H$, et al. Efficacy of adalimumab in the treatment of axial spondylarthritis without radiographically defined sacroiliitis: results of a twelve-week randomized, double-blind, placebo-controlled trial followed by an open-label extension up to week fifty-two. Arthritis Rheum. 2008;58(7):1981-91.

131. Sieper J, van der Heijde D, Dougados M, Mease PJ, Maksymowych WP, Brown MA, et al. Efficacy and safety of adalimumab in patients with nonradiographic axial spondyloarthritis: results of a randomised placebocontrolled trial (ABILITY-1). Ann Rheum Dis. 2013;72(6):815-22.

132. Wang H, Zuo D, Sun M, Hua Y, Cai Z. Randomized, placebo controlled and double-blind trials of efficacy and safety of adalimumab for treating ankylosing spondylitis: a meta-analysis. Int J Rheum Dis. 2014;17(2):142-8.

133. Inman RD, Davis JC Jr, Heijde D, Diekman L, Sieper J, Kim SI, et al. Efficacy and safety of golimumab in patients with ankylosing spondylitis: results of a randomized, double-blind, placebo-controlled, phase III trial. Arthritis Rheum. 2008;58(11):3402-12.

134. Braun J, Deodhar A, Inman RD, van der Heijde D, Mack M, Xu S, et al. Golimumab administered subcutaneously every 4 weeks in ankylosing spondylitis: 104-week results of the GO-RAISE study. Ann Rheum Dis. 2012;71(5):661-7.

135. Deodhar A, Braun J, Inman RD, van der Heijde D, Zhou Y, Xu S, et al. Golimumab administered subcutaneously every 4 weeks in ankylosing spondylitis: 5-year results of the GO-RAISE study. Ann Rheum Dis. 2015;74(4):757-61.

136. Bao C, Huang F, Khan MA, Fei K, Wu Z, Han C, et al. Safety and efficacy of golimumab in Chinese patients with active ankylosing spondylitis: 1-year results of a multicentre, randomized, double-blind, placebo-controlled phase III trial. Rheumatology. 2014;53(9):1654-63.

137. Sieper J, van der Heijde D, Dougados M, Maksymowych WP, Scott BB, Boice JA, et al. A randomized, double-blind, placebo-controlled, sixteen-week study of subcutaneous golimumab in patients with active nonradiographic axial spondyloarthritis. Arthritis Rheumatol. 2015;67(10):2702-12.

138. Deodhar A, Reveille JD, Harrison DD, Kim L, Lo KH, Leu JH, et al. Safety and Efficacy of Golimumab Administered Intravenously in Adults with Ankylosing Spondylitis: Results through Week 28 of the GO-ALIVE Study. J Rheumatol. 2018;45(3):341-8.

139. Landewé R, Braun J, Deodhar A, Dougados M, Maksymowych WP, Mease PJ, et al. Efficacy of certolizumab pegol on signs and symptoms of axial spondyloarthritis including ankylosing spondylitis: 24-week results of a double-blind randomised placebo-controlled Phase 3 study. Ann Rheum Dis. 2013;73:39-47.

140. Sieper J, Landewe R, Rudwaleit M, van der Heijde D, Dougados M, Mease PJ, et al. Effect of certolizumab pegol over ninety-six weeks in patients with axial spondyloarthritis: results from a phase III randomized trial. Arthritis Rheumatol. 2015;67(3):668-77.

141. van der Heijde D, Dougados M, Landewe R, Sieper J, Maksymowych WP, Rudwaleit M, et al. Sustained efficacy, safety and patient-reported outcomes of certolizumab pegol in axial spondyloarthritis: 4-year outcomes from RAPID-axSpA. Rheumatology (Oxford). 2017;56(9):1498-509.

142. Baeten D, Sieper J, Braun J, Baraliakos X, Dougados M, Emery P, et al. Secukinumab, an Interleukin-17A Inhibitor, in Ankylosing Spondylitis. N Engl J Med. 2015;373(26):2534-48

143. Sieper J, Deodhar A, Marzo-Ortega H, Aelion JA, Blanco R, Jui-Cheng T, et al. Secukinumab efficacy in anti-TNF-naive and anti-TNF-experienced subjects with active ankylosing spondylitis: results from the MEASURE 2 Study. Ann Rheum Dis. 2017;76(3):571-92.

144. Deodhar A, Conaghan PG, Kvien TK, Strand V, Sherif B, Porter B, et al. Secukinumab provides rapid and persistent relief in pain and fatigue symptoms in patients with ankylosing spondylitis irrespective of baseline Creactive protein levels or prior tumour necrosis factor inhibitor therapy: 2year data from the MEASURE 2 study. Clin Exp Rheumatol. 2018.

145. Braun J, Baraliakos X, Deodhar A, Baeten D, Sieper J, Emery P, et al. Effect of secukinumab on clinical and radiographic outcomes in ankylosing spondylitis: 2-year results from the randomised phase III MEASURE 1 study. Ann Rheum Dis. 2017;76(6):1070-7.

146. Marzo-Ortega H, Sieper J, Kivitz A, Blanco R, Cohen M, Martin R, et al. Secukinumab and Sustained Improvement in Signs and Symptoms of Patients With Active Ankylosing Spondylitis Through Two Years: Results From a Phase III Study. Arthritis Care Res. 2017;69(7):1020-9. 
147. Baraliakos X, Kivitz AJ, Deodhar AA, Braun J, Wei JC, Delicha EM, et al. Long-term effects of interleukin-17A inhibition with secukinumab in active ankylosing spondylitis: 3-year efficacy and safety results from an extension of the Phase 3 MEASURE 1 trial. Clin Exp Rheumatol. 2018; 36(1):50-5.

148. van der Heijde D, Cheng-Chung Wei J, Dougados M, Mease P, Deodhar A Maksymowych WP, et al. Ixekizumab, an interleukin-17A antagonist in the treatment of ankylosing spondylitis or radiographic axial spondyloarthritis in patients previously untreated with biological disease-modifying antirheumatic drugs (COAST-V): 16 week results of a phase 3 randomised, double-blind, active-controlled and placebo-controlled trial. Lancet. 2018; 392(10163):2441-51

149. Deodhar A, Poddubnyy D, Pacheco-Tena C, Salvarani C, Lespessailles E, Rahman P, et al. Efficacy and Safety of Ixekizumab in the Treatment of Radiographic Axial Spondyloarthritis: 16 Week Results of a Phase 3 Randomized, Double-Blind, Placebo Controlled Trial in Patients with Prior Inadequate Response or Intolerance to Tumor Necrosis Factor Inhibitors. Arthritis Rheumatol. 2019;71(4):599-611.

150. Giardina AR, Ferrante A, Ciccia F, Impastato R, Miceli MC, Principato A, et al. A 2-year comparative open label randomized study of efficacy and safety of etanercept and infliximab in patients with ankylosing spondylitis. Rheumatol Int. 2010;30(11):1437-40

151. Park W, Hrycaj P, Jeka S, Kovalenko V, Lysenko G, Miranda P, et al. A randomised, double-blind, multicentre, parallel-group, prospective study comparing the pharmacokinetics, safety, and efficacy of CT-P13 and innovator infliximab in patients with ankylosing spondylitis: the PLANETAS study. Ann Rheum Dis. 2013;72(10):1605-12.

152. Ruwaard J, I'Ami MJ, Marsman AF, Kneepkens EL, van Denderen JC, van der Horst-Bruinsma IE, et al. Comparison of drug survival and clinical outcome in patients with ankylosing spondylitis treated with etanercept or adalimumab. Scand J Rheumatol. 2018;47(2):122-6.

153. Liu W, Wu YH, Zhang L, Liu XY, Bin X, Bin L, et al. Efficacy and safety of TNFalpha inhibitors for active ankylosing spondylitis patients: Multiple treatment comparisons in a network meta-analysis. Sci Rep. 2016;6:32768.

154. Corbett M, Soares M, Jhuti G, Rice S, Spackman E, Sideris E, et al. Tumour necrosis factor-alpha inhibitors for ankylosing spondylitis and nonradiographic axial spondyloarthritis: a systematic review and economic evaluation. Health Technol Assess. 2016;20(9):1-334 v-vi.

155. Ungprasert P, Erwin PJ, Koster MJ. Indirect comparisons of the efficacy of biological agents in patients with active ankylosing spondylitis: a systematic review and meta-analysis. Clin Rheumatol. 2017;36(7):1569-77.

156. Wang S, He Q, Shuai Z. Risk of serious infections in biological treatment of patients with ankylosing spondylitis and non-radiographic axial spondyloarthritis: a meta-analysis. Clin Rheumatol. 2018;37(2):439-50.

157. Hou LQ, Jiang GX, Chen YF, Yang XM, Meng L, Xue M, et al. The Comparative Safety of TNF Inhibitors in Ankylosing Spondylitis-a MetaAnalysis Update of 14 Randomized Controlled Trials. Clin Rev Allergy Immunol. 2018:54(2):234-43.

158. Wallis D, Thavaneswaran A, Haroon N, Ayearst R, Inman RD. Tumour necrosis factor inhibitor therapy and infection risk in axial spondyloarthritis: results from a longitudinal observational cohort. Rheumatology. 2015;54(1): 152-6.

159. Desai RJ, Thaler KJ, Mahlknecht P, Gartlehner G, McDonagh MS, Mesgarpour B, et al. Comparative Risk of Harm Associated With the Use of Targeted Immunomodulators: A Systematic Review. Arthritis Care Research. 2016; 68(8):1078-88.

160. Kim EM, Uhm WS, Bae SC, Yoo DH, Kim TH. Incidence of tuberculosis among korean patients with ankylosing spondylitis who are taking tumor necrosis factor blockers. J Rheumatol. 2011;38(10):2218-23.

161. Kim HW, Park JK, Yang JA, Yoon Yl, Lee EY, Song YW, et al. Comparison of tuberculosis incidence in ankylosing spondylitis and rheumatoid arthritis during tumor necrosis factor inhibitor treatment in an intermediate burden area. Clin Rheumatol. 2014;33(9):1307-12.

162. Cagatay T, Bingol Z, Kiyan E, Yegin Z, Okumus G, Arseven O, et al. Follow-up of 1887 patients receiving tumor necrosis-alpha antagonists: Tuberculin skin test conversion and tuberculosis risk. Clin Respir J. 2018;12(4):1668-75.

163. Kisacik B, Pamuk ON, Onat AM, Erer SB, Hatemi G, Ozguler Y, et al. Characteristics Predicting Tuberculosis Risk under Tumor Necrosis Factoralpha Inhibitors: Report from a Large Multicenter Cohort with High Background Prevalence. J Rheumatol. 2016;43(3):524-9.
164. Carmona L, Abasolo L, Descalzo MA, Perez-Zafrilla B, Sellas A, de Abajo F, et al. Cancer in patients with rheumatic diseases exposed to TNF antagonists. Semin Arthritis Rheum. 2011;41(1):71-80.

165. Westhovens I, Lories RJ, Westhovens R, Verschueren P, de Vlam K. Anti-TNF therapy and malignancy in spondyloarthritis in the Leuven spondyloarthritis biologics cohort (BIOSPAR). Clin Exp Rheumatol. 2014;32(1):71-6.

166. Hellgren K, Dreyer L, Arkema EV, Glintborg B, Jacobsson LT, Kristensen LE, et al. Cancer risk in patients with spondyloarthritis treated with TNF inhibitors: a collaborative study from the ARTIS and DANBIO registers. Ann Rheum Dis. 2017;76(1):105-11.

167. Haroon N, Inman R, Learch T, Weisman M, Lee M, Rahbar MH, et al. The Impact of Tumor Necrosis Factor Alfa Inhibitors on Radiographic Progression in Ankylosing Spondylitis. Arthritis Rheum. 2013;65(10):2645-54.

168. Molnar C, Scherer A, Baraliakos X, de Hooge M, Micheroli R, Exer P, et al. TNF blockers inhibit spinal radiographic progression in ankylosing spondylitis by reducing disease activity: results from the Swiss Clinical Quality Management cohort. Ann Rheum Dis. 2018;77(1):63-9.

169. Maas F, Spoorenberg A, Brouwer E, Bos R, Efde M, Chaudhry RN, et al. Spinal radiographic progression in patients with ankylosing spondylitis treated with TNF-alpha blocking therapy: a prospective longitudinal observational cohort study. PLoS One. 2015;10(4):e0122693.

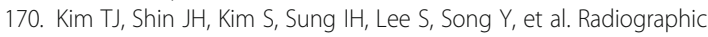
progression in patients with ankylosing spondylitis according to tumor necrosis factor blocker exposure: Observation Study of Korean Spondyloarthropathy Registry (OSKAR) data. Joint Bone Spine. 2016;83(5): 569-72.

171. van der Heijde D, Landewe R, Baraliakos $X$, Houben $H$, van Tubergen A, Williamson $P$, et al. Radiographic findings following two years of infliximab therapy in patients with ankylosing spondylitis. Arthritis Rheum. 2008:58(10):3063-70.

172. Baraliakos X, Listing J, Brandt J, Haibel H, Rudwaleit M, Sieper J, et al. Radiographic progression in patients with ankylosing spondylitis after 4 yrs of treatment with the anti-TNF-alpha antibody infliximab. Rheumatology (Oxford). 2007;46(9):1450-3.

173. van der Heijde D, Landewe R, Einstein S, Ory P, Vosse D, Ni L, et al. Radiographic progression of ankylosing spondylitis after up to two years of treatment with etanercept. Arthritis Rheum. 2008;58(5):1324-31.

174. van der Heijde D, Salonen D, Weissman BN, Landewe R, Maksymowych WP,

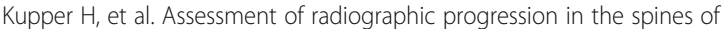
patients with ankylosing spondylitis treated with adalimumab for up to 2 years. Arthritis Res Therapy. 2009;11(4):R127.

175. Braun J, Baraliakos X, Hermann KG, Deodhar A, van der Heijde D, Inman R, et al. The effect of two golimumab doses on radiographic progression in ankylosing spondylitis: results through 4 years of the GO-RAISE trial. Ann Rheum Dis. 2014;73(6):1107-13.

176. van der Heijde D, Baraliakos X, Hermann KA, Landewe RBM, Machado PM, Maksymowych WP, et al. Limited radiographic progression and sustained reductions in MRI inflammation in patients with axial spondyloarthritis: 4year imaging outcomes from the RAPID-axSpA phase III randomised trial. Ann Rheum Dis. 2018;77(5):699-705.

177. Braun J, Baraliakos X, Deodhar A, Poddubnyy D, Emery P, Delicha EM, et al. Secukinumab shows sustained efficacy and low structural progression in ankylosing spondylitis: 4-year results from the MEASURE 1 study. Rheumatology (Oxford). 2019;58(5):859-868.

178. Baraliakos X, Haibel H, Listing J, Sieper J, Braun J. Continuous long-term anti-TNF therapy does not lead to an increase in the rate of new bone formation over 8 years in patients with ankylosing spondylitis. Ann Rheum Dis. 2014;73(4):710-5.

179. Braun J, Baraliakos X, Listing J, Sieper J. Decreased incidence of anterior uveitis in patients with ankylosing spondylitis treated with the anti-tumor necrosis factor agents infliximab and etanercept. Arthritis Rheum. 2005;52(8):2447-51.

180. Rudwaleit M, Rodevand E, Holck P, Vanhoof J, Kron M, Kary S, et al. Adalimumab effectively reduces the rate of anterior uveitis flares in patients with active ankylosing spondylitis: results of a prospective open-label study. Ann Rheum Dis. 2009;68(5):696-701.

181. van Denderen JC, Visman IM, Nurmohamed MT, Suttorp-Schulten MS, van der Horst-Bruinsma IE. Adalimumab significantly reduces the recurrence rate of anterior uveitis in patients with ankylosing spondylitis. J Rheumatol. 2014; 41(9):1843-8.

182. Sieper J, Koenig A, Baumgartner S, Wishneski C, Foehl J, Vlahos B, et al. Analysis of uveitis rates across all etanercept ankylosing spondylitis clinical trials. Ann Rheum Dis. 2010;69(1):226-9. 
183. Yazgan S, Celik U, Isik M, Yesil NK, Baki AE, Sahin H, et al. Efficacy of golimumab on recurrent uveitis in HLA-B27-positive ankylosing spondylitis. Int Ophthalmol. 2017;37(1):139-45.

184. Calvo-Rio V, Blanco R, Santos-Gomez M, Rubio-Romero E, Cordero-Coma M, Gallego-Flores A, et al. Golimumab in refractory uveitis related to spondyloarthritis. Multicenter study of 15 patients. Semin Arthritis Rheum. 2016;46(1):95-101.

185. Hernández M, Mesquida M, Llorens V, Maza MSdl, Blanco R, Calvo V, et al. THU0381 Certolizumab pegol is effective in uveitis associated to spondyloarthritis refractory to other tumour necrosis factor inhibitors. Ann Rheumatic Dis. 2017;76(Suppl 2):350-

186. Rudwaleit M, Rosenbaum JT, Landewe R, Marzo-Ortega H, Sieper J, van der Heijde D, et al. Observed Incidence of Uveitis Following Certolizumab Pegol Treatment in Patients With Axial Spondyloarthritis. Arthritis Care Research. 2016;68(6):838-44.

187. van Bentum RE, Heslinga SC, Nurmohamed MT, Gerards AH, Griep EN, Koehorst C, et al. Reduced Occurrence Rate of Acute Anterior Uveitis in Ankylosing Spondylitis Treated with Golimumab - The GO-EASY Study. J Rheumatol. 2019;46(2):153-159.

188. Wu D, Guo YY, Xu NN, Zhao S, Hou LX, Jiao T, et al. Efficacy of anti-tumor necrosis factor therapy for extra-articular manifestations in patients with ankylosing spondylitis: a meta-analysis. BMC Musculoskelet Disord. 2015;16:19

189. Braun J, Baraliakos X, Listing J, Davis J, van der Heijde D, Haibel H, et al. Differences in the incidence of flares or new onset of inflammatory bowel diseases in patients with ankylosing spondylitis exposed to therapy with anti-tumor necrosis factor alpha agents. Arthritis Rheum. 2007:57(4):639-47.

190. Wendling D, Paccou J, Berthelot JM, Flipo RM, Guillaume-Czitrom S, Prati C, et al. New onset of uveitis during anti-tumor necrosis factor treatment for rheumatic diseases. Semin Arthritis Rheum. 2011;41(3):503-10.

191. Wendling D, Joshi A, Reilly P, Jalundhwala YJ, Mittal M, Bao Y. Comparing the risk of developing uveitis in patients initiating anti-tumor necrosis factor therapy for ankylosing spondylitis: an analysis of a large US claims database. Curr Med Res Opin. 2014;30(12):2515-21.

192. Lian F, Zhou J, Wei C, Wang Y, Xu H, Liang L, et al. Anti-TNFalpha agents and methotrexate in spondyloarthritis related uveitis in a Chinese population. Clin Rheumatol. 2015;34(11):1913-20.

193. Lie E, Lindstrom U, Zverkova-Sandstrom T, Olsen IC, Forsblad-d'Elia H, Askling J, et al. Tumour necrosis factor inhibitor treatment and occurrence of anterior uveitis in ankylosing spondylitis: results from the Swedish biologics register. Ann Rheum Dis. 2017;76(9):1515-21.

194. Kim MJ, Lee EE, Lee EY, Song YW, Yu HG, Choi Y, et al. Preventive effect of tumor necrosis factor inhibitors versus nonsteroidal anti-inflammatory drugs on uveitis in patients with ankylosing spondylitis. Clin Rheumatol. 2018; 37(10):2763-70.

195. Kavanaugh A, Krueger GG, Beutler A, Guzzo C, Zhou B, Dooley LT, et al. Infliximab maintains a high degree of clinical response in patients with active psoriatic arthritis through 1 year of treatment: results from the IMPACT 2 trial. Ann Rheum Dis. 2007;66(4):498-505.

196. Mease PJ, Kivitz AJ, Burch FX, Siegel EL, Cohen SB, Ory P, et al. Etanercept treatment of psoriatic arthritis: safety, efficacy, and effect on disease progression. Arthritis Rheum. 2004;50(7):2264-72.

197. Mease PJ, Goffe BS, Metz J, VanderStoep A, Finck B, Burge DJ. Etanercept in the treatment of psoriatic arthritis and psoriasis: a randomised trial. Lancet. 2000;356(9227):385-90

198. Mease PJ, Gladman DD, Ritchlin CT, Ruderman EM, Steinfeld SD, Choy EH, et al. Adalimumab for the treatment of patients with moderately to severely active psoriatic arthritis: results of a double-blind, randomized, placebocontrolled trial. Arthritis Rheum. 2005;52(10):3279-89.

199. Kavanaugh A, Mclnnes I, Mease P, Krueger GG, Gladman D, Gomez-Reino J, et al. Golimumab, a new human tumor necrosis factor alpha antibody, administered every four weeks as a subcutaneous injection in psoriatic arthritis: Twenty-four-week efficacy and safety results of a randomized, placebo-controlled study. Arthritis Rheum. 2009;60(4):976-86.

200. Mease PJ, Fleischmann R, Deodhar AA, Wollenhaupt J, Khraishi M, Kielar $D$, et al. Effect of certolizumab pegol on signs and symptoms in patients with psoriatic arthritis: 24-week results of a Phase 3 doubleblind randomised placebo-controlled study (RAPID-PSA). Ann Rheum Dis. 2014:73(1):48-55.

201. Mease PJ, Mclnnes IB, Kirkham B, Kavanaugh A, Rahman P, van der Heijde D, et al. Secukinumab Inhibition of Interleukin-17A in Patients with Psoriatic Arthritis. N Engl J Med. 2015;373(14):1329-39.
202. Mclnnes IB, Mease PJ, Kirkham B, Kavanaugh A, Ritchlin CT, Rahman P, et al. Secukinumab, a human anti-interleukin-17A monoclonal antibody, in patients with psoriatic arthritis (FUTURE 2): a randomised, double-blind, placebo-controlled, phase 3 trial. Lancet. 2015;386(9999):1137-46.

203. Sandborn WJ, Hanauer SB, Katz S, Safdi M, Wolf DG, Baerg RD, et al. Etanercept for active Crohn's disease: a randomized, double-blind, placebocontrolled trial. Gastroenterology. 2001;121(5):1088-94.

204. Hueber W, Sands BE, Lewitzky S, Vandemeulebroecke M, Reinisch W, Higgins PD, et al. Secukinumab, a human anti-IL-17A monoclonal antibody, for moderate to severe Crohn's disease: unexpected results of a randomised, double-blind placebo-controlled trial. Gut. 2012;61(12):1693-700.

205. Cantini F, Niccoli L, Benucci M, Chindamo D, Nannini C, Olivieri I, et al. Switching from infliximab to once-weekly administration of $50 \mathrm{mg}$ etanercept in resistant or intolerant patients with ankylosing spondylitis: results of a fifty-four-week study. Arthritis Rheum. 2006;55(5):812-6.

206. Coates LC, Cawkwell LS, Ng NW, Bennett AN, Bryer DJ, Fraser AD, et al. Real life experience confirms sustained response to long-term biologics and switching in ankylosing spondylitis. Rheumatology. 2008; 47(6):897-900.

207. Pradeep DJ, Keat AC, Gaffney K, Brooksby A, Leeder J, Harris C. Switching antiTNF therapy in ankylosing spondylitis. Rheumatology. 2008;47(11):1726-7.

208. Haberhauer G, Strehblow C, Fasching P. Observational study of switching anti-TNF agents in ankylosing spondylitis and psoriatic arthritis versus rheumatoid arthritis. Wien Med Wochenschr. 2010;160(9-10):220-4.

209. Lie E, van der Heijde D, Uhlig T, Mikkelsen K, Rodevand E, Koldingsnes W, et al. Effectiveness of switching between TNF inhibitors in ankylosing spondylitis: data from the NOR-DMARD register. Ann Rheum Dis. 2011;70(1): 157-63.

210. Glintborg B, Ostergaard M, Krogh NS, Tarp U, Manilo N, Loft AG, et al. Clinical response, drug survival and predictors thereof in 432 ankylosing spondylitis patients after switching tumour necrosis factor alpha inhibitor therapy: results from the Danish nationwide DANBIO registry. Ann Rheum Dis. 2013;72(7):1149-55.

211. Gulyas K, Bodnar N, Nagy Z, Szamosi S, Horvath A, Vancsa A, et al. Real-life experience with switching TNF-alpha inhibitors in ankylosing spondylitis. Eur Health Econ. 2014;15(Suppl 1):S93-100.

212. Cantini F, Niccoli L, Nannini C, Cassara E, Kaloudi O, Giulio Favalli E, et al. Second-line biologic therapy optimization in rheumatoid arthritis, psoriatic arthritis, and ankylosing spondylitis. Semin Arthritis Rheum. 2017:47(2):18392.

213. Deodhar A, Yu D. Switching tumor necrosis factor inhibitors in the treatment of axial spondyloarthritis. Semin Arthritis Rheum. 2017;47(3):34350.

214. Navarro-Compan V, Plasencia-Rodriguez C, de Miguel E, Balsa A, MartinMola E, Seoane-Mato D, et al. Anti-TNF discontinuation and tapering strategies in patients with axial spondyloarthritis: a systematic literature review. Rheumatology. 2016;55(7):1188-94.

215. Sebastian A, Wojtala P, Lubinski L, Mimier M, Chlebicki A, Wiland P. Disease activity in axial spondyloarthritis after discontinuation of TNF inhibitors therapy. Reumatologia. 2017;55(4):157-62.

216. Landewe $R$, Sieper J, Mease $P$, Inman RD, Lambert RG, Deodhar A, et al. Efficacy and safety of continuing versus withdrawing adalimumab therapy in maintaining remission in patients with non-radiographic axial spondyloarthritis (ABILITY-3): a multicentre, randomised, double-blind study. Lancet. 2018;392(10142):134-44.

217. Arends S, van der Veer E, Kamps FB, Houtman PM, Bos R, Bootsma H, et al. Patient-tailored dose reduction of TNF-alpha blocking agents in ankylosing spondylitis patients with stable low disease activity in daily clinical practice. Clin Exp Rheumatol. 2015;33(2):174-80.

218. Fong W, Holroyd C, Davidson B, Armstrong R, Harvey N, Dennison E, et al. The effectiveness of a real life dose reduction strategy for tumour necrosis factor inhibitors in ankylosing spondylitis and psoriatic arthritis. Rheumatology. 2016;55(10):1837-42.

219. Almirall M, Salman-Monte TC, Lisbona MP, Maymo J. Dose reduction of biological treatment in patients with axial spondyloarthritis in clinical remission: Are there any differences between patients who relapsed and to those who remained in low disease activity? Rheumatol Int. 2015;35(9): 1565-8.

220. Lian F, Zhou J, Wang Y, Chen D, Xu H, Liang L. Efficiency of dose reduction strategy of etanercept in patients with axial spondyloarthritis. Clin Exp Rheumatol. 2018;36(5):884-90. 
221. Chen MH, Lee MH, Liao HT, Chen WS, Lai CC, Tsai CY. Health-related quality of life outcomes in patients with rheumatoid arthritis and ankylosing spondylitis after tapering biologic treatment. Clin Rheumatol. 2018;37(2): 429-38.

222. Redondo C, Martinez-Feito A, Plasencia-Rodriguez C, Navarro-Compan V, Nuno-Nuno L, Peiteado D, et al. Golimumab Tapering Strategy Based on Serum Drug Levels in Patients With Spondyloarthritis. Arthritis Rheumatol. 2018;70(8):1356-8.

223. Plasencia C, Kneepkens EL, Wolbink G, Krieckaert CL, Turk S, NavarroCompan V, et al. Comparing Tapering Strategy to Standard Dosing Regimen of Tumor Necrosis Factor Inhibitors in Patients with Spondyloarthritis in Low Disease Activity. J Rheumatol. 2015;42(9):1638-46.

224. Park JW, Yoon YI, Lee JH, Park JK, Lee EB, Song YW, et al. Low dose etanercept treatment for maintenance of clinical remission in ankylosing spondylitis. Clin Exp Rheumatol. 2016;34(4):592-9.

225. Park JW, Kwon HM, Park JK, Choi JY, Lee EB, Song YW, et al. Impact of Dose Tapering of Tumor Necrosis Factor Inhibitor on Radiographic Progression in Ankylosing Spondylitis. PLoS One. 2016;11(12):e0168958.

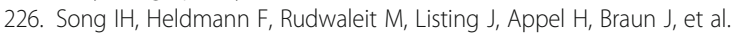
Different response to rituximab in tumor necrosis factor blocker-naive patients with active ankylosing spondylitis and in patients in whom tumor necrosis factor blockers have failed: a twenty-four-week clinical trial. Arthritis Rheum. 2010;62(5):1290-7.

227. Song $\mid H$, Heldmann F, Rudwaleit M, Listing J, Appel H, Haug-Rost I, et al. One-year follow-up of ankylosing spondylitis patients responding to rituximab treatment and re-treated in case of a flare. Ann Rheum Dis. 2013: 72(2):305-6.

228. Song $I H$, Heldmann F, Rudwaleit M, Haibel H, Weiss A, Braun J, et al. Treatment of active ankylosing spondylitis with abatacept: an open-label, 24-week pilot study. Ann Rheum Dis. 2011;70(6):1108-10.

229. Lekpa FK, Farrenq V, Canoui-Poitrine F, Paul M, Chevalier X, Bruckert R, et al. Lack of efficacy of abatacept in axial spondylarthropathies refractory to tumor-necrosis-factor inhibition. Joint Bone Spine : Revue Du Rhumatisme. 2012;79(1):47-50

230. Sieper J, Porter-Brown B, Thompson L, Harari O, Dougados M. Assessment of short-term symptomatic efficacy of tocilizumab in ankylosing spondylitis: results of randomised, placebo-controlled trials. Ann Rheum Dis. 2014;73(1): 95-100.

231. Sieper J, Braun J, Kay J, Badalamenti S, Radin AR, Jiao L, et al. Sarilumab for the treatment of ankylosing spondylitis: results of a Phase II, randomised double-blind, placebo-controlled study (ALIGN). Ann Rheum Dis. 2015;74(6): $1051-7$

232. Poddubnyy D, Hermann KG, Callhoff J, Listing J, Sieper J. Ustekinumab for the treatment of patients with active ankylosing spondylitis: results of a 28week, prospective, open-label, proof-of-concept study (TOPAS). Ann Rheum Dis. 2014;73(5):817-23.

233. Deodhar A, Gensler LS, Sieper J, Clark M, Calderon C, Wang Y, et al. Three Multicenter, Randomized, Double-Blind, Placebo-Controlled Studies Evaluating the Efficacy and Safety of Ustekinumab in Axial Spondyloarthritis. Arthritis Rheumatol. 2018;71:258-270.

234. Pathan E, Abraham S, Van Rossen E, Withrington R, Keat A, Charles PJ, et al. Efficacy and safety of apremilast, an oral phosphodiesterase 4 inhibitor, in ankylosing spondylitis. Ann Rheum Dis. 2013;72(9):1475-80.

235. van der Heijde D, Deodhar A, Wei JC, Drescher E, Fleishaker D, Hendrikx T, et al. Tofacitinib in patients with ankylosing spondylitis: a phase II, 16-week, randomised, placebo-controlled, dose-ranging study. Ann Rheum Dis. 2017; 76(8):1340-7.

236. Maksymowych WP, Heijde DV, Baraliakos X, Deodhar A, Sherlock SP, Li D, et al. Tofacitinib is associated with attainment of the minimally important reduction in axial magnetic resonance imaging inflammation in ankylosing spondylitis patients. Rheumatology. 2018;57(8):1390-9.

237. van der Heijde D, Baraliakos X, Gensler LS, Maksymowych WP, Tseluyko V, Nadashkevich $\mathrm{O}$, et al. Efficacy and safety of filgotinib, a selective Janus kinase 1 inhibitor, in patients with active ankylosing spondylitis (TORTUGA) results from a randomised, placebo-controlled, phase 2 trial. Lancet. 2018; 392(10162):2378-87.

\section{Publisher's Note}

Springer Nature remains neutral with regard to jurisdictional claims in published maps and institutional affiliations.

\section{Ready to submit your research? Choose BMC and benefit from}

- fast, convenient online submission

- thorough peer review by experienced researchers in your field

- rapid publication on acceptance

- support for research data, including large and complex data types

- gold Open Access which fosters wider collaboration and increased citations

- maximum visibility for your research: over $100 \mathrm{M}$ website views per year

At $\mathrm{BMC}$, research is always in progress.

Learn more biomedcentral.com/submissions 